\title{
Petrogénesis ígnea de la Faja Volcánica Transmexicana
}

\author{
Arturo Gómez-Tuena*, Ma. Teresa Orozco-Esquivel, Luca Ferrari \\ Centro de Geociencias, Universidad Nacional Autónoma de México, Campus Juriquilla, \\ Apartado postal 1-742, Querétaro, Qro., 76001, México \\ * tuena@geociencias.unam.mx
}

\begin{abstract}
Resumen
La extraordinaria diversidad magmática de la Faja Volcánica Transmexicana está controlada (directa o indirectamente) por dos placas oceánicas independientes cuyos parámetros geofísicos y composicionales se modifican constantemente a lo largo de la trinchera, por un régimen tectónico esencialmente distensivo que opera con distinta intensidad sobre la placa continental, por un basamento cortical con diferentes edades, espesores y composiciones, y por una fuente mantélica primaria de composición extremadamente variable que ha sido influenciada, en mayor o menor medida, por los agentes químicos derivados de la subducción. El régimen tectónico convergente y, en consecuencia, el arco magmático, tampoco han evolucionado de forma homogénea a lo largo su historia, sino que han mostrado transformaciones notables en su posición, geometría y composición. Por estos motivos, la Faja Volcánica Transmexicana es el resultado de uno de los sistemas tectónicos convergentes más complejos del planeta, el objeto de más de un siglo de investigaciones científicas, y también el centro de las controversias más notables sobre la geología mexicana.
\end{abstract}

Palabras clave: Faja Volcánica Transmexicana, México, subducción, arco magmático, petrología ígnea, manto, corteza.

\section{Abstract}

The magmatic diversity of the Transmexican Volcanic Belt is directly or indirectly controlled by two independent oceanic plates with differing geophysical and compositional parameters, by an extensional tectonic regime that operates with different intensities over the upper plate, by a continental basement with a diversity of ages, thicknesses and compositions, and by a compositionally heterogeneous mantle wedge that has been modified to various extents by the subduction-derived chemical agents. The convergent margin and the magmatic arc have not been evolving homogenously though their geologic histories, but instead have shown significant changes in position, geometry and composition. For these reasons, the Transmexican Volcanic Belt is the result of one of the most complex convergent margins on the planet, the subject of more than a century of scientific investigations, and the core of the most notable debates on the Mexican geology.

Key words: Transmexican Volcanic Belt, Mexico, subduction, magmatic arc, igneous petrology, mantle, crust. 


\section{Introducción y objetivos}

La provincia geológica denominada como la Faja Volcánica Transmexicana (FVTM) es probablemente la región de nuestro país que mayor atención ha tenido en las investigaciones geológicas y geofísicas. Esta gran actividad científica está ampliamente justificada dada la importancia que tiene el estudio detallado de una región geológicamente activa que además concentra a la mayor parte de la población e infraestructura del país. Sin embargo, y a pesar del abultado volumen de publicaciones sobre su estructura, estratigrafía, petrología, geoquímica, geofísica y entorno ambiental, es todavía difícil asegurar que se encuentre adecuadamente descrita y comprendida. Cada año las aportaciones científicas ofrecen nuevas hipótesis que nos acercan a una comprensión global de su origen, pero también es cierto que muy pocas de ellas han despertado un consenso generalizado entre la comunidad científica. Por estos motivos, no cabe duda que la FVTM representa todavía uno de los temas más apasionantes de la investigación geológica mexicana, y estamos convencidos de que lo seguirá siendo en tiempos venideros.

El principal objetivo de esta contribución es promover y facilitar el estudio interdisciplinario del arco magmático mexicano mediante la revisión de los datos y las ideas que han sido planteadas a lo largo de los años para explicar su origen. Lograr este objetivo de manera exhaustiva dista mucho de ser una tarea sencilla. Los textos publicados sobre los volcanes mexicanos representan más de un siglo de investigaciones, y su sola compilación y lectura podría llevar fácilmente varios meses de arduo trabajo. Por eso deseamos hacer notar que esta revisión estará muy lejos de ser enciclopédica, y que probablemente dedicaremos mucho más espacio e interés a aquellos descubrimientos y problemas que han sido planteados en las últimas dos décadas y que consideramos serán de mayor provecho para los lectores.

En la primera parte del trabajo revisaremos el estado actual del conocimiento geológico y geofísico del arco, pues es evidente que estos parámetros representan el marco de referencia bajo el cual debe elaborarse cualquier interpretación petrogenética. Posteriormente, se analizarán las características petrológicas y geoquímicas de las diversas secuencias volcánicas emplazadas en el arco, utilizando una base de datos con más de mil análisis geoquímicos. Por último, se revisarán las ideas que han sido planteadas en los últimos años para explicar el origen de la extraordinaria diversidad de magmas emplazados en la FVTM. Buscaremos afrontar las distintas hipótesis con un sentido crítico, haciendo énfasis en las premisas y suposiciones, sin dejar de lado las inconsistencias y las observaciones no resueltas. De esta forma esperamos poder abrir los caminos necesarios y ubicar los nichos adecuados para las investigaciones futuras.

\section{Contexto geológico y geodinámico}

Se acostumbra definir a la Faja Volcánica Transmexicana (FVTM) como un arco magmático continental, constituido por cerca de 8000 estructuras volcánicas y algunos cuerpos intrusivos, que se extiende desde las costas del Pacífico, en San Blás, Nayarit y Bahía de Banderas, Jalisco, hasta las costas del Golfo de México en Palma Sola, Veracruz (Demant, 1978). La provincia tiene aproximadamente 1000 $\mathrm{km}$ de longitud y una amplitud irregular entre los 80 y 230 $\mathrm{km}$, y se distribuye con una dirección preferencial E-W en su parte central y oriental, WNW-ESE en su parte occidental, formando un ángulo cercano a los $16^{\circ}$ con respecto a la Trinchera Mesoamericana (Figura 1). Esta característica ha dado lugar a que la provincia reciba el nombre de Faja Volcánica Transmexicana, pues claramente muestra una distribución transversal con respecto a las grandes provincias geológicas mexicanas que corren con una orientación preferencial NNW-SSE (Ortega-Gutiérrez et al., 1992).

Se ha vuelto costumbre dividir a la FVTM en tres sectores o porciones con base en su geología y tectónica (Demant, 1978; Pasquaré et al., 1988) (Figura 1): una porción occidental entre la costa del Golfo de California y la junta triple de los rifts de Zacoalco, Chapala y Colima (Allan, 1986); una porción central comprendida entre dicha estructura y el sistema de fallas Taxco-San Miguel de Allende (Alaniz-Álvarez et al., 2002a); y una porción oriental entre este sistema y la costa del Golfo de México. Consideramos que esta subdivisión es conveniente y por lo tanto es la que adoptaremos en el presente trabajo.

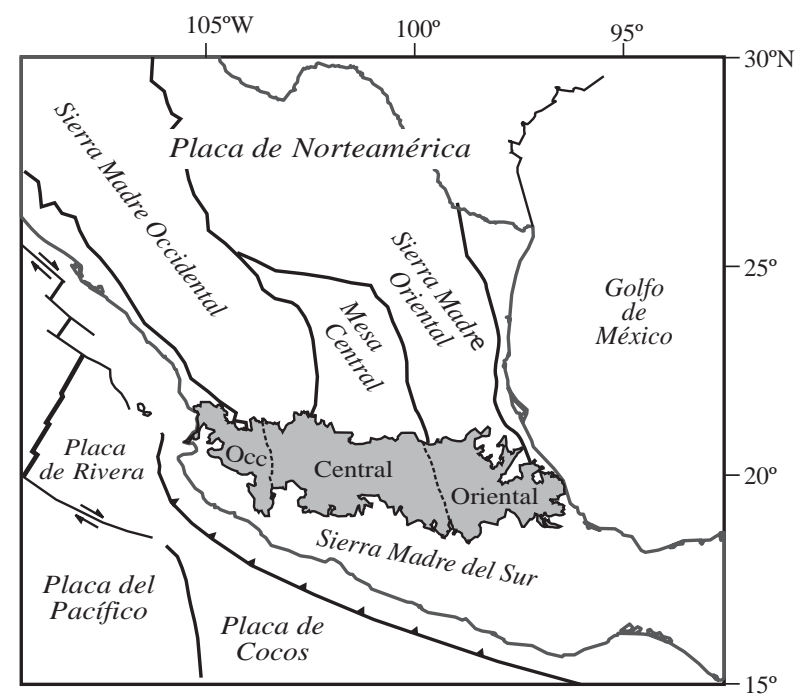

Figura 1. Ubicación de la Faja Volcánica Transmexicana (en gris), de las principales provincias geológicas de México y de las placas tectónicas actuales. También se muestra la ubicación de los tres sectores de la FVTM que serán mencionados en este trabajo. 
2.1. Evolución geológica de la Faja Volcánica Transmexicana

Aunque la evolución espacio-temporal del magmatismo, y particularmente la transición entre la Sierra Madre Occidental y la FVTM, estuvo sujeta a discusión por largo tiempo (Mooser, 1972; Demant, 1978; Cantagrel y Robin, 1979; Demant, 1981; Robin y Cantagrel, 1982; Venegas et al., 1985; Nixon et al., 1987), en la actualidad, y gracias a la abundancia de fechamientos isotópicos obtenidos en las últimas dos décadas, parece ser claro que la individualización de la FVTM como una entidad geológica distintiva ocurrió durante el Mioceno medio y tardío, como resultado de una rotación antihoraria del arco que formó la Sierra Madre Occidental (Ferrari et al., 1999).

Recientemente, Ferrari et al. (2005a) elaboraron la primera cartografía geológica digital de la FVTM. Este documento, que incluye una base de datos con más de 1300 edades y cerca de 3000 análisis químicos, constituye la plataforma para la síntesis de la evolución geológica de la FVTM que se presenta aquí (Lámina 1, Figura 2). De manera muy sintética la historia geológica de la FVTM se puede dividir en cuatro episodios principales: (1) la instauración de un arco de composición intermedia en el Mioceno medio y tardío, (2) un episodio máfico del Mioceno tardío, (3) un episodio silícico de finales de Mioceno que llega a ser bimodal en el Plioceno temprano, y (4) la reinstauración de un arco con gran variabilidad composicional a partir del Plioceno tardío.

\subsubsection{Arco del Mioceno medio y tardío}

Los albores de la actividad volcánica en la FVTM se remontan al Mioceno medio, cuando un arco con orientación aproximada E-W se emplaza en el centro de México, entre la longitud de Morelia-Querétaro y las costas del Golfo de México (Figura 2a). Los vestigios de esta actividad inicial se encuentran en proximidad con el frente volcánico actual del sector central de la FVTM: en los complejos volcánicos de la sierra de Mil Cumbres y la sierra de Angangueo, en Michoacán (Pasquaré et al., 1991; Capra et al., 1997), así como en el área de Tenancingo y Malinalco, Estado de México, y en las rocas de la parte más profunda del relleno de la cuenca de la Ciudad de México (Ferrari et al., 2003a). Secuencias de lavas basálticas y andesíticas en el frente de la FVTM en el área de Tenancingo y Malinalco, Estado de México, han sido consideradas del Mioceno tardío por García-Palomo et al. (2000), quien las correlaciona con una lava fechada por K-Ar en 7.5 Ma emplazada $20 \mathrm{~km}$ más al norte. Sin embargo, recientemente Ferrari et al. (2003a) obtuvieron cinco edades Ar-Ar en un rango entre $19.5 \mathrm{y}$ 16 Ma para las secuencias lávicas basales de Malinalco y Tenancingo, las cuales además resultan más acorde con la edad de 21 Ma que García-Palomo et al. (2000) reportan para una lava ubicada justo al norte de Malinalco. Por lo anterior, estas secuencias se consideran aquí como parte de la actividad inicial del Mioceno medio en la FVTM (Lámina 1).

Posteriormente, el vulcanismo se aleja de la trinchera $\mathrm{y}$ forma estratovolcanes y conos de lava con edades que varían entre $\sim 13$ y $10 \mathrm{Ma}$. Entre éstos se encuentran el grupo de estratovolcanes Palo Huérfano, La Joya y Zamorano en Querétaro-Guanajuato (Carrasco-Núñez et al., 1989; Pérez-Venzor et al., 1996; Valdez-Moreno et al., 1998; Verma y Carrasco-Núñez, 2003), el volcán Cerro Grande en Puebla (Carrasco-Núñez et al., 1997; Gómez-Tuena y Carrasco-Núñez, 2000), la sierra de Guadalupe y varios centros volcánicos al noroeste de la Ciudad de México (Jacobo-Albarrán, 1986), así como el campo volcánico de Apan (García-Palomo et al., 2002) (Lámina 1 y Figura 2a). Hacia el extremo oriental, en la región de Palma Sola, los vestigios de este episodio volcánico están representados por cuerpos plutónicos y subvolcánicos de composición gabroica a diorítica con edades que varían entre $\sim 15$ y $11 \mathrm{Ma}$ (Gómez-Tuena et al., 2003; Ferrari et al., 2005b). Muchas de las rocas del final de Mioceno medio e inicio de Mioceno tardío, emplazadas lejos de la trinchera desde Querétaro hasta Palma Sola, tienen composiciones geoquímicas similares a las adakitas descritas por Kay (1978) y Defant y Drummond (1990), lo que ha llevado a sugerir que puedan ser el producto de la fusión de la placa subducida durante un periodo de subducción de bajo ángulo o subhorizontal (Gómez-Tuena et al., 2003). Esta hipótesis es consistente con el alejamiento progresivo del magmatismo de arco desde la trinchera a partir del Mioceno medio.

No existen evidencias que indiquen la presencia de un arco del Mioceno medio al oeste de Morelia y Querétaro (Figura 2a). La ausencia de vulcanismo no parece deberse a que los productos volcánicos se encuentren cubiertos por rocas más recientes, ya que las secuencias del Mioceno tardío en los Altos de Jalisco y en el área de Cotija, Michoacán, cubren directamente a ignimbritas del Oligoceno-Mioceno temprano (Ferrari y Rosas-Elguera, 2000; Rosas-Elguera et al., 2003). En los pozos profundos perforados en el área del Ceboruco y en la caldera de la Primavera, las lavas del Mioceno superior también sobreyacen directamente a lavas andesíticas del Eoceno (Ferrari y Rosas-Elguera, 2000; Ferrari et al., 2003b). En cambio, algunos centros volcánicos aislados del Mioceno medio se encuentran en Nayarit, cerca de la boca del Golfo de California (Figura 2a) (Gastil et al., 1979; Ferrari et al., 2000a). Este vulcanismo puede considerarse como la terminación meridional del arco Comondú, cuyos vestigios están ampliamente distribuidos en la parte oriental de la península de Baja California y para el cual se han obtenido edades de $\sim 30$ a 12 $\mathrm{Ma}$, aunque su eje principal fue migrando paulatinamente hacia el oeste (Umhoefer et al., 2001).

\subsubsection{Episodio máfico del Mioceno tardío}

El vulcanismo de arco relativamente normal que se desarrolló durante el Mioceno medio se ve interrumpido en el 
Mioceno tardío cuando un extenso episodio de vulcanismo máfico se emplaza de costa a costa, desde Nayarit hasta Veracruz, inmediatamente al norte del arco precedente, con edades que se vuelven progresivamente mas jóvenes de oeste a este (Ferrari et al., 2000b; Ferrari, 2004; Ferrari et al., 2005b) (Figura 2b). Este episodio está esencialmente conformado por mesetas basálticas, por lo general emplazadas a través de fisuras, con edades que varían entre $\sim 11$ y 8.9 Ma en la costa de Nayarit y al noroeste de Tepic (Righter et al., 1995; Ferrari et al., 2000a); entre $\sim 11$ y 8 Ma al norte de Guadalajara, en los Altos de Jalisco y en Cotija, Michoacán (Nieto-Obregón et al., 1981; Verma et al., 1985; Moore et al., 1994; Rosas-Elguera et al., 1997; Alva-Valdivia et al., 2000; Rossotti et al., 2002; RosasElguera et al., 2003); y entre $\sim 9$ y 7 Ma en Querétaro y en el área de Pathé, Hidalgo (Pasquaré et al., 1991; Suter et al., 1995a; Aguirre-Díaz y López-Martínez, 2001). Este vulcanismo continúa hacia el área de Tlanchinol-Huejutla, y alcanza la costa norte de Veracruz (Tantima-Álamo), con coladas de basalto alcalino y conos monogenéticos con edades comprendidas entre 7.5 y $6.5 \mathrm{Ma}$ (Cantagrel y Robin, 1979; López-Infanzón, 1991; Ferrari et al., 2005b). Ferrari et al. (2000b) mostraron que el vulcanismo máfico del Mioceno superior que se emplazó desde el Golfo de California hasta el este del estado de Hidalgo (Pathé) tiene las características geoquímicas típicas de la subducción, aunque su composición es ligeramente variable. En cambio, el vulcanismo de la parte oriental de Hidalgo y norte de Veracruz (Tlanchinol, Tantima, Álamo, y buena parte de las mesetas de Palma Sola) presentan características intraplaca (Orozco-Esquivel et al., 2003).

\subsubsection{Vulcanismo silícico del final de Mioceno y vulca- nismo bimodal del Plioceno temprano}

Después del episodio de magmatismo máfico, el vulcanismo decrece significativamente y se vuelve más diferenciado. Hacia el final del Mioceno superior y durante el Plioceno temprano se emplazaron complejos de domos dacíticos y riolíticos, así como grandes volúmenes de ignimbritas emitidas por calderas regionales, formando una franja que se distribuye justo al sur de las rocas producidas en el episodio máfico anterior (Figura 2c). Volúmenes importantes de coladas riolíticas e ignimbritas se emplazaron entre Santa María del Oro y Plan de Barrancas [Grupo Jala (Ferrari et al., 2000a)], en la parte oeste de la FVTM; mientras que entre la Presa de Santa Rosa y San Cristóbal, al norte de Guadalajara [Grupo Guadalajara (Ferrari et al., 2000a; Rossotti et al., 2002)], dominan los complejos de domos exógenos y algunos flujos piroclásticos. Estas rocas tienen edades comprendidas entre 7.5 y $\sim 3 \mathrm{Ma}$ (Gilbert et al., 1985; Rossotti et al., 2002; Ferrari et al., 2003b; Frey et al., 2004) y prácticamente representan el único vestigio de actividad volcánica en la parte oeste de la FVTM hasta los $\sim 5$ Ma. Ferrari et al. (2001) estimaron un volumen de $\sim 930 \mathrm{~km}^{3}$ para este episodio volcánico. Las primeras manifestaciones posteriores al vulcanismo silícico del Mioceno tardío se presentan en el área de Guadalajara y en la parte norte del rift de Colima. En la región de Guadalajara, estas rocas están conformadas por coladas de lava de dimensiones relativamente modestas de basaltos alcalinos de tipo intraplaca que se emplazaron a partir de los 5.5 Ma (Gilbert et al., 1985; Moore et al., 1994). Rocas de este tipo siguieron siendo extruidas durante todo el Plioceno temprano, en conjunción con complejos de domos y algunas ignimbritas silícicas (Moore et al., 1994; Ferrari et al., 2000a; Frey et al., 2004). También es interesante notar que la gran mayoría de las lavas de tipo intraplaca se emplazan en la parte más alejada del arco, donde, junto con las riolitas, constituyen una típica asociación bimodal (Ferrari, 2004). Durante todo el Plioceno temprano, en la parte norte del rift de Colima y en el campo volcánico de Ayutla domina un vulcanismo máfico de composición alcalina con una ligera firma de subducción (Allan, 1986; Righter y Rosas-Elguera, 2001). Esta misma secuencia se encuentra alrededor de la Laguna de Chapala, aunque las edades más antiguas indican que se inició a finales del Mioceno tardío a $\sim 6$ Ma (DelgadoGranados et al., 1995).

En la porción central de la FVTM dominan las grandes calderas que producen tobas pumicíticas e ignimbritas con volúmenes de decenas de kilómetros cúbicos que se distribuyen sobre una superficie de varios miles de kilómetros cuadrados. Dentro de las más notables se encuentran las calderas de Amazcala (7.3-6.6 Ma; Aguirre-Díaz y López-Martínez, 2001), Amealco (4.7 Ma; Aguirre-Díaz y McDowell, 2000), Huichapan (4.7-3.4 Ma; Aguirre-Díaz et al., 1997), Los Azufres ( 6-3 Ma; Ferrari et al., 1991; Pradal y Robin, 1994), Zitácuaro (Mioceno superiorPlioceno temprano; Capra et al., 1997), Apaseo y Los Agustinos (Plioceno temprano; Aguirre-Díaz et al., 1997). En esta zona, las lavas de composición máfica a intermedia del final del Mioceno al Plioceno temprano ( 6-3.4 Ma) están distribuidas en una franja WSW-ENE ubicada al norte de las depresiones de Zacapu, Laguna de Cuitzeo, Presa Solís y Presa Tuxpan (Ferrari et al., 1991; Pasquaré et al., 1991; Aguirre-Díaz, 1996) (Lámina 1; Figura 2c). Estas lavas se encuentran generalmente interestratificadas con las ignimbritas más recientes descritas anteriormente. En la porción oriental de la FVTM, entre Pachuca y Tlanchinol, Hidalgo, en el borde de la Sierra Madre Oriental, también han sido reportadas secuencias piroclásticas del Plioceno temprano (4.9-4.5 Ma) que se encuentran intercaladas y cubiertas por lavas basálticas y que constituyen, aquí también, un arreglo petrológico bimodal (Cantagrel y Robin, 1979; Ochoa-Camarillo, 1997).

\subsubsection{Arco del Plioceno tardío-Cuaternario}

En casi toda la FVTM el vulcanismo silícico y bimodal se ve reemplazado por un arco volcánico de composición predominantemente andesítico-basáltica que comienza a desarrollarse a partir del límite del Plioceno temprano y el Plioceno tardío (Figura 2d). En la porción occidental de la FVTM, las lavas con características intraplaca siguen 


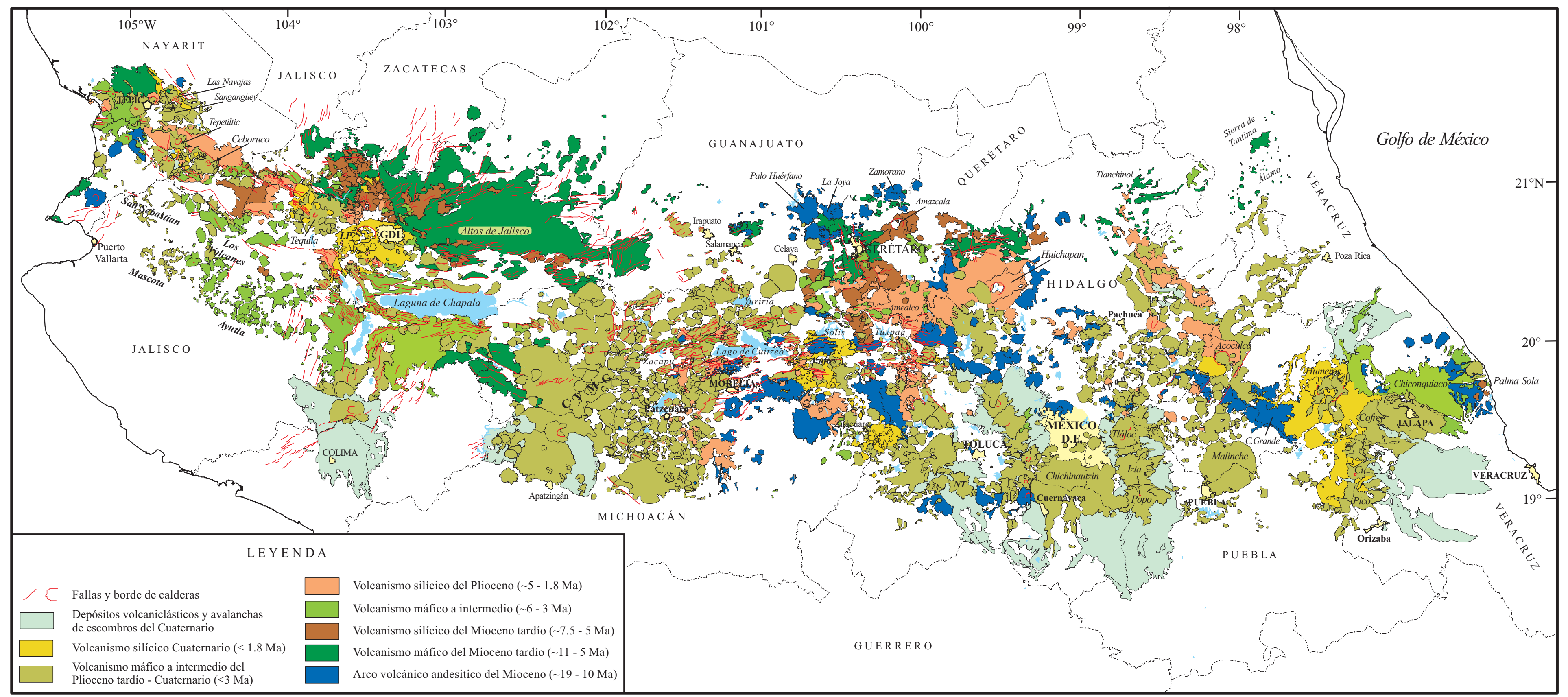



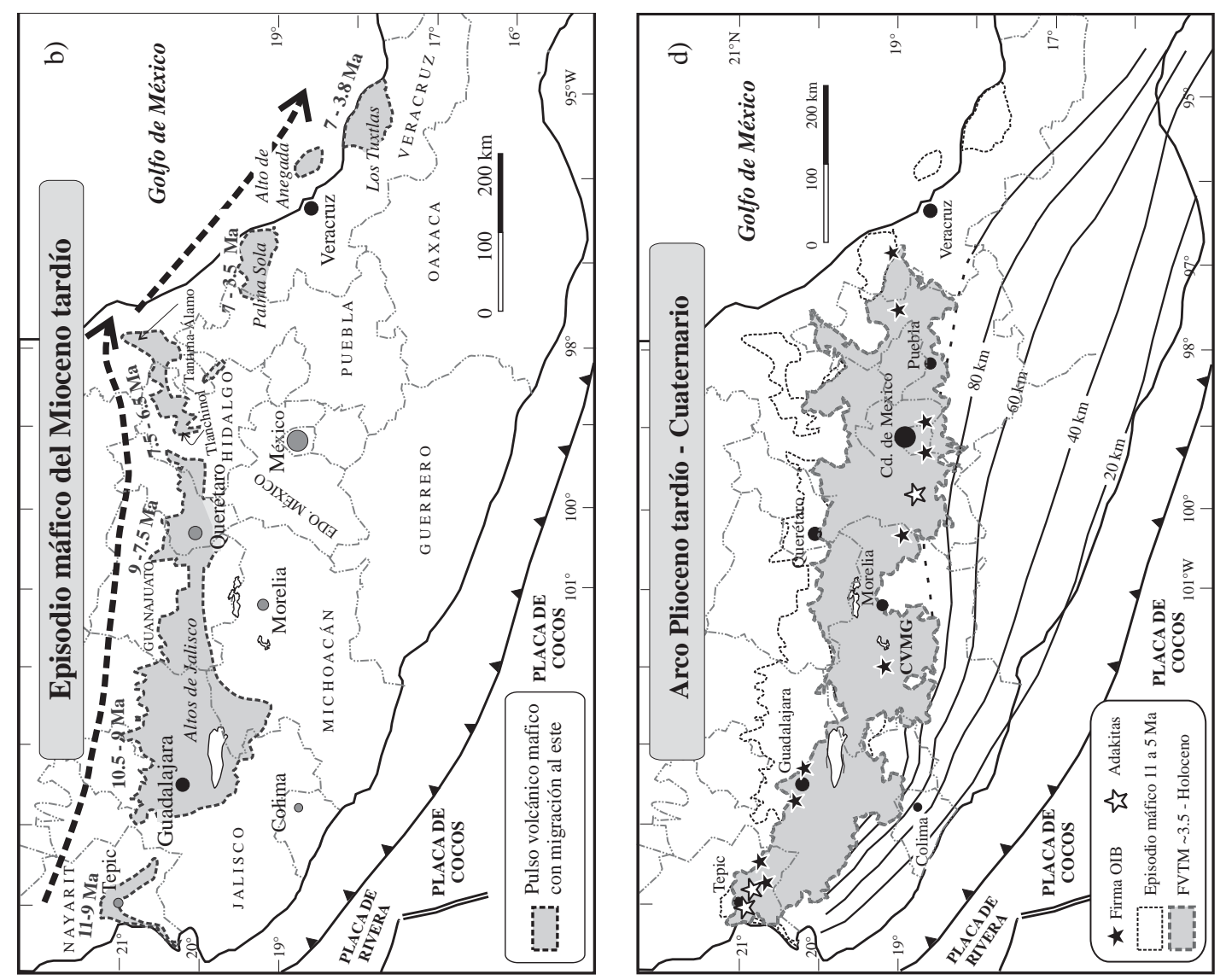

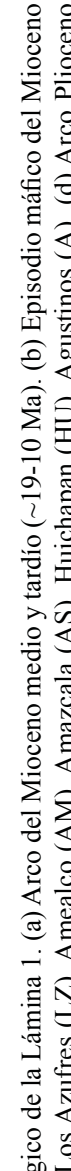
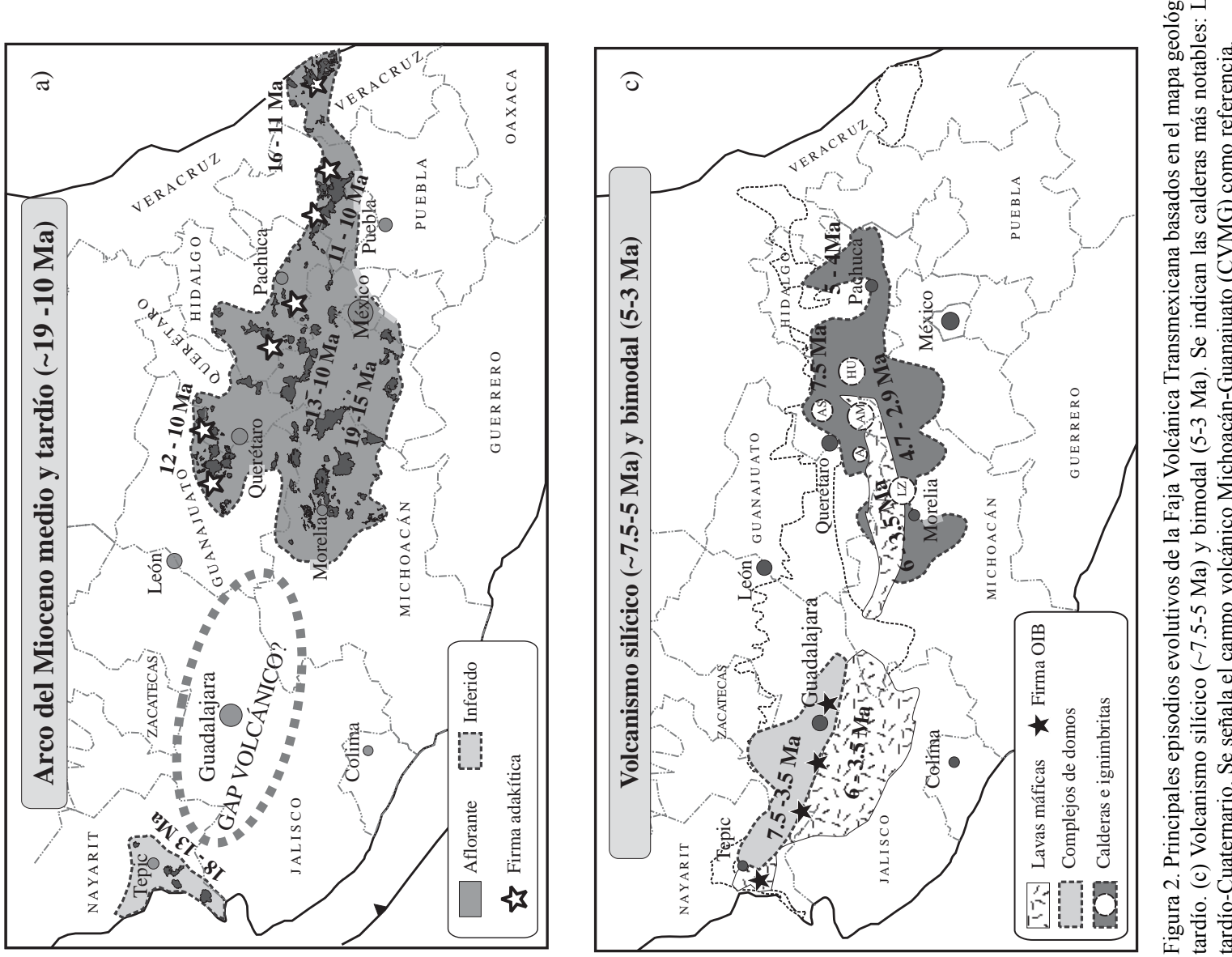
emplazándose a partir de $3.6 \mathrm{Ma}$, pero también existen lavas con características más típicas de subducción en la parte noroccidental del arco (Righter et al., 1995; Ferrari et al., 2000a). A partir del Plioceno tardío, el frente volcánico está dominado por campos de volcanes monogenéticos (Mascota, Los Volcanes, San Sebastián, Atenguillo), cuyos productos tienden a formar asociaciones petrológicas lamprofídicas con altos contenidos de potasio (Wallace y Carmichael, 1989; Lange y Carmichael, 1990; Lange y Carmichael, 1991; Righter y Carmichael, 1992; Carmichael et al., 1996). Es también durante el Cuaternario que se construyen los principales estratovolcanes de la FVTM occidental. El complejo volcánico de Colima, emplazado en la terminación meridional del rift homónimo, representa por mucho el mayor volumen de material volcánico emplazado en la región ( $\sim 700 \mathrm{~km}^{3}$; Robin et al., 1987). El resto de los estratovolcanes tienen volúmenes menores a los $100 \mathrm{~km}^{3}$ (Tequila, Ceboruco, Tepetiltic, Sangangüey, Las Navajas y San Juan), y se alinean a lo largo de fallas regionales de orientación WNW-ESE que definen la frontera norte del bloque Jalisco (Figura 3). El bloque Jalisco se define como un cuerpo batolítico de edad cretácica (100-75 Ma) (Schaaf et al., 1995) que aparentemente se levantó durante el Paleógeno (Rosas-Elguera et al., 1996).

Hacia la porción central de la FVTM, el campo volcánico Michoacán-Guanajuato (CVMG) cubre una extensa región entre la Laguna de Chapala y el estado de Querétaro (Lámina 1). El vulcanismo comienza hacia los $\sim 2.8 \mathrm{Ma}$ y continúa activo hasta nuestros días (e. g., los volcanes Jorullo y Parícutin). Este campo volcánico incluye más de
1000 conos monogenéticos y, en menor medida, domos de composición intermedia a silícica (Hasenaka y Carmichael, 1985). El campo también cuenta con más de 400 centros poligenéticos, principalmente volcanes escudo de dimensiones modestas (Hasenaka, 1994). El único estratovolcán del campo es el Cerro Tancítaro, que ha sido fechado en $\sim 0.5 \mathrm{Ma}$ (Ban et al., 1992).

Al oriente del campo Michoacán-Guanajuato el vulcanismo se vuelve menos continuo y ligeramente más evolucionado. En la región de Maravatío-Zitácuaro-Valle de Bravo, los conos monogenéticos del Pleistoceno medio al Holoceno se encuentran generalmente alineados a lo largo de estructuras regionales (Capra et al., 1997; Blatter et al., 2001), y algunos conjuntos de domos dacíticos de edad cuaternaria se emplazaron en la periferia de la caldera de Los Azufres y en la caldera de Zitácuaro (Ferrari et al., 1991; Capra et al., 1997).

Si se excluye a los basaltos alcalinos de la región de Palma Sola y a la secuencia bimodal de PachucaTlanchinol, el vulcanismo de la porción oriental de la FVTM experimenta un hiato que cubre el final del Mioceno y todo el Plioceno temprano. El vulcanismo se reestablece a los 3.7 Ma con el emplazamiento de diferentes centros poligenéticos alineados NNW-SSE, formando la sierra de las Cruces, al occidente de la Ciudad de México (MoraÁlvarez et al., 1991; Osete et al., 2000), y algunos centros poligenéticos medianos del campo volcánico de Apan, ubicado al norte de la cuenca de la Ciudad de México (García-Palomo et al., 2002). Sin embargo, la mayor parte del vulcanismo del sector oriental de la FVTM se desarrolla

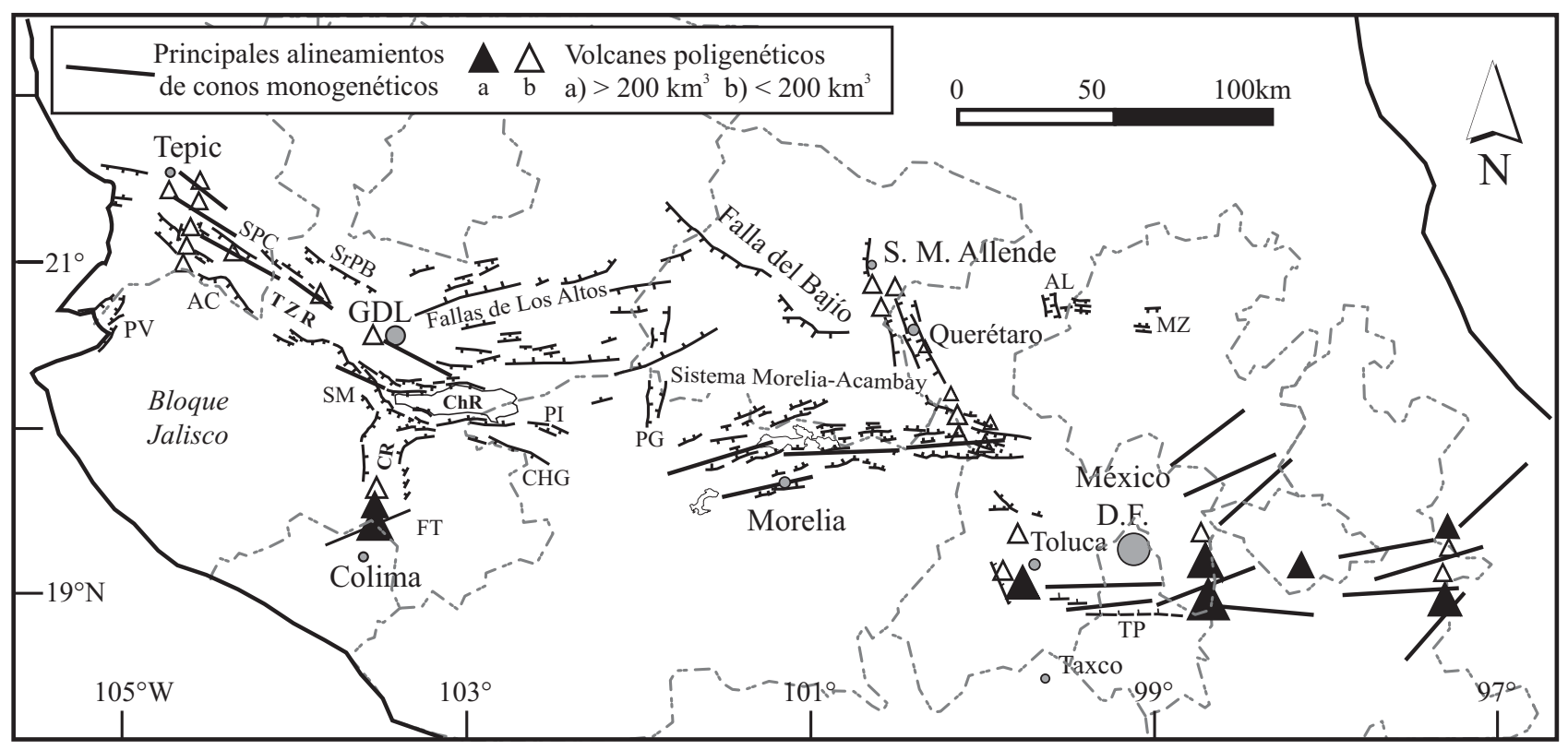

Figura 3. Relaciones entre los principales sistemas de fallas del Mioceno-Cuaternario y el volcanismo de la FVTM (ver sección 2.1 para referencias). TZR: rift Tepic-Zacoalco; PV: graben de Puerto Vallarta; SPC: graben San Pedro-Ceboruco; AC: semigraben de Amatlán de Cañas; SrPB: graben Santa Rosa-Plan de Barrancas; SM: falla de San Marcos; CR: rift de Colima; FT: sistema de fallas Tamazula; ChR: rift de Chapala; PI: fallas PajacuaránIxtlán de los Hervores; CHG: semigraben de Cotija; PG: graben de Penjamillo; AL: semigraben de Aljibes; MZ: graben de Mezquital; TP: sistema de fallas La Pera. 
durante el Cuaternario. El vulcanismo máfico se concentra en los conos monogenéticos de los campos de la Sierra de Chichinautzin (Martín-Del Pozzo, 1982; Márquez et al., 1999c; Siebe et al., 2004b) y Apan (García-Palomo et al., 2002); y en la región del Pico de Orizaba y Cofre de Perote (Lámina 1) (Siebert y Carrasco-Núñez, 2002). Los productos más evolucionados se encuentran en las calderas de Acoculco (Verma, 2001a), Los Humeros (Ferriz y Mahood, 1984; Verma, 2000b), el centro silícico de Las Cumbres (Rodríguez-Elizarrarás et al., 2002), y los domos de Las Derrumbadas y el Cerro Pizarro (Riggs y Carrasco-Núñez, 2004), todos ubicados en el estado de Puebla. Al oriente de la ciudad de México se desarrolla la Sierra Nevada: una cadena volcánica con orientación N-S constituida por el Cerro Tláloc, el complejo volcánico Iztaccíhuatl y el volcán Popocatépetl, con edades que se vuelven progresivamente más jóvenes hacia el sur (Nixon, 1989). Más al oriente se encuentra el volcán La Malinche y el alineamiento $\sim \mathrm{N}-\mathrm{S}$ del Pico de Orizaba-Cofre de Perote (Carrasco-Núñez y Ban, 1994). Aparentemente, todos los estratovolcanes de esta parte de la FVTM tienen edades menores a 1 Ma.

\subsubsection{Geología Estructural y Neotectónica}

El notable alineamiento oblicuo de la FVTM con respecto a la trinchera, y su orientación transversal con respecto a las principales provincias geológicas y tectónicas de México, propició que muchos investigadores sugirieran la existencia de una importante estructura tectónica por debajo del arco volcánico. La idea de una zona de deformación de escala cortical fue propuesta originalmente por von Humboldt (1808), y retomada por Mooser (1972) y Gastil y Jensky (1973), quienes sugirieron que la FVTM representaba una antigua zona de sutura o de cizalla que se reactivó durante el Terciario. Esta idea fue retomada posteriormente por varios autores quienes en sus reconstrucciones de la apertura del Golfo de México y la evolución del Caribe se encontraban con la necesidad geométrica de poner una megacizalla más en algún lugar de México central (Silver y Anderson, 1974; Pindell, 1985; Ross y Scotese, 1988). Los trabajos geológicos estructurales de los últimos 15 años han permitido definir la geometría, cinemática y edad de los principales sistemas de fallas que afectan a la FVTM (Figura 3). Estos estudios han puesto de manifiesto que en buena parte de la FVTM ha existido una estrecha relación espacio-temporal entre el fallamiento y el vulcanismo.

En la porción occidental de la FVTM, Demant (1981) fue el primero en señalar la existencia de tres depresiones tectónicas organizadas en una junta triple al sur de Guadalajara. Demant (1981) nombró a estas estructuras como graben Tepic-Chapala (posteriormente definido como Tepic-Zacoalco), graben de Colima y graben de Chapala. Posteriormente, Allan (1986) estudió con detalle el volcanismo de la región de la junta triple, y proporcionó numerosos fechamientos que permitieron establecer que el fallamiento había iniciado en el Plioceno temprano. El descubrimiento de rocas alcalinas asociada al fallamiento extensional llevó a Luhr et al. (1985) a formular el modelo de rifting activo en el bloque Jalisco por efecto del "salto" al oriente de un segmento de la Dorsal del Pacífico Oriental. Este modelo, que perduró en la literatura por más de una década (Allan et al., 1991; Bourgois y Michaud, 1991; Michaud et al., 1991), preveía movimientos laterales derechos durante el Plioceno y Cuaternario a lo largo del rift Tepic-Zacoalco, aunque sus autores no realizaron estudios estructurales en la región. Paralelamente, Barrier et al. (1990), Allan et al. (1991) y Garduño y Tibaldi (1991) describieron al rift Tepic-Zacoalco como una serie de grábenes y cuencas de pull-apart del Plioceno-Holoceno; mientras que NietoObregón et al. (1985) y Moore et al. (1994) sostuvieron que existía un fallamiento lateral derecho activo en su parte oriental. Sin embargo, a partir de los primeros años de la década de 1990, los estudios estructurales detallados empezaron a documentar una tectónica esencialmente extensional para los sistemas de fallas del rift Tepic-Zacoalco durante el Plioceno-Cuaternario (Nieto-Obregón et al., 1992; Quintero-Legorreta et al., 1992; Ferrari et al., 1994; Rosas-Elguera et al., 1997), aunque también se reconoció que efectivamente había ocurrido una deformación transcurrente en esta región durante el Mioceno medio y tardío (Ferrari, 1995). En un estudio detallado de los distintos sistemas de fallas entre Guadalajara y la boca del Golfo de California, Ferrari y Rosas-Elguera (2000) concluyen que el rift Tepic-Zacoalco está constituido por una serie de grábenes y semigrábenes desarrollados en distintos episodios a partir del Mioceno tardío. Las estructuras más meridionales del rift Tepic-Zacoalco (graben de Puerto Vallarta, semigraben de Amatlán de Cañas, falla de San Marcos y zona de fallas de Zacoalco) muestran evidencias geológicas (Ferrari et al., 1994; Rosas-Elguera et al., 1997) y sismológicas (Suárez et al., 1994; Pacheco et al., 1999) de actividad neotectónica durante el Cuaternario. Con base en la batimetría de la región marina frente a Puerto Vallarta, Alvarez (2002) también propone la existencia de una zona de fallamiento normal activo en la Bahía de Banderas que parece estar confirmada por la pronunciada actividad sísmica registrada en la zona durante los últimos años (Núñez-Cornú et al., 2002).

El rift de Colima había sido descrito esencialmente como un graben de edad pliocénica-cuaternaria con una burda orientación N-S, dividido en tres segmentos (norte, centro y sur) (Allan et al., 1991). Sin embargo, algunos estudios estructurales y geofísicos cuestionaron la existencia de un fallamiento normal del Plioceno-Cuaternario en el segmento sur del rift (al sur del volcán de Colima), donde sólo hay evidencias de una deformación transpresiva previa al Plioceno (Serpa et al., 1992). Posteriormente, Rosas-Elguera et al. (1996) y Garduño-Monroy et al. (1998) documentaron la existencia de la denominada falla Tamazula, que consta de un conjunto de estructuras transcurrentes y normales de orientación NE-SW pasando por el complejo volcánico de Colima y que llegaría hasta la costa en el área de Manzanillo. Estos autores proponen que 
dicha falla representa el límite oriental del bloque Jalisco, al sur del volcán de Colima. Como resultado de todos estos trabajos, el modelo de Luhr et al. (1985) fue reconsiderado por Rosas-Elguera et al. (1996) y Ferrari y Rosas-Elguera (2000) quienes propusieron que los rifts Tepic-Zacoalco y Colima representan los límites continentales del bloque Jalisco que fueron parcialmente reactivados durante el Plioceno-Cuaternario con movimientos esencialmente extensionales, como consecuencia de los esfuerzos aplicados en el límite de las placas de Rivera y de Norteamérica.

El brazo oriental de la junta triple de Guadalajara lo conforma el rift de Chapala, que fue definido inicialmente como un graben de dirección E-W (Demant, 1978) formado en respuesta a una extensión $\sim \mathrm{N}-\mathrm{S}$ durante el Plioceno-Cuaternario (Garduño-Monroy et al., 1993). Estudios posteriores demostraron que se trata en realidad de una estructura compuesta por dos semigrábenes con vergencia opuesta: sur en la parte oeste y norte en la parte este (Urrutia-Fucugauchi y Rosas-Elguera, 1994; RosasElguera y Urrutia-Fucugauchi, 1998). Las fallas maestras de estos semigrábenes cortan a rocas de 3.4 Ma en el área de Chapala (Rosas-Elguera y Urrutia-Fucugauchi, 1998) y 3.3 Ma en Pajacuarán-Ixtlán de los Hervores (RosasElguera et al., 1989), aunque la morfología de los escarpes de fallas sugiere que la tectónica no fue activa durante el Cuaternario. Un fallamiento de edad cuaternaria se sugiere, en cambio, en el graben de Citlala, una estructura paralela ubicada inmediatamente al sur de la Laguna de Chapala (Garduño-Monroy et al., 1993; Rosas-Elguera y UrrutiaFucugauchi, 1998). Más al sur, el semigraben de Cotija es una estructura extensional de dirección WNW-ESE con vergencia al SSW que corta a las rocas del Mioceno tardío (Rosas-Elguera et al., 2003).

Hacia el sector central de la FVTM, el extenso vulcanismo del campo volcánico Michoacán-Guanajuato enmascara la posible existencia de un fallamiento anterior al Plioceno. Sin embargo, existen fallas normales de dirección WNW-ESE y WSW-ENE cortando rocas del Plioceno en los extremos occidental y oriental del campo, respectivamente (Lámina 1). Así mismo, un análisis estadístico de la orientación que siguen los centros de emisión magmática muestra que la mayor parte de los alineamientos de 3 a 6 conos monogenéticos tienen una orientación paralela a estos sistemas de fallas (Connor, 1990). Existen también sistemas de fallas normales con una pequeña componente lateral izquierda afectando a basaltos del Mioceno tardío en la región de los Altos de Jalisco (Lámina 1) (Ferrari et al., 2000b). Estas fallas tienen dirección WSW-ENE y son paralelas al alineamiento de algunos conos de lava de la parte central de la meseta de Los Altos. Por este motivo, Ferrari et al. (2000b) consideran que estas fallas deben haber iniciado su actividad durante la fase final del volcanismo máfico, hace $\sim 8 \mathrm{Ma}$.

Más al oriente, entre las longitudes de León y Querétaro, el volcanismo pliocénico-cuaternario de la FVTM ocupa una gran depresión asimétrica limitada al norte por el sis- tema de fallas normales del Bajío y al sur por el sistema de Morelia-Acambay. El sistema del Bajío tiene una longitud mayor a los $70 \mathrm{~km}$ y un desplazamiento mínimo superior a los $2 \mathrm{~km}$. Estas fallas estuvieron activas durante el Eoceno y el Oligoceno, principalmente, pero también existió un desplazamiento de por lo menos $500 \mathrm{~m}$ después del Mioceno medio (Nieto-Samaniego et al., 1999; Alaniz-Álvarez y Nieto-Samaniego, 2005). El sistema de Morelia-Acambay fue descrito inicialmente por Martínez-Reyes y NietoSamaniego (1990) y, en su parte central, por Pasquaré et al. (1988); Ferrari et al. (1990) y Pasquaré et al. (1991), como una franja de $\sim 30 \mathrm{~km}$ de ancho de fallas de dirección WSW-ENE responsable de las depresiones tectónicas de Zacapu, Cuitzeo, Morelia y Acambay, entre otras. El análisis cinemático indica que se trata de fallas que empezaron su actividad posiblemente en el Plioceno temprano con movimientos laterales izquierdos a transtensivos, para luego volverse progresivamente más extensionales (Ferrari et al., 1990; Suter et al., 1995b). La mayoría de las fallas de la parte occidental del sistema tienen una inclinación hacia norte y basculan al sur a las secuencias volcánicas del Mioceno y Plioceno. Sin embargo, también se han reportado evidencias de movimientos cuaternarios en la región de Morelia (Garduño-Monroy et al., 2001). En cambio, la parte oriental del sistema se caracteriza por una estructura tipo graben asimétrico, formado por las fallas Epitacio Huerta y Acambay-Tixmadeje, al norte, y las fallas Venta de Bravo y Pastores, al sur, que exhiben una pequeña componente lateral izquierda (Suter et al., 1992; Suter et al., 1995b). Este sector es el más activo del sistema, y prueba de ello es el sismo de 1912 con magnitud 6.9 y epicentro en Acambay (Urbina y Camacho, 1913; Suter et al., 1995b; Suter et al., 1996), para el cual se ha estimado una recurrencia de 3600 años durante el Holoceno (Langridge et al., 2000). Un análisis detallado de la neotectónica de todo el sistema Morelia-Acambay ha sido descrito recientemente por Suter et al. (2001) y Szynkaruk et al. (2004).

El sistema de fallas Taxco-San Miguel de Allende (TSMA) fue identificado por Demant (1981) como un conjunto de estructuras transversal a la FVTM que se desarrolla con una dirección NNW entre las ciudades homóminas. Varios segmentos de este sistema de fallas han sido estudiados con detalle durante la última década. En su estudio de síntesis Alaniz-Álvarez et al. (2002b) describen el TSMA como una estructura continental mayor con más de $500 \mathrm{~km}$ de longitud y hasta $35 \mathrm{~km}$ de ancho que constituye el límite entre bloques corticales con distintos espesores y topografías. Varias porciones de este sistema se han visto reactivadas con cinemáticas distintas desde el Oligoceno (Alaniz-Álvarez et al., 2002a; 2002b).

La deformación es más antigua en la porción oriental de la FVTM. La cuenca de la Ciudad de México es una depresión tectónica con más de $2 \mathrm{~km}$ de profundidad cuya formación se remonta al Oligoceno o hasta al Eoceno (Ferrari et al., 2003a; Alaniz-Álvarez y Nieto-Samaniego, 2005). La depresión está limitada al oeste por el TSMA 
y al sur por el sistema de fallas de La Pera-Tenango con orientación E-W (García-Palomo et al., 2000; Ferrari et al., 2003a), que también parece controlar el volcanismo monogenético de la Sierra Chichinautzin (Márquez et al., 1999c). En el resto de la FVTM oriental, las únicas estructuras tectónicas evidentes son el semigraben de Aljibes, el graben Mezquital (Suter et al., 2001) y las fallas normales del campo volcánico de Apan (García-Palomo et al., 2002). El semigraben de Aljibes está conformado por cuatro fallas normales de dirección E-W ubicadas en el límite norte de la FVTM, a 140 km al NNW de la Ciudad de México (Suter et al., 1995a). Las fallas basculan al sur, cortan basaltos del Mioceno tardío, y se consideran potencialmente activas (Suter et al., 1995a; Suter et al., 1996). El graben del Mezquital es una estructura de dirección E-W ubicada $\sim 40$ $\mathrm{km}$ al este de Aljibes. Algunos estudios gravimétricos sugieren que ambas estructuras son parte de una sola depresión tectónica (Campos-Enríquez y Sánchez-Zamora, 2000). El graben está limitado al norte por la falla Cardonal que llega a afectar a rocas con edades mayores a los $4.6 \mathrm{Ma}$ (Suter $e t$ al., 2001). Sin embargo, y aunque la sismicidad es difusa en el área, la presencia de dos eventos sísmicos de magnitud $(\mathrm{Mw}) \sim 5$ indican que esta estructura es potencialmente activa (Suter et al., 1996; Quintanar et al., 2004). Por su parte, García-Palomo et al. (2002) describen varias fallas normales de dirección NE en el campo volcánico de Apan (Lámina 1). Aparentemente estas fallas afectan únicamente a rocas del Mioceno medio y no parecen ser activas.

En resumen, las evidencias geológicas reportadas hasta el momento señalan que la FVTM se encuentra en buena medida bajo un régimen tectónico distensivo, aunque las fallas cuaternarias de la porción central de la FVTM tienen una pequeña y variable componente lateral izquierda. El régimen débilmente transtensivo se explica considerando que la convergencia entre las placas de Cocos y de Norteamérica es ligeramente oblicua, y que existe una partición de la deformación en el límite de placa que hace necesario acomodar la componente de movimiento paralela a la trinchera (izquierda) en la placa superior (Ego y Ansan, 2002). La FVTM es el lugar más apropiado para acomodar esta componente lateral izquierda debido a que representa la principal zona de debilidad cortical al norte de la trinchera (Ego y Ansan, 2002).

La relación que existe entre los mecanismos de emplazamiento magmático y el sistema de deformación estructural a lo largo del arco ha sido motivo de intensa discusión entre investigadores. Diversos estudios han sugerido que la conspicua alineación de los grandes estratovolcanes mexicanos con una orientación general $\mathrm{N}-\mathrm{S}$ debe estar relacionada con un sistema de fallamiento distensivo que sigue esa orientación (Cantagrel y Robin, 1979; Höskuldsson y Robin, 1993; Alaniz-Álvarez et al., 1998). Aunque este modelo podría explicar el alineamiento de estratovolcanes a lo largo del TSMA, hasta la fecha no se han reportado evidencias claras que señalen la existencia de fallas distensivas o laterales afectando a los estratovol- canes del sistema Popopocatépetl-Iztaccíhuatl-Tláloc o al Cofre de Perote-Pico de Orizaba. Se ha sugerido también que las rocas volcánicas más primitivas del sector oriental, asociadas generalmente a los campos monogenéticos y/o a derrames fisurales (Chichinautzin y Tenango, por ejemplo), se han emplazado a lo largo de fallas y fisuras que siguen una orientación preferencial E-W (Márquez et al., 1999c; García-Palomo et al., 2000). En efecto, dicho sistema de fallamiento parece favorecer en buena medida el rápido ascenso de magmas primitivos en este sector, $\mathrm{y}$ aparentemente comparte muchas de las características del sistema de deformación que afecta al sector central del arco volcánico (Suter et al., 2001). En ese sentido AlanizÁlvarez et al. (1998) propusieron un modelo general para explicar el contraste en la orientación preferencial de los centros monogenéticos (paralela al arco) con respecto a los estratovolcanes (transversal al arco). Estos autores proponen que la oblicuidad del arco con respecto a la trinchera hace que las fallas paralelas al arco acomoden la mayor parte de la extensión, favoreciendo que los magmas asciendan rápidamente formando centros monogenéticos, mientras que las fallas transversales al arco, al acomodar una pequeña parte de la extensión, tienen una baja tasa de deformación y favorecen el entrampamiento de magmas y la formación de estratovolcanes. Aunque este modelo ha recibido críticas por diversos investigadores (Contreras y Gómez-Tuena, 1999; Siebe et al., 1999; Suter, 1999), quienes señalaron numerosas inconsistencias al modelo con base en argumentos estructurales, petrológicos y observaciones de campo, también es cierto que hasta la fecha no existe ningún modelo alternativo que permita explicar convincentemente el conspicuo alineamiento de los estratovolcanes en la FVTM (Alaniz-Álvarez et al., 1999).

\subsection{Las placas oceánicas}

\subsubsection{Historia y geometría de las placas oceánicas en subducción}

Aunque por más de un siglo se han propuesto un raudal de hipótesis sobre el origen de la FVTM y la misteriosa falta de paralelismo entre la trinchera mesoamericana y el arco magmático (von Humboldt, 1808; De Cserna, 1958; Mooser, 1972; Gastil y Jensky, 1973; Johnson y Harrison, 1989), las múltiples evidencias geofísicas con las que contamos en la actualidad indican claramente que las placas oceánicas de Cocos y de Rivera se introducen hacia el manto por debajo del continente (Figura 4). Por este motivo, la mayor parte de los investigadores asumen que la formación de magmas en la FVTM, y su distribución oblicua con respecto a la trinchera, deben estar de alguna manera ligados al proceso en subducción (Urrutia-Fucugauchi y Del Castillo, 1977; Urrutia-Fucugauchi y Böhnel, 1987; Pardo y Suárez, 1993; Pardo y Suárez, 1995). No obstante dichas evidencias, algunos investigadores encuentran difícil esta relación debido a las peculiaridades petrológicas 


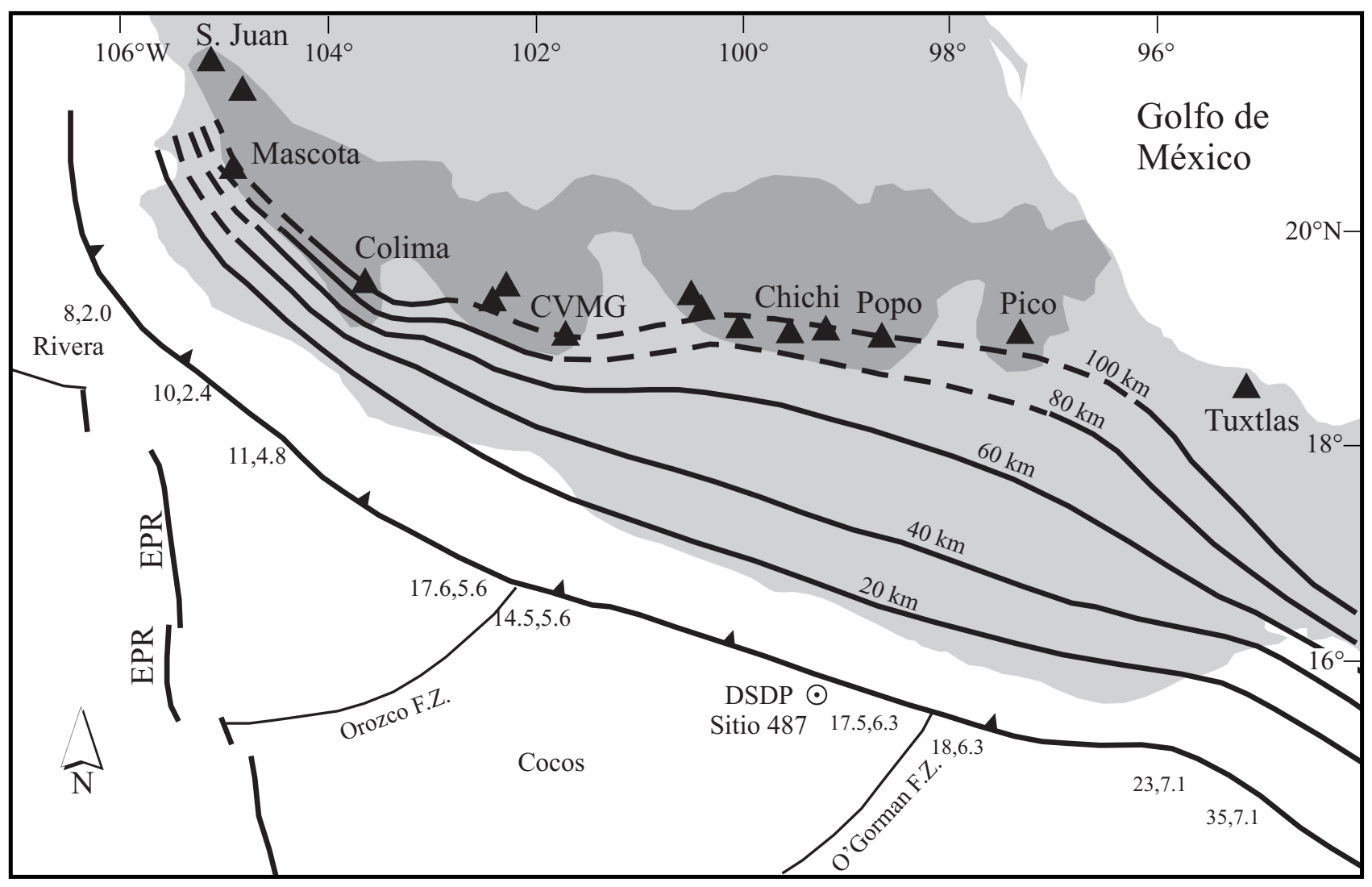

Figura 4. Mapa tectónico generalizado del sistema de subducción mexicano (modificado de Pardo y Suárez, 1995). Los números separados por comas indican la edad de la corteza oceánica (en Ma) y la velocidad de convergencia (en cm/a), respectivamente. Las curvas de nivel representan la profundidad de la placa oceánica (la curva segmentada es una inferencia). Una sección representativa de la corteza oceánica fue muestreada por el Deep Sea Drilling Project en el sitio 487 (DSDP sitio 487). Se incluyen también como referencia algunos campos volcánicos importantes: Campo volcánico de Los Tuxtlas (Tuxtlas), volcán Pico de Orizaba (Pico), volcán Popocatépetl (Popo), campo volcánico de Chichinautzin (Chichi), campo volcánico de Michoacán-Guanajuato (CVMG), volcán de Colima (Colima), campo volcánico de Mascota (Mascota), y volcán San Juan (S. Juan).

de las rocas magmáticas, a la conspicua presencia de una tectónica distensiva asociada al emplazamiento de magmas primitivos, y a que el plano de Wadati-Benioff no se encuentra bien definido debajo de la mayor parte del arco (Márquez et al., 1999a; Verma, 1999; Sheth et al., 2000; Verma, 2000a; Verma, 2002). Es evidente que dichas consideraciones deben ser tomadas también en cuenta al evaluar de manera integral el origen de la FVTM, y una discusión más amplia sobre estos problemas será posteriormente plasmada en este trabajo.

La historia tectónica de las placas oceánicas del Pacífico ha sido explorada en diversas publicaciones mediante la observación de los patrones de anomalías magnéticas (Atwater, 1970; Menard, 1978; Mammerickx y Klitgord, 1982; Londsdale, 1991). Dichos estudios han mostrado que la configuración tectónica actual de la zona de subducción mexicana es el resultado de la fragmentación sucesiva que sufrió la placa Farallón al momento en que las crestas meso-oceánicas llegaron en proximidad con la zona de subducción de la placa de Norteamérica. Este proceso de fragmentación produjo importantes reorganizaciones en la configuración de las crestas meso-oceánicas y también originaron cambios en la dirección y en la velocidad del vector de convergencia a lo largo del margen continental pacífico (Engebretson et al., 1985).

En la actualidad, la porción occidental del arco se encuentra subyacida por la placa de Rivera, mientras que la porción central y oriental se encuentran subyacidas por la placa de Cocos (Figura 4). Aunque existen algunas divergencias en cuanto a las edades absolutas de las placas oceánicas y las velocidades de convergencia, todos los autores coinciden en afirmar que la placa de Rivera es relativamente más joven y converge a una velocidad menor que la placa de Cocos (Nixon, 1982; Pardo y Suárez, 1993; DeMets et al., 1994; Kostoglodov y Bandy, 1995; Pardo y Suárez, 1995). La placa de Rivera tiene aparentemente una edad menor a los $13 \mathrm{Ma}$ a lo largo de la trinchera, y su velocidad de convergencia varía entre 1.7 y $2.2 \mathrm{~cm} /$ año (DeMets et al., 1994) o 4 y 4.9 cm/año (Kostoglodov y Bandy, 1995), según el modelo que se utilice. En cambio, la edad de la placa de Cocos varía entre los 12.7 y $16 \mathrm{Ma}$, mostrando un incremento gradual hacia la porción oriental de la trinchera. La velocidad de convergencia también se incrementa hacia el oriente y varía desde $\sim 4.7$ hasta $\sim 6.7 \mathrm{~cm} /$ año. 
Los estudios sobre la profundidad de los mecanismos focales muestran que la placa de Rivera se introduce hacia el manto con un ángulo cercano a los $50^{\circ}$ y la señal sísmica puede alcanzar $\sim 120 \mathrm{~km}$ de profundidad (Pardo y Suárez, 1993, 1995). El ángulo de subsidencia de la placa de Cocos es mucho más variable, y es notable que los hipocentros sísmicos se limiten a profundidades menores a $70 \mathrm{~km}$ (Figura 4). De esta forma, los datos sísmicos indican que la placa de Cocos disminuye paulatinamente su inclinación desde su límite con la placa de Rivera hasta aproximadamente la longitud $101^{\circ} \mathrm{W}$ para volverse posteriormente subhorizontal debajo de una parte de la porción central y la porción oriental de la FVTM. Al sureste de Palma Sola, la placa de Cocos aumenta rápidamente su inclinación para alcanzar otra vez un ángulo de $45-50^{\circ}$ entre el Istmo de Tehuantepec y el Arco Centroamericano (Pardo y Suárez, 1995). Esta peculiar configuración tectónica parece ser la responsable de la oblicuidad del arco magmático, así como de la lejanía de su parte oriental con respecto a la trinchera mesoamericana.

La evolución del sistema de subducción mexicano y el origen de la peculiar geometría que observamos en la actualidad no se conocen con claridad. Las reconstrucciones globales indican que la placa de Cocos comenzó a existir a los $\sim 24$ Ma por efecto de la fracturación de la placa Farallón, que tambien dio origen a la placa de Nazca (Atwater, 1989). Recientemente se ha establecido que la separación de la placa de Rivera ocurrió a los $\sim 10 \mathrm{Ma}$, debido a que ésta es la edad más antigua para la cual es posible comprobar una deformación en la parte norte de la cresta abandonada de los Matemáticos (DeMets y Traylen, 2000).

También se ha propuesto que la trinchera mesoamericana que conocemos actualmente es el resultado de la migración hacia el este del bloque Chortis, cuya margen occidental se encontraba, probablemente, a la altura de Zihuatanejo antes del Oligoceno (Ratschbacher et al., 1991; Herrmann et al., 1994; Schaaf et al., 1995; Morán-Zenteno et al., 1996; Morán-Zenteno et al., 1999). La margen occidental del bloque Chortis se encontraba probablemente a la longitud de Oaxaca oriental al final del Mioceno temprano, lo que implica que la trinchera frente a la FVTM ya estaba establecida en su posición actual para ese periodo (MoránZenteno et al., 1999). La presencia del arco del Mioceno medio en una ubicación no muy lejana del frente volcánico actual en la parte centro-oriental de la FVTM (Lámina 1, Figura 2) podría indicar que la geometría subhorizontal de la placa de Cocos se remonte también a este periodo. Por lo que respecta a la parte occidental de la FVTM, la notable migración del frente volcánico hacia la trinchera desde $~ 8.5$ Ma ha llevado a Ferrari et al. (2001) a sugerir que la placa de Rivera haya iniciado un proceso de retroceso o rollback desde el final del Mioceno, una hipótesis que parece ser consistente con la drástica disminución en la velocidad de convergencia relativa entre esta última y la placa de Norteamérica a partir de los $9 \mathrm{Ma}$ (DeMets y Traylen, 2000).

\subsubsection{Estructura térmica de la zona de subducción mexicana}

La estructura térmica de la zona de subducción mexicana ha sido poco estudiada, y aunque los modelos numéricos publicados hasta el momento tienen ya un grado avanzado de sofisticación, aún es necesario incorporar mayores complejidades que describan adecuadamente las variaciones de la estructura térmica a todo lo largo del arco, y asociar estos resultados con el registro geológico y petrológico.

El flujo térmico medido en el sur y centro de México muestra a grandes rasgos las características típicas de una zona de subducción (Smith et al., 1979; Polak et al., 1985; Prol-Ledezma y Juárez, 1985; Ziagos et al., 1985): los valores más bajos se encuentran en la zona del antearco (13-22 $\left.\mathrm{mWm}^{-2}\right)$, y se incrementan de forma significativa hacia el arco magmático $\left(\sim 100 \mathrm{mWm}^{-2}\right)$. No obstante, los valores de flujo térmico registrados tienen aún demasiadas incertidumbres. Las mediciones directas realizadas en perforaciones son aún muy pocas y relativamente someras $(<200 \mathrm{~m})$, y la variación en las características topográficas, geológicas e hidrológicas de cada región añaden complejidades adicionales a nivel local que son difíciles de evaluar y corregir. Por eso, la principal limitación de los modelos térmicos actuales de la zona de subducción mexicana es la carencia de un parámetro de flujo térmico lo suficientemente robusto que permita acotar los modelados numéricos (Currie et al., 2002).

Los principales parámetros físicos que han sido tomados en cuenta para la construcción de los modelos térmicos de la zona de subducción mexicana (y de otras partes del mundo) son la geometría y la edad de las placas oceánicas subducidas, el espesor de la cobertura sedimentaria y la velocidad de convergencia (Currie et al., 2002; Manea et al., 2004; Manea et al., 2005). Sin embargo, existen otros parámetros físicos que son mucho más difíciles de evaluar pero que en su conjunto pueden llegar a controlar de manera significativa los resultados numéricos: la conductividad térmica de las unidades geológicas involucradas (continentales y oceánicas), la generación de calor por decaimiento radiactivo, la extensión del acoplamiento entre las dos litósferas involucradas y el calor generado a través de la fricción en la zona de contacto, y la viscosidad del manto astenosférico.

Los modelos térmicos de Currie et al. (2002), enfocados a caracterizar la profundidad y extensión de la zona sismogénica en la zona de subducción, indican que a pesar de que las cortezas oceánicas que están siendo subducidas debajo de México son jóvenes, la temperatura de las placas oceánicas es anómalamente fría debido a que aparentemente existe una vigorosa circulación hidrotermal en la litósfera oceánica antes de ser subducida (Prol-Ledezma et al., 1989), y a la ausencia de un espesor importante de sedimentos aislantes cubriendo a la corteza basáltica. En estos modelos, la zona sismogénica se restringe a temperaturas menores a los $\sim 350^{\circ} \mathrm{C}$ que, en el caso de México, se traduce a profundidades menores a $40 \mathrm{~km}$. Sin embargo, 
estos modelos predicen temperaturas extraordinariamente bajas para la cuña del manto ubicada debajo del arco $(<1000$ ${ }^{\circ} \mathrm{C}$ ) y no parecen ser capaces de reproducir adecuadamente los valores de flujo térmico medidos en la zona del arco y el trasarco mexicanos.

Recientemente se han elaborado modelos térmicos más sofisticados en donde se toma en cuenta la existencia de una amplia zona de acoplamiento $(\sim 200 \mathrm{~km})$ entre la placa oceánica y la continental para el perfil Guerrero-Ciudad de México (Kostoglodov et al., 2003), y en donde se asume que la viscosidad del manto depende de la temperatura (Manea et al., 2004). Estos modelos proponen que la zona sismogénica de la zona de subducción se localiza entre las isotermas de $150^{\circ} \mathrm{C} \mathrm{y} 450{ }^{\circ} \mathrm{C}$. Adicionalmente, Manea et al. (2004) grafican los resultados de su modelo térmico en un diagrama de fases para basaltos oceánicos y el manto peridotítico, y sugieren la aparición de facies eclogíticas a $>450{ }^{\circ} \mathrm{C}$ y $1.3 \mathrm{GPa}$, precisamente en el lugar en donde la placa oceánica se desacopla de la placa continental. En estos modelos, la profundidad máxima a la que ocurren los sismos intraplaca $(\sim 80 \mathrm{~km})$ coincide con la desaparición de fases mineralógicas hidratadas. Por otro lado, al considerar que la viscosidad del manto depende de la temperatura, y utilizando las viscosidades nominales del olivino a presiones y temperaturas del manto superior determinadas experimentalmente (Hirth y Kohlstedt, 2003), Manea et al. (2005) predicen que la corteza oceánica subducida puede experimentar fusión parcial a profundidades de 50-60 km y que el manto astenosférico hidratado alcanza temperaturas lo suficientemente altas como para lograr fundirse (>1 200 ${ }^{\circ} \mathrm{C}$ ). Sin embargo, los modelos no predicen temperaturas lo suficientemente altas como para poder fundir el manto peridotítico en condiciones anhidras, y por lo tanto no son capaces de explicar la génesis de los magmas de tipo intraplaca emplazados en el frente del arco magmático.

\subsubsection{Composición de las placas oceánicas en subducción}

Aunque es difícil tener una visión exacta de las variaciones composicionales de la corteza oceánica que subduce y del espesor e importancia de su cobertura sedimentaria, los sondeos realizados en la costa pacífica mexicana por el Deep Sea Drilling Project (DSDP) y las interpretaciones realizadas recientemente en los perfiles de anomalías gravimétricas a lo largo de la trinchera (Manea et al., 2003) nos permiten tener, al menos, una aproximación objetiva y tangible de estas variables. Los estudios de Manea et al. (2003) permiten interpretar que la columna sedimentaria sobre la placa de Rivera no debe alcanzar más de 20 metros de espesor, y que este espesor se incrementa gradualmente hacia el SE. Por otra parte, el DSDP realizó varios sondeos sísmicos y perforaciones exploratorias en la trinchera mesoamericana, en la denominada Leg 66 (Moore et al., 1982). De todas ellas, la perforación realizada a unos 11 $\mathrm{km}$ de las costas de Guerrero, en el sitio 487 (15 51.210' de latitud Norte y $99^{\circ} 10.518^{\prime}$ de longitud W), penetró completamente en la pila sedimentaria y alcanzó la corteza basáltica subyacente (Figuras 4 y 5). La columna sedimentaria en este sitio está compuesta por $\sim 100 \mathrm{~m} \mathrm{de}$ sedimentos hemipelágicos de edad cuaternaria, subyacidos por $\sim 70 \mathrm{~m}$ de sedimentos pelágicos con edades del Mioceno tardío-Plioceno. Tomando en cuenta el patrón de anomalías magnéticas, la corteza basáltica debe pertenecer al Mioceno tardío $(\sim 13 \mathrm{Ma})$.

La columna litológica de este sitio (Figura 5) ha sido descrita y estudiada con cierto detalle por varios autores (Moore et al., 1982; Plank y Langmuir, 1998; Verma, 2000a; LaGatta et al., 2003). Los sedimentos hemipelágicos tienen un carácter terrígeno y deben derivarse de la denudación de las rocas continentales de la margen pacífica mexicana. Esta capa está principalmente compuesta por un lodo grisáceo con cristales de cuarzo, feldespato y mica, mineralogías típicas de los plutones costeros del margen continental pacífico (Schaaf et al., 1995). Los sedimentos pelágicos están compuestos principalmente por arcillas y presenta coloraciones pardas, rojizas y negras. El origen primario de estos sedimentos debe estar asociado a la actividad hidrotermal de las crestas meso-oceánicas. Los fragmentos de corteza oceánica recuperados en este sitio están conformados principalmente por un basalto con cristales de plagioclasa y olivino, y menores proporciones de un basalto afírico (Verma, 2000a).

Aunque es evidente que la composición de los sedimentos y la corteza oceánica pueden variar de manera significativa a lo largo de la trinchera, los materiales colectados y analizados en el sitio 487 representan la única aproximación directa que tenemos a los componentes que están siendo subducidos. Por este motivo, varios autores han realizado estudios geoquímicos en los distintos componentes asociados a la columna sedimentaria del sitio 487 (Plank y Langmuir, 1998; Verma, 2000a; LaGatta, 2003). La Figura 5 muestra los patrones de elementos traza y de Tierras Raras de los distintos componentes sedimentarios y los de la corteza basáltica alterada (LaGatta, 2003). Los horizontes pelágicos y hemipelágicos son geoquímicamente distintos. En general, el componente pelágico tiene mayores concentraciones de elementos traza que su contraparte terrígena. Por ejemplo, los sedimentos pelágicos tienen casi cinco veces más $\mathrm{Ba}$, cerca del doble de elementos de las Tierras Raras ligeras (LREE por sus siglas en inglés) y poco más del triple de elementos de las Tierras Raras pesadas (HREE por sus siglas en inglés) que los sedimentos hemipelágicos. La diferencia más notable entre ambos horizontes reside en la denominada "anomalía de Ce". La Figura 5 muestra claramente que, a diferencia de los sedimentos terrígenos, el componente pelágico tiene menores concentraciones relativas de $\mathrm{Ce}$ con respecto a sus vecinos inmediatos (La y Pr). Esta anomalía es una característica común en los sedimentos marinos, y resulta de la solubilidad relativa del Ce tetravalente en el agua de mar (Rollinson, 1993; Plank y Langmuir, 1998). Curiosamente, ambos horizontes sedimentarios 

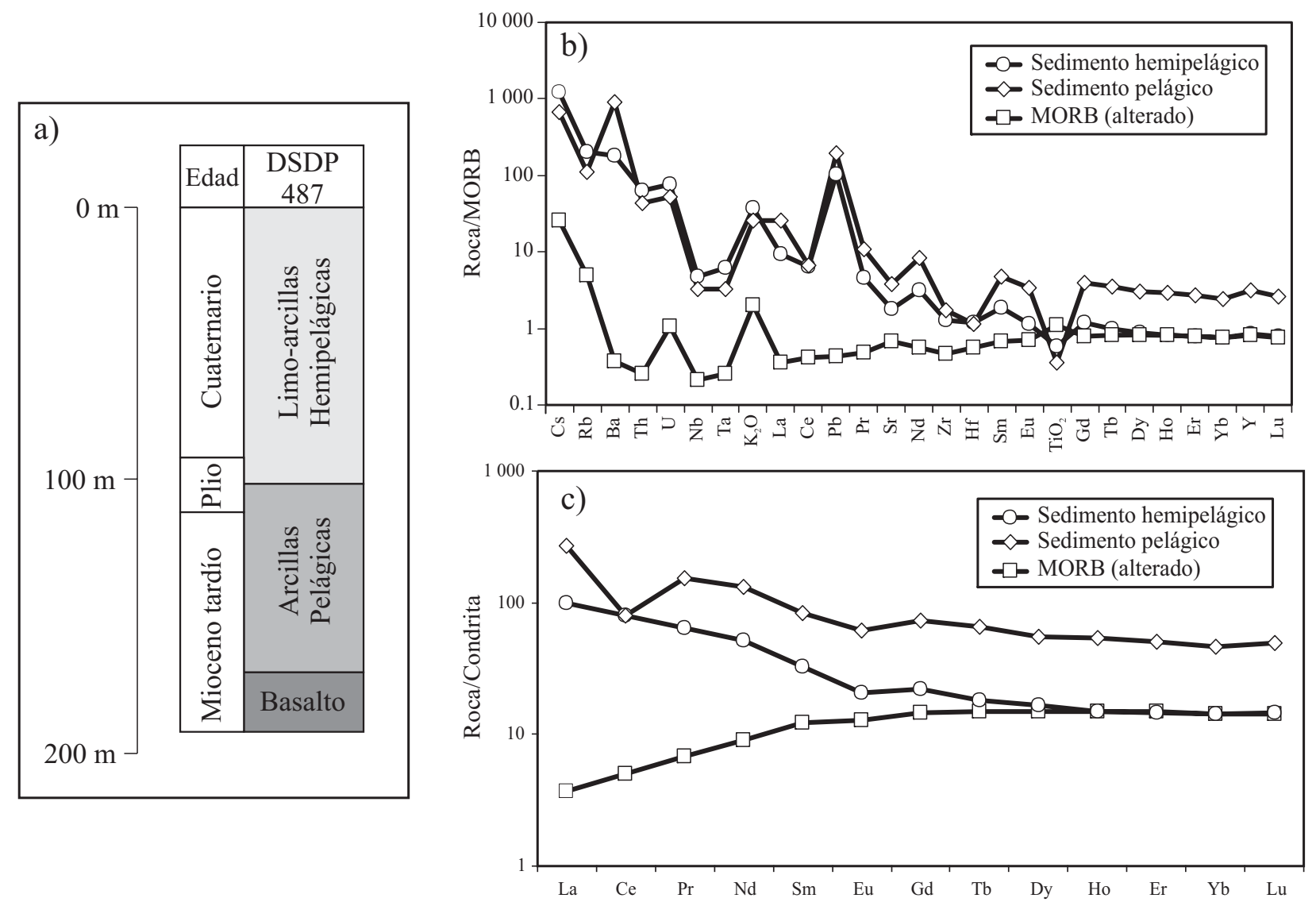

Figura 5. (a) Litología y estratigrafía de la placa de Cocos muestreada en el sitio DSDP 487. (b) Patrones normalizados de elementos traza y (c) Tierras Raras de los distintos horizontes litológicos del sitio DSDP 487 (Legget, 1982; Plank y Langmuir, 1998; Verma, 2000a; LaGatta, 2003). Valores de normalización con respecto al N-MORB (Sun y McDonough, 1989) y las Condritas CI (McDonough y Sun, 1995).

presentan poca variación en la composición isotópica de Sr y $\mathrm{Nd}(0.7085$ y 0.5125 , en promedio), pero difieren significativamente en la composición isotópica de $\mathrm{Pb}$. Los sedimentos terrígenos presentan valores muy radiogénicos en la relación ${ }^{206} \mathrm{~Pb} /{ }^{204} \mathrm{~Pb}(\sim 18.8$, en promedio), mientras que las capas pelágicas presentan valores similares a los basaltos de dorsales meso-oceánicas (mid-ocean ridge basalts o MORB) ( 18.5, en promedio) (Verma, 2000a; LaGatta et al., 2003).

\subsection{La placa continental}

\subsubsection{Estructura cortical}

La información más completa sobre la estructura cortical a todo lo largo de la FVTM ha sido principalmente determinada con base en estudios de anomalías gravimétricas (Molina-Garza y Urrutia-Fucugauchi, 1993; De la Fuente et al., 1994; Urrutia-Fucugauchi y Flores-Ruiz, 1996; Flores-Ruiz, 1997; García-Perez y Urrutia-Fucugauchi, 1997; Campos-Enríquez y Sánchez-Zamora, 2000) y estudios sísmicos (Urrutia-Fucugauchi, 1986; Valdés et al., 1986; Nava et al., 1988; Geolimex Working Group, 1994;
Campillo et al., 1996). Existen también algunos estudios de anomalías magnéticas (Campos-Enríquez et al., 1990) y levantamientos magnetotelúricos (Jording et al., 2000) que cubren de manera aislada ciertos sectores del arco, y aunque sus interpretaciones son aún demasiado generalizadas y difíciles de evaluar en un contexto geológico regional, en general parecen ser consistentes con los trabajos sísmicos y gravimétricos.

Los patrones de anomalías gravimétricas a lo largo del arco magmático muestran una estructura relativamente sencilla, compatible con un incremento en el espesor cortical desde las costas hacia el interior del continente (Figura 6a). Sin embargo, la figura permite también distinguir regiones con espesores corticales contrastantes. La región con el mayor espesor cortical se localiza en el sector oriental de la FVTM, extendiéndose desde el frente volcánico hasta el norte de Puebla. Los valores mayores se encuentran sobre todo en las cercanías del Valle de México y el Valle de Toluca $(\sim 47 \mathrm{~km})$. El sector central de la FVTM muestra un espesor cortical relativamente menor $(<40 \mathrm{~km})$ y más variable. Las zonas en donde la corteza es más delgada se localizan hacia las costas del Pacífico y el Golfo de México (15-20 km). La estructura 

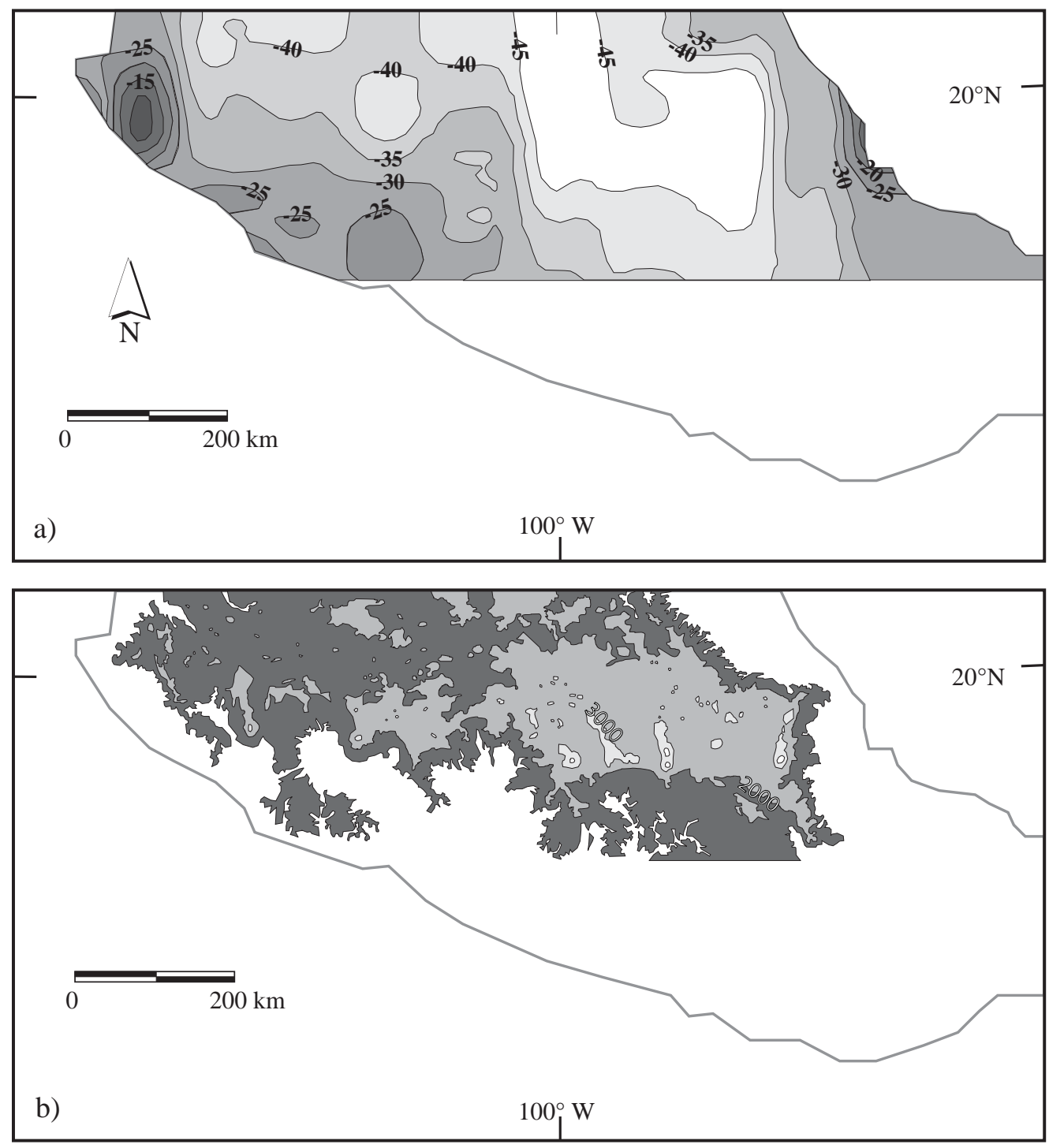

Figura 6. (a) Esquema del espesor cortical de la FVTM interpretado a partir de las anomalías gravimétricas (Molina-Garza y Urrutia-Fucugauchi, 1993; De la Fuente et al., 1994; Urrutia-Fucugauchi y Flores-Ruiz, 1996; Flores-Ruiz, 1997). (b) Mapa hipsométrico de la FVTM (modificado del Atlas Nacional de México, 1999). Curvas de nivel a cada $1000 \mathrm{~m}$. Es notable la buena correlación que existe entre el espesor cortical y la topografía.

cortical determinada para la zona del arco es consistente con los datos obtenidos mediante estudios sísmicos en el sur de México, en donde el espesor cortical se incrementa desde la costa pacífica y alcanza cerca de $47 \mathrm{~km}$ debajo del Complejo Oaxaqueño (Urrutia-Fucugauchi, 1986; Valdés et al., 1986).

El mapa hipsométrico de la Faja Volcánica Transmexicana muestra características que correlacionan en buena medida con los datos gravimétricos y de espesor cortical (Figura 6b). La topografía a lo largo del arco magmático muestra elevaciones promedio de $200 \mathrm{msnm}$ y concentra los picos de mayor elevación del país. De manera general, la topografía muestra un incremento desde las costas hacia el interior del continente. Las mayores elevaciones $(>3500$ $\mathrm{msnm}$ ) se localizan hacia la porción oriental del arco mag- mático, destacando la presencia de grandes estratovolcanes alineados a lo largo del paralelo $19^{\circ} \mathrm{N}$, orientación que marca el frente volcánico activo. Es también evidente un aumento en la densidad de estratovolcanes en el sector oriental del arco, coincidente de manera general con el incremento en el espesor cortical. A todo lo largo de la FVTM, la elevación disminuye de manera gradual hacia el norte del frente volcánico.

\subsubsection{Geología del basamento}

La naturaleza geológica, edad y composición del basamento sobre el cual está emplazada la FVTM son en gran parte desconocidas debido a que se encuentran ocultas debajo de una amplia cobertura volcánica y sedimentaria de edad posterior al Mesozoico. Por esta razón, la extensión 
geográfica de los terrenos cristalinos que afloran en el sur de México, y sus correlaciones con afloramientos aislados y con los xenolitos colectados en secuencias volcánicas recientes al norte de la FVTM, han estado sujetos a múltiples discusiones (Keppie y Ortega-Gutiérrez, 1998; Ruiz et al., 1999).

Los trabajos pioneros de Campa y Coney (1983) propusieron que gran parte del territorio mexicano está constituido por un ensamble de masas corticales, con historias geológicas diferentes, que fueron acrecionadas a la placa de Norteamérica en distintos eventos tectónicos. Más tarde, los trabajos de Sedlock et al. (1993) y Ortega-Gutiérrez et al. (1994) propusieron una subdivisión de México en terrenos tectonoestratigráficos siguiendo algunos de los lineamientos de Campa y Coney (1983). El resultado fue una subdivisión mucho más compleja que, sin embargo, se ha ido simplificando con la acumulación de nuevos fechamientos, datos estructurales y petrológicos en las zonas donde estos terrenos afloran en superficie, con la investigación de xenolitos acarreados por rocas volcánicas recientes, y con la inspección de las rocas colectadas en perforaciones profundas.

Atendiendo a las reconstrucciones tectónicas y correlaciones estratigráficas propuestas por Sedlock et al. (1993) y Ortega-Gutiérrez et al. (1994), y al reconocimiento del microcontinente Grenvilliano Oaxaquia (Ruiz et al., 1988; Keppie y Ortega-Gutiérrez, 1995; Ortega-Gutiérrez et al., 1995), la FVTM podría estar emplazada sobre al menos tres terrenos tectonoestratigráficos distintos: Guerrero, Mixteco y Oaxaquia (Figura 7). Aunque todos ellos muestran una evolución geológica compleja, y varios aspectos acerca de su extensión, límites tectónicos y composición siguen siendo polémicos en la actualidad, a continuación se resumirán sus principales características geológicas, debido a que la petrogénesis de los magmas en la FVTM podría estar influenciada por la asimilación de estas unidades corticales.

\subsubsection{Terreno Guerrero}

El terreno Guerrero cubre una extensión cercana a $700000 \mathrm{~km}^{2}$ y es por lo tanto el terreno cordillerano más extenso de América del Norte. El terreno fue definido originalmente por Campa y Coney (1983), modificado por Sedlock et al. (1993) y ha sido también estudiado más detalladamente en sus características geoquímicas y petrológicas por varios autores (Lapierre et al., 1992; Centeno-García et al., 1993; Freydier et al., 1996; ElíasHerrera y Orterga-Gutiérrez, 1997; Freydier et al., 1997; Elías-Herrera y Ortega-Gutiérrez, 1998; Elías-Herrera $e t$ al., 1998). De manera general, el terreno Guerrero está com-

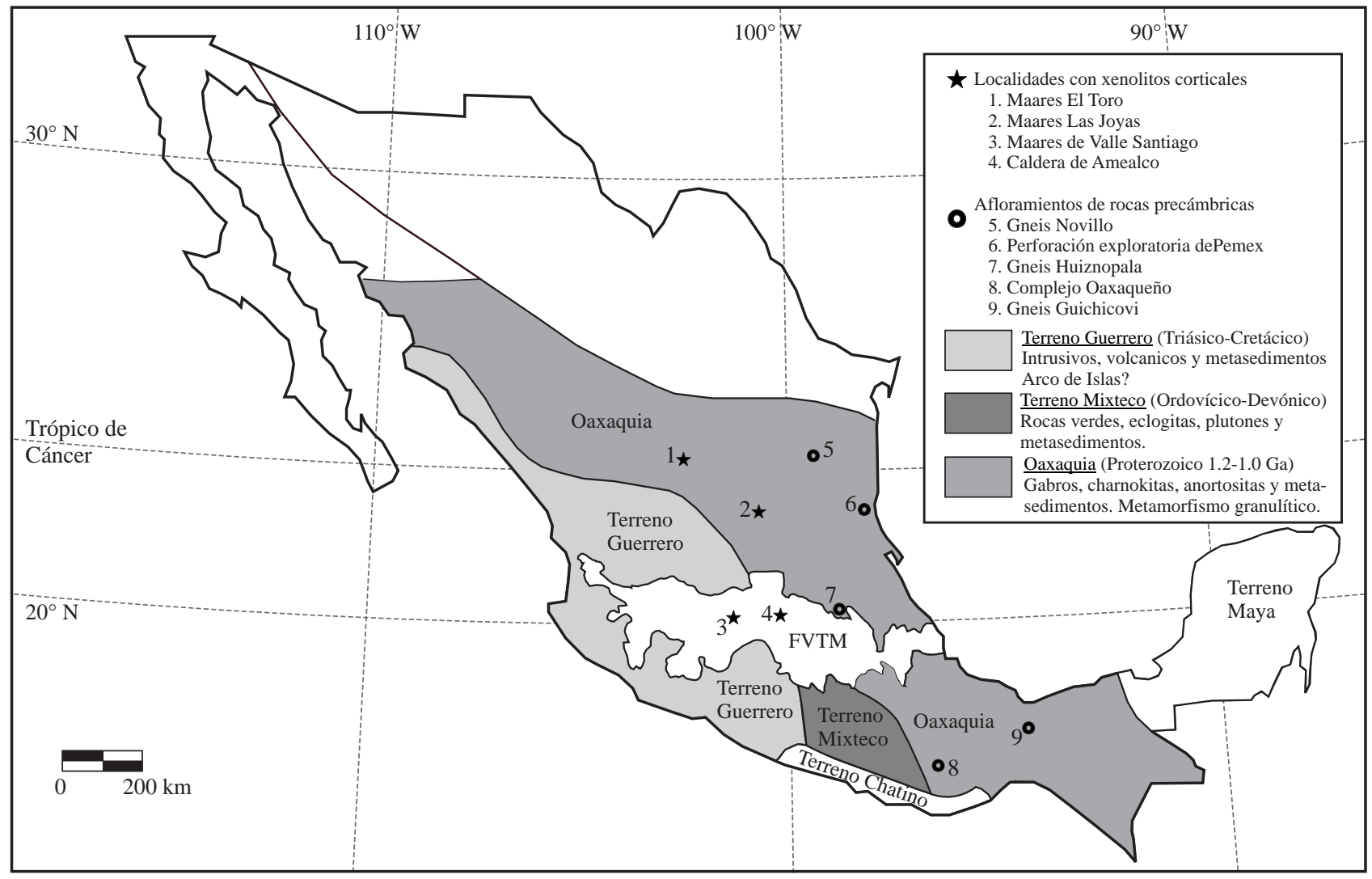

Figura 7. Mapa simplificado de los terrenos tectonoestratigráficos mexicanos que podrían formar el basamento de la FVTM (Campa y Coney, 1983; Ruiz et al., 1988; Sedlock et al., 1993; Ortega-Gutiérrez et al., 1994; Ortega-Gutiérrez et al., 1995). 
puesto por rocas volcánicas y volcaniclásticas de afinidad oceánica a continental, con una importante componente de rocas sedimentarias marinas. Utilizando información esencialmente geoquímica, Centeno-García et al. (1993) sugieren que la base estructural del terreno Guerrero refleja un ambiente marino profundo, relativamente cercano al continente, sobre el cual se emplazó un arco de islas intraoceánico que fue acrecionado a la placa de Norteamérica durante el Cretácico Superior.

A pesar de que tradicionalmente se ha considerado que la mayor parte del terreno Guerrero está constituido por rocas de afinidad oceánica y de arco magmático, otros estudios estratigráficos, geocronológicos y estructurales han cuestionado la aloctonía del terreno Guerrero, y en cambio lo consideran como un conjunto de rocas volcánicas y sedimentarias depositadas sobre la corteza atenuada de la placa de Norteamérica, que fue posteriormente deformada por la orogenia Larámide (Cabral-Cano et al., 2000b; CabralCano et al., 2000a). Así mismo, algunos datos geoquímicos recientes, obtenidos en xenolitos incorporados en rocas volcánicas del Oligoceno, han sugerido la existencia de rocas continentales silícicas debajo del terreno Guerrero (Elías-Herrera y Ortega-Gutiérrez, 1997; Elías-Herrera y Ortega-Gutiérrez, 1998; Elías-Herrera et al., 1998). Las edades modelo de $\mathrm{Nd}$ encontradas en las rocas intrusivas de la margen pacífica mexicana (Schaaf et al., 1995), así como la de un xenolito granulítico encontrado en los depósitos piroclásticos de la caldera de Amealco, Querétaro (Aguirre-Díaz et al., 2002), también sugieren la presencia de un basamento más antiguo. Estas evidencias indican que el terreno Guerrero se encuentra probablemente emplazado sobre rocas cristalinas de afinidad continental de edad precámbrica.

\subsubsection{Terreno Mixteco}

El basamento del terreno Mixteco está conformado por el denominado Complejo Acatlán (Yañez et al., 1991; Sedlock et al., 1993; Ortega-Gutiérrez et al., 1994). Las rocas que lo conforman son principalmente metasedimentos y metabasitas de afinidad oceánica a continental metamorfizadas en facies de anfibolita, eclogita y esquisto verde, que son intrusionados por granitos e influenciados por periodos de migmatización.

La estratigrafía del complejo Acatlán comprende los subgrupos Acateco y Petlalcingo, la Formación Tecomate, los troncos Totoltepec y el intrusivo San Miguel. La división de estas unidades está basada en los diferentes estilos de deformación y metamorfismo que las afectan. El subgrupo Petlalcingo está conformado por esquistos pelíticos, cuarcitas, metagrauvacas y diques gabroicos de la Formación Chazumba, y por anfibolitas, cuarcitas, pedernales, esquistos calcáreos y rocas verdes de la Formación Cosoltepec. Las rocas de este subgrupo han sido interpretadas como rocas sedimentarias marinas interestratificadas con rocas máficas de afinidad oceánica, que han sido metamorfizadas a presión moderada y alta temperatura. Las rocas del subgrupo Acateco incluyen rocas verdes miloníticas, anfibolitas, metagabros, serpentinitas, eclogitas, cuarcitas y metapelitas de la Formación Xayacatlán; y rocas plutónicas graníticas, aplíticas y pegmatíticas del Ordovícico-Silúrico denominadas como los Granitoides Esperanza (440-428 Ma). Las rocas eclogíticas de la Formación Xayacatlán alcanzan picos metamórficos de $15 \mathrm{~kb}$ y $500-550{ }^{\circ} \mathrm{C}$ (Ortega-Gutiérrez, 1981). Esta secuencia de basamento se encuentra discordantemente cubierta por conglomerados, arcosas, lutitas y calizas de la llamada Formación Tecomate del Devónico. Posteriormente, la Formación Tecomate fue deformada y metamorfizada antes del depósito de sedimentos marinos del Misisípico-Pérmico (Formación Patlanoaya), y continentales del Pensilvánico(?)-Pérmico (Formación Matzitzi). El Complejo Acatlán fue afectado por un evento intrusivo del Pensilvánico tardío (287 \pm 2 Ma) denominado tronco de Totoltepec, y por un evento tectonotérmico del Jurásico Inferior al Medio (205-170 Ma) en donde se emplazaron los intrusivos San Miguel y la Migmatita Magdalena. La cobertura de las secuencias paleozoicas incluyen: (1) rocas volcánicas e intrusivas del Triásico al Jurásico Medio (Formación Rosario e Intrusivos San Miguel), (2) rocas sedimentarias marinas (conglomerados, calizas, lutitas y areniscas) del Jurásico al Cretácico Superior, (3) conglomerados, areniscas, lutitas y rocas volcánicas del Paleógeno, (4) ignimbritas riolíticas, secuencias volcaniclásticas, lavas andesíticas, cuerpos hipabisales andesíticos y secuencias sedimentarias lacustres del Oligoceno al Plioceno (Morán-Zenteno et al., 1999).

El terreno Mixteco limita al oriente con Oaxaquia, al sur con el terreno Chatino, y al occidente con el terreno Guerrero. La frontera norte del terreno Mixteco se encuentra cubierta por la FVTM y por lo tanto se desconoce si el límite con Oaxaquia representa una anisotropía cortical en el centro de México.

\subsubsection{Oaxaquia}

El concepto del microcontinente Oaxaquia (OrtegaGutiérrez et al., 1995) es uno de los temas de la geología mexicana que ha despertado gran atención en los últimos años. De manera simple, Oaxaquia representaría una gran masa cortical de edad Grenvilliana ( 1 Ga), con una extensión que podría alcanzar cerca de $1000000 \mathrm{~km}^{2}$. El microcontinente estaría conformado por los terrenos Oaxaca, Juárez, Sierra Madre, Maya y partes del terreno Coahuila de Campa y Coney (1983); o por sus equivalentes de Sedlock et al. (1993): Zapoteco, Guachichil, Tepehuano, Maya y partes del terreno Coahuiltecano. No obstante, la unificación de estos terrenos en el microcontinente Oaxaquia atiende únicamente a la similitud de las rocas que conforman el basamento del Proterozoico Medio (Grenvillianas) y no necesariamente a las rocas de cobertura.

El microcontinente Oaxaquia está definido por distintos afloramientos localizados hacia la porción oriental de México (Figura 7): Gneis Novillo (Ciudad Victoria, Tamaulipas) (Ortega-Gutiérrez, 1978), Gneis Huiznopala 
(Molango, Hidalgo) (Lawlor et al., 1999), Complejo Oaxaqueño (Oaxaca) (Ortega-Gutiérrez, 1984), Complejo Guichicovi (La Mixtequita, Oaxaca) (Murrillo-Muñetón, 1994; Weber y Köhler, 1998); por las edades modelo de $\mathrm{Nd}$ e isócronas de $\mathrm{Sm}-\mathrm{Nd}$ encontradas en xenolitos de la corteza inferior acarreados por rocas volcánicas cenozoicas: maares de La Joya y La Olivina (San Luis Potosí) (Ruiz et al., 1988; Schaaf et al., 1994); y mediante su identificación en perforaciones profundas hechas por PEMEX en Tampico, Tamaulipas (Quezadas-Flores, 1961).

Los afloramientos del Complejo Oaxaqueño están conformados principalmente por metapelitas, gneises cuarzofeldespáticos, calcisilicatos, anfibolitas y mármoles, comúnmente intrusionados por anortositas, charnokitas y gneises máficos granatíferos. Toda la secuencia se encuentra metamorfizada en facies de granulita, y localmente reequilibrada en facies de anfibolita. Las rocas descritas en los afloramientos de los Gneises Novillo, Huiznopala y Guichicovi presentan de manera general las mismas características litológicas, condiciones metamórficas y estructurales que las descritas en el Complejo Oaxaqueño. Por su parte, los xenolitos colectados en las secuencias volcánicas tienen dominantemente un carácter máfico a intermedio, y están constituidos por gabros y tonalitas metamorfizados en facies de granulita.

\section{Petrogénesis ígnea de la Faja Volcánica Transmexicana}

En este capítulo se revisarán las características composicionales de las rocas volcánicas emplazadas en la FVTM desde el Mioceno medio y tardío, echando mano de una extensa base de datos geoquímicos compilada de la literatura. Para efectos de claridad, y con ánimo de facilitar la lectura de este trabajo, hemos convenido dividir la gran variedad composicional de las rocas volcánicas en cuatro grandes grupos: rocas alcalino-sódicas, rocas alcalino-potásicas, rocas calcialcalinas y vulcanismo riolítico. Aunque esta división es a todas luces arbitraria (pues las composiciones químicas de las rocas de los distintos grupos tienden a traslaparse), la división obedece a que tradicionalmente los estudios petrológicos han estado enfocados a definir secuencias volcánicas específicas, y a que nos permite explorar a grandes rasgos los distintos procesos petrogenéticos que les dan origen.

\subsection{Composición química de las rocas volcánicas}

Este trabajo incluye una compilación de los análisis químicos de elementos mayores, traza y relaciones isotópicas reportadas en la literatura en cientos de muestras de roca volcánica de la Faja Volcánica Transmexicana (http://satori. geociencias.unam.mx/Centenario/Gomez-Tuena.xls). La base de datos contiene las coordenadas geográficas del punto de muestreo, así como la edad de emplazamiento determinada por métodos isotópicos o, en su caso, estimada a partir de las relaciones estratigráficas establecidas en el campo (Ferrari et al., 2005a).

Los datos utilizados en las Figuras 8-13 muestran las abundancias relativas de los elementos mayores recalculadas al $100 \%$ en base anhidra, y con el contenido de $\mathrm{FeO}$ y $\mathrm{Fe}_{2} \mathrm{O}_{3}$ recalculado de acuerdo a los criterios establecidos por Middlemost (1989). Es posible que los resultados obtenidos con este esquema de cálculo no coincidan con los presentados por los autores originales, pero consideramos que la aplicación de un criterio de normalización uniforme es indispensable para fines comparativos. Deseamos aclarar que una evaluación exhaustiva de las variaciones geoquímicas en la FVTM en el tiempo y en el espacio está más allá de los objetivos de este trabajo, y que simplemente pretendemos presentar diagramas de variación que permiten ilustrar las características composicionales más relevantes del arco. Así mismo consideramos necesario hacer notar que aunque las muestras incluidas en esta compilación se distribuyen a lo largo de todo el arco magmático, los datos reportados no son necesariamente representativos de la diversidad geoquímica de toda la FVTM. Esto se debe a que ciertas zonas del arco han recibido una atención especial en las investigaciones, mientras que en otras zonas los datos siguen siendo escasos.

La Figura 8 muestra el diagrama clásico de clasificación geoquímica basado en el contenido de álcalis totales y sílice (Le Bas et al., 1986) para todas las rocas incluidas en la compilación, así como la línea que divide las rocas alcalinas de las subalcalinas definida por Irvine y Baragar (1971). El diagrama muestra que las rocas con afinidades subalcalinas son claramente dominantes $(83 \%$ de los análisis), mientras que las rocas alcalinas se presentan de manera subordinada. En el esquema de clasificación de Le

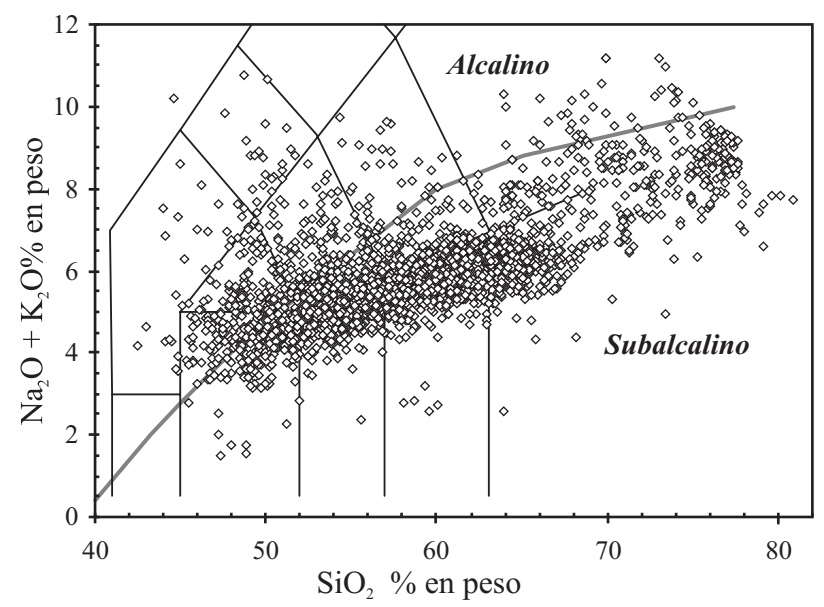

Figura 8. Diagrama de clasificación basado en el contenido de álcalis totales vs. sílice (Le Bas et al., 1986) para los análisis compilados de la Faja Volcánica Transmexicana. Se incluye la línea que divide los campos de las rocas alcalinas y subalcalinas (Irvine y Baragar, 1971). 
Maitre (1989), la gran mayoría de las rocas subalcalinas pertenecen a la serie calcialcalina con contenido medio de $\mathrm{K}(\sim 86 \%$ de los análisis), mientras que las rocas calcialcalinas ricas en $\mathrm{K}$ son menos abundantes (Figura 9). Por su parte, las rocas alcalinas se pueden dividir en sódicas y potásicas utilizando el diagrama de Le Bas et al. (1986) (Figura 9b). En este caso, las rocas alcalino sódicas son relativamente más abundantes (62\% de los análisis).

La Figura 10 muestra la distribución geográfica de las distintas series magmáticas. En este caso se grafican únicamente las rocas con $\mathrm{MgO}>5 \%$ con la finalidad de filtrar los efectos de cristalización y/o contaminación en el contenido de álcalis. Las rocas subalcalinas (calcialcalinas) y alcalinas se encuentran ampliamente distribuidas a todo lo largo de la FVTM, pero es notable que las rocas alcalinas (tanto sódicas como potásicas) tienden a concentrarse hacia los extremos occidental y oriental del arco. Así mismo, las rocas alcalino-potásicas se encuentran ubicadas en una franja que marca la ubicación del frente magmático occidental del arco y se observa también que su abundancia relativa tiende a desvanecerse hacia el oriente.

La composición de elementos mayores es significativamente diferente en los tres tipos de rocas. Las rocas alcalinas tienden a mostrar concentraciones de $\mathrm{SiO}_{2}$ me-

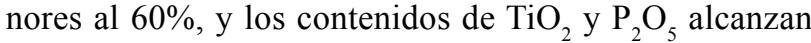
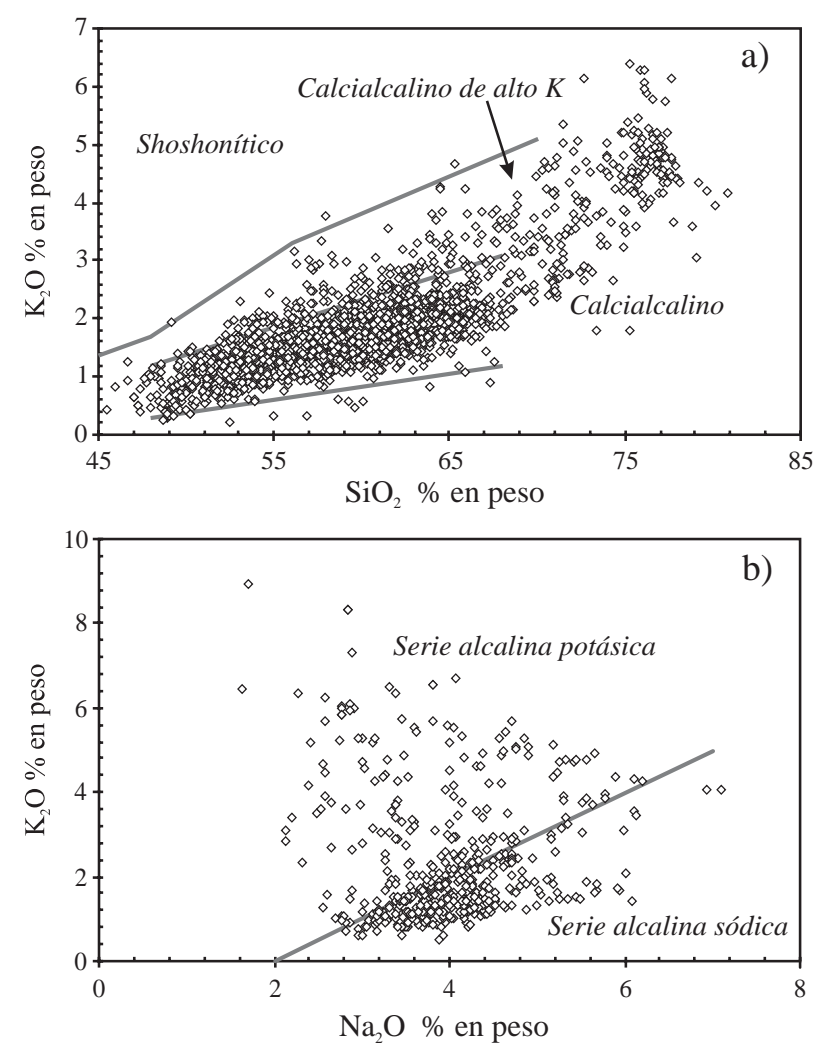

Figura 9. (a) Clasificación de las rocas subalcalinas (Le Maitre, 1989). (b) Subdivisión de las rocas alcalinas en las series sódicas y potásicas. La línea de división corresponde a $\mathrm{Na}_{2} \mathrm{O}-2=\mathrm{K}_{2} \mathrm{O}$ (Le Bas et al., 1986). los valores más elevados (Figura 11). La diferencia más obvia entre las rocas alcalinas potásicas y sódicas es el contenido más alto de $\mathrm{K}_{2} \mathrm{O}$ en las primeras y de $\mathrm{Na}_{2} \mathrm{O}$ en las segundas, a concentraciones equivalentes de $\mathrm{SiO}_{2}$. Las rocas alcalino-potásicas menos diferenciadas también tienen los contenidos más altos de $\mathrm{P}_{2} \mathrm{O}_{5}$. Por otra parte, las rocas subalcalinas alcanzan los valores más altos de $\mathrm{SiO}_{2}$ y sus datos muestran una menor dispersión que los de las rocas alcalinas.

En términos de los elementos traza las diferencias entre los tres tipos de rocas se ejemplifican con las variaciones relativas en $\mathrm{Nb}, \mathrm{Sr}$ y $\mathrm{Ba}$ (Figura 12). El Nb está marcadamente enriquecido en las rocas alcalinas, alcanzando valores algo más elevados en las rocas alcalinas sódicas. La mayoría de las rocas subalcalinas tienen valores bajos de $\mathrm{Nb}(<20 \mathrm{ppm})$, aunque algunas muestras alcanzan valores hasta de 40 ppm y son notorios los altos contenidos que presentan las rocas riolíticas. En cambio, las rocas alcalinas potásicas se caracterizan por alcanzar contenidos muy elevados de Sr (hasta 5,109 ppm) y Ba (hasta 4,765 ppm), mientras las rocas alcalinas sódicas pueden presentar valores sólo ligeramente más elevados que las rocas subalcalinas.

Las diferencias en la composición química son especialmente notorias entre las rocas alcalinas sódicas y potásicas, mientras que las rocas subalcalinas pueden mostrar traslape con esos tipos de rocas. Esto se ejemplifica con el diagrama $\mathrm{Ba} / \mathrm{Nb}$ vs. $\mathrm{TiO}_{2} / \mathrm{K}_{2} \mathrm{O}$ (Figura 13), en el que se compara el comportamiento de elementos litófilos de ión grande (LILE, e. g., Ba, K) respecto a los elementos de alto potencial iónico (HFSE, e. g., Nb, Ti). La Figura 13 muestra únicamente las rocas con contenidos de $\mathrm{MgO}>5 \%$ con el fin de eliminar en lo posible los efectos de la diferenciación y/o contaminación. En su gran mayoría, las rocas alcalinas sódicas muestran valores bajos de la relación $\mathrm{Ba} / \mathrm{Nb}$ y elevados de $\mathrm{TiO}_{2} / \mathrm{K}_{2} \mathrm{O}$, aunque sólo una parte de ellas presentan los bajos valores de $\mathrm{Ba} / \mathrm{Nb}$ característicos de las rocas intraplaca o de los basaltos asociados a las crestas meso-oceánicas. En las rocas alcalinas potásicas se observa un comportamiento opuesto, pues están enriquecidas en los LILE respecto a los HFSE mostrando valores bajos de $\mathrm{TiO}_{2} / \mathrm{K}_{2} \mathrm{O}$ y una tendencia a valores elevados de $\mathrm{Ba} / \mathrm{Nb}$. Los datos de rocas subalcalinas muestran mayor dispersión, y es notable que sus valores traslapen con los observados tanto de las rocas alcalinas sódicas como de las potásicas, aunque tienden a concentrarse en valores intermedios entre esos dos tipos.

\subsection{Rocas alcalinas sódicas y el magmatismo intraplaca}

En diversas localidades de la Faja Volcánica Transmexicana se han identificado rocas alcalinas de carácter sódico con características geoquímicas similares a las observadas en rocas generadas en ambientes tectónicos intraplaca ( $i$. e., islas oceánicas y rifts continentales). 


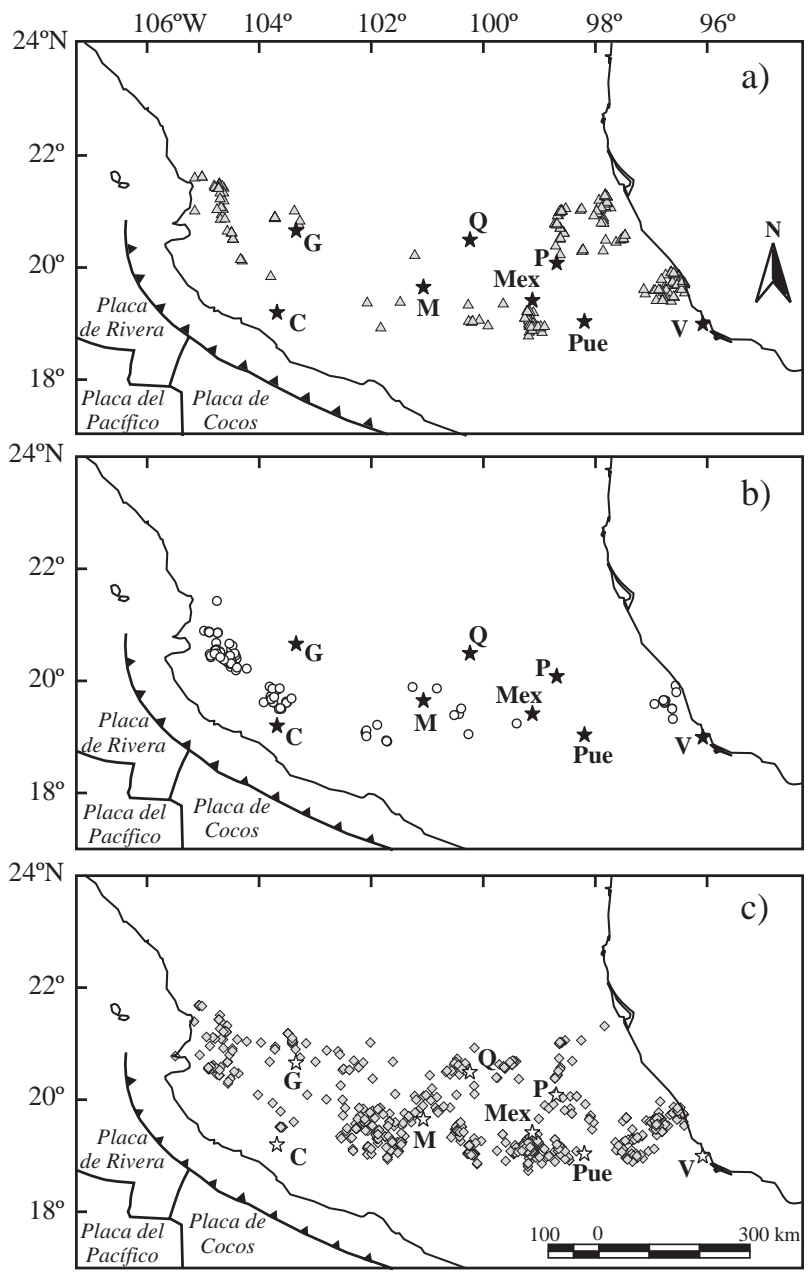

Figura 10. Distribución geográfica de las rocas (a) alcalinas sódicas, (b) alcalinas potásicas, y (c) subalcalinas (calcialcalinas) con contenido de $\mathrm{MgO}>5 \%$ en peso. Las estrellas indican las principales ciudades del centro de México. C: Colima; G: Guadalajara; M: Morelia; Q: Querétaro; Mex: Ciudad de México; P: Pachuca; Pue: Puebla; V: Veracruz.

Aunque este tipo de rocas tiende a mostrar composiciones variables, es notable que en general no muestren señales geoquímicas que permitan asumir contribuciones significativas de la placa en subducción o de la corteza continental. No obstante, las rocas con estas características constituyen un volumen relativamente pequeño dentro de la FVTM y, por lo general, han sido emplazadas en estrecha relación espacial y temporal con rocas que presentan señales apreciables de subducción.

En la actualidad se reconoce que las denominadas rocas intraplaca se han emplazado en una gran diversidad de ambientes tectónicos y que no necesariamente se ubican en zonas muy alejadas de los márgenes tectónicos activos. Sin embargo, y dada la similitud composicional con los basaltos de islas oceánicas (Ocean Island Basalts, OIB), se considera que las rocas continentales de tipo intraplaca se generan por fusión parcial de zonas del manto relativamente enriquecidas en elementos incompatibles, que contrastan con aquellas porciones empobrecidas del manto que dan origen a los basaltos de crestas meso-oceánicas (MORB). Sin embargo, el origen de este enriquecimiento del manto, y la razón por la cual aparece en zonas relativamente restringidas, siguen siendo motivo de acalorada discusión entre los investigadores. La gran mayoría de los investigadores consideran que las características geoquímicas del manto tipo OIB se relaciona al reciclaje de cortezas oceánicas antiguas (incluyendo a sus porciones sedimentarias y gabroicas) que han sido incorporados dentro del manto astenosférico en un mecanismo ligado al proceso global de subducción que ha operado durante la mayor parte de la historia geológica del planeta (Hofmann, 2003). Sin embargo, otros autores han sugerido que la fuente de los magmas de tipo OIB se localiza en el manto litosférico que ha sido metasomatizado por magmas mantélicos enriquecidos en volátiles y elementos incompatibles (Sun y McDonough, 1989; Halliday et al., 1995; Pilet et al., 2004). También se ha sugerido que su origen podría estar relacionado con una delaminación de la litósfera continental metasomatizada y su incorporación dentro del manto astenosférico (McKenzie y O’Nions, 1995).

Pero independientemente de las discusiones sobre el origen del manto que genera los OIB, lo cierto es que la presencia de lavas basálticas con características intraplaca en la FVTM implica que existen fuentes del manto enriquecidas que no han sido modificadas significativamente por el proceso de subducción. Por mucho tiempo se ha pensado que la generación contemporánea de magmas de intraplaca y magmas con señales de subducción no concuerda con los modelos clásicos de magmatismo asociado a márgenes convergentes, y por este motivo muchos investigadores han enfocado sus esfuerzos a tratar de resolver esta aparente discrepancia. Sin embargo, también hay que reconocer que cada vez son frecuentes los reportes de rocas con características de OIB en varios arcos magmáticos del orbe (Hickey-Vargas et al., 1986; Carr et al., 2003; Strong y Wolff, 2003) y que su presencia parece ser más común de lo que se pensaba anteriormente.

Aunque las lavas alcalinas sódicas representan un volumen relativamente pequeño, su presencia es significativa en los extremos occidental y oriental de la FVTM, y también se presentan de manera aislada en los campos monogenéticos de Michoacán-Guanajuato (Hasenaka y Carmichael, 1987), Chichinautzin (Wallace y Carmichael, 1999; Verma, 2000a), Valle de Bravo-Zitácuaro (Blatter et al., 2001), en las calderas de Los Humeros (Verma, 2000b) y Acoculco (Verma, 2001a).

Las rocas alcalinas sódicas más antiguas de la FVTM se encuentran en el extremo oriental, en los campos volcánicos de Chiconquiaco-Palma Sola, Álamo, sierra de Tantima y Tlanchinol (Figura 14). A partir del Mioceno tardío ( 7.5 Ma) y continuando hasta el Plioceno temprano ( $3 \mathrm{Ma}$ ) los magmas emplazados en estos campos son casi exclusivamente alcalinos sódicos. Durante este periodo 

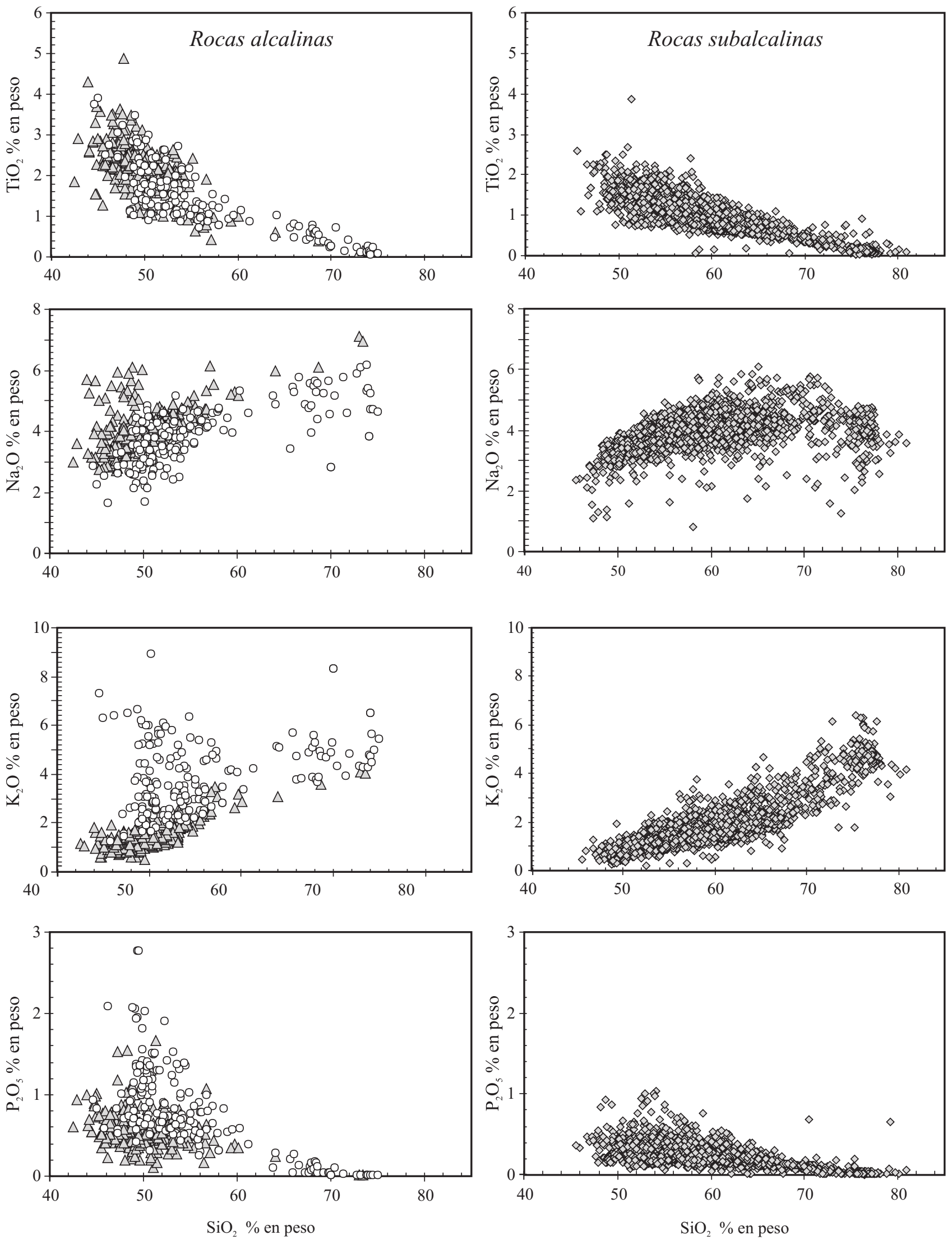

Figura 11. Diagramas de variación de algunos elementos mayores en función del contenido de $\mathrm{SiO}_{2}$ para rocas alcalinas sódicas (triángulos grises), alcalinas potásicas (círculos blancos), y subalcalinas (rombos grises). 
dominan las emisiones de tipo fisural que formaron grandes mesetas de lava de composición máfica (Cantagrel y Robin, 1979; Negendank et al., 1985; López-Infanzón, 1991; Gómez-Tuena et al., 2003; Ferrari et al., 2005b). Hacia el Pleistoceno-Holoceno también se emplazaron lavas alcalinas sódicas en este sector, pero en volúmenes subordinados respecto a las rocas calcialcalinas coexistentes (Negendank et al., 1985; López-Infanzón, 1991; Siebert y Carrasco-Núñez, 2002; Gómez-Tuena et al., 2003; Ferrari et al., 2005b). Rocas de edad y composición similar a las de la FVTM oriental también han sido reportadas en el campo volcánico de Los Tuxtlas (Nelson y González-Caver, 1992; Nelson et al., 1995). Sin em- bargo, y aunque el magmatismo asociado a Los Tuxtlas también parece estar influenciado por la subducción de la placa de Cocos, hemos decidido dejarlo fuera de esta revisión pues no se encuentra ubicado dentro de los límites tradicionales de la Faja Volcánica Transmexicana (Lámina 1 y Figura 1).

Originalmente, los campos volcánicos alcalinos del sector oriental fueron interpretados como pertenecientes a una provincia magmática independiente asociada a procesos extensionales paralelos a la costa del Golfo de México, sin relación con el sistema de subducción del Pacífico. Esta provincia fue definida como Provincia Alcalina Oriental por Demant y Robin (1975) y Robin
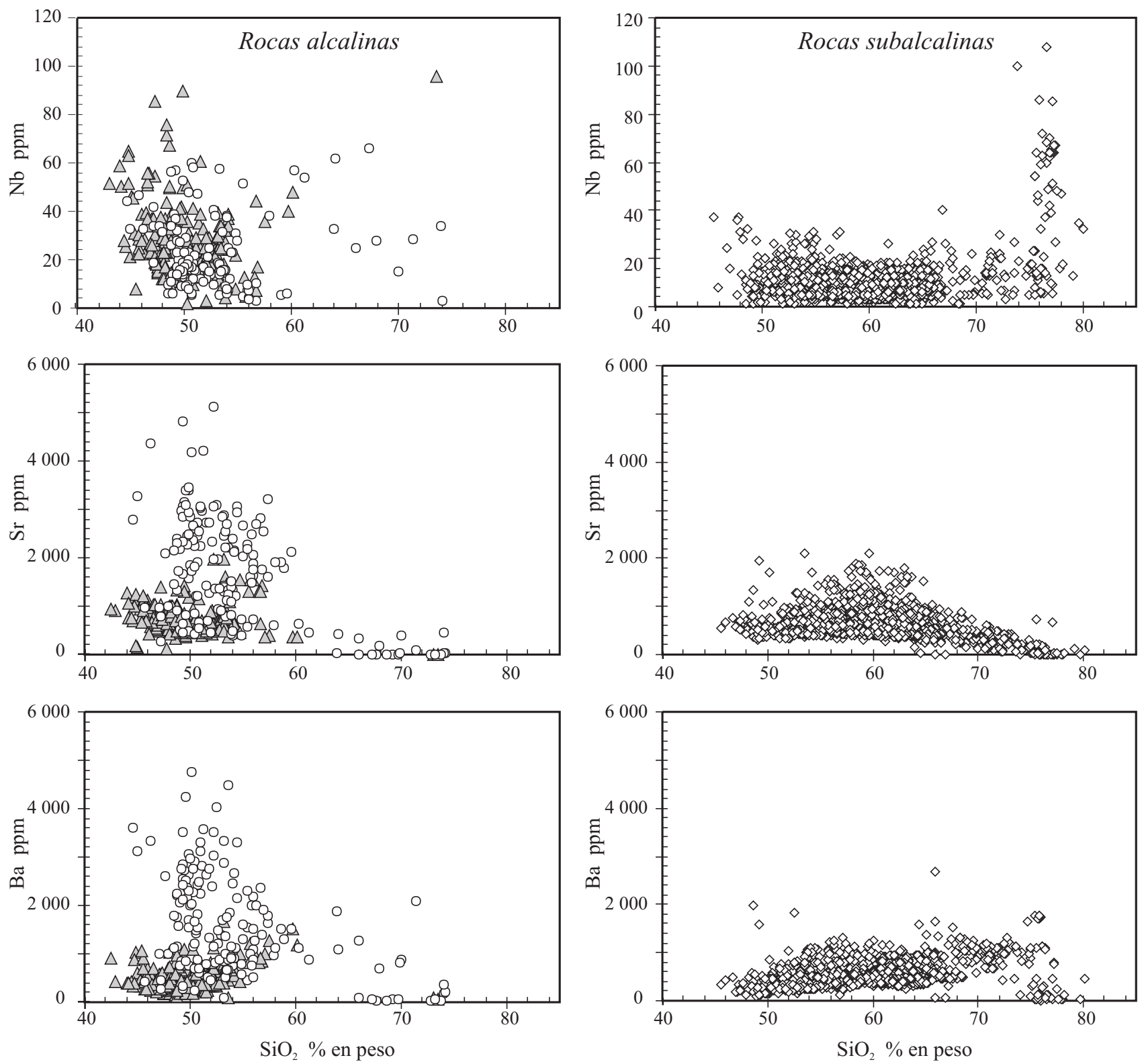

Figura 12. Diagramas de variación de algunos elementos traza en función del contenido de $\mathrm{SiO}_{2}$ para rocas alcalinas sódicas (triángulos grises), alcalinas potásicas (ćrculos blancos), y subalcalinas (rombos blancos). 
(1976a). Sin embargo, trabajos posteriores han reportado evidencias geoquímicas e isotópicas de la contribución de material subducido a los magmas alcalinos emplazados en Chiconquiaco-Palma Sola (Negendank et al., 1985; López-Infanzón, 1991; Gómez-Tuena et al., 2003). Por otra parte, Ferrari et al. (2005b) observan que el emplazamiento de magmas alcalinos inicia en toda el área de manera casi simultánea, lo que sugiere un mecanismo regional común para su origen, pero descartan el modelo de rifting debido a la ausencia tanto de fallas normales del Terciario tardío paralelas al Golfo de México (N-S a NNW-SSE), como de fallamiento extensional significativo capaz de producir fusión del manto por descompresión. Además establecen que diques, alineamientos de conos y alargamiento de conos presentan una orientación preferencial NE-SW y NNW-SSE paralela a estructuras corticales preexistentes, las cuales pudieron haber facilitado y controlado el ascenso de magmas, pero que no fueron responsables de inducir la fusión del manto. Con base en las evidencias geoquímicas, geocronológicas y geológicas, diversos autores coinciden en que los campos volcánicos en cuestión forman parte de la FVTM y se relacionan con el sistema de subducción del Pacífico (Negendank et al., 1985; López-Infanzón, 1991; Gómez-Tuena et al., 2003).

Ferrari et al. (2005b) realizaron un estudio geológico y geocronológico en los campos volcánicos al norte del sector oriental. Estos autores reportan edades de 7.6-5.7 Ma para la sierra de Tantima, campo volcánico de Álamo, y flujos lávicos de Tlanchinol. En los campos volcánicos de la sierra de Tantima y Tlanchinol, las secuencias de flujos de lava alcanzan espesores totales de $700 \mathrm{~m}$ y 250 $\mathrm{m}$, respectivamente. El alargamiento al NE de la Sierra de Tantima se considera el resultado de la erupción a través de una fisura de dirección NE. Al sur de la sierra de Tantima, el campo volcánico de Álamo está formado por al menos 40 volcanes monogenéticos, de los cuales sólo se han preservado cuellos volcánicos o diques alimentadores que presentan alargamiento y alineamientos en dirección NE-SW y NNW-SSE. Las lavas en estos campos tienen composición de basanita, basalto alcalino, hawaiita y fonotefrita. Los magmas más alcalinos se encuentran en los volcanes monogenéticos de Álamo, donde las rocas contienen nefelina (ne) en la norma CIPW (2.6-11.4\%), mientras que en la sierra de Tantima y en los flujos de Tlanchinol se presentan tanto rocas normativas en nefelina (ne: $1.4-4.7 \%$ ) como en hiperstena (hy: 2.9-9.5\%). Todas estas rocas presentan la composición geoquímica característica de magmas de intraplaca (Orozco-Esquivel, 1995; Ferrari et al., 2005b).

En la parte sur del sector oriental, el área de Chiconquiaco-Palma Sola presenta una historia magmática más larga y compleja, durante la cual se han generado rocas calcialcalinas, transicionales, alcalinas sódicas y potásicas en un período que comprende del Mioceno medio al Reciente. En esta área, los flujos de lava fisurales de composición alcalina sódica suelen formar mesetas (plateaus) que en conjunto alcanzan $800 \mathrm{~m}$ de espesor y cubren una extensión de aprox. 1700 km². Aparentemente, el emplazamiento de las lavas fue controlado por un sistema de fallas del basamento de orientación ENE, que facilitaron el ascenso de los magmas primitivos (Ferrari et al., 2005b). El estilo de emplazamiento y la presencia de xenolitos de lherzolita de espinela y xenocristales de clinopiroxeno en algunos flujos indican que los magmas ascendieron rápidamente desde el manto hasta la superficie (Gómez-Tuena et al., 2003). Para las lavas del plateau se han reportado edades del Mioceno tardío al Plioceno tardío o Cuaternario (Cantagrel y Robin, 1979; López-Infanzón, 1991), pero análisis de rocas fechadas por el método K-Ar indican que el evento en el que predominan las rocas alcalinas sódicas se restringe a un rango de edad entre 6.9 y $3.2 \mathrm{Ma}$, lapso en el que se formó la mayor parte del plateau, y que en
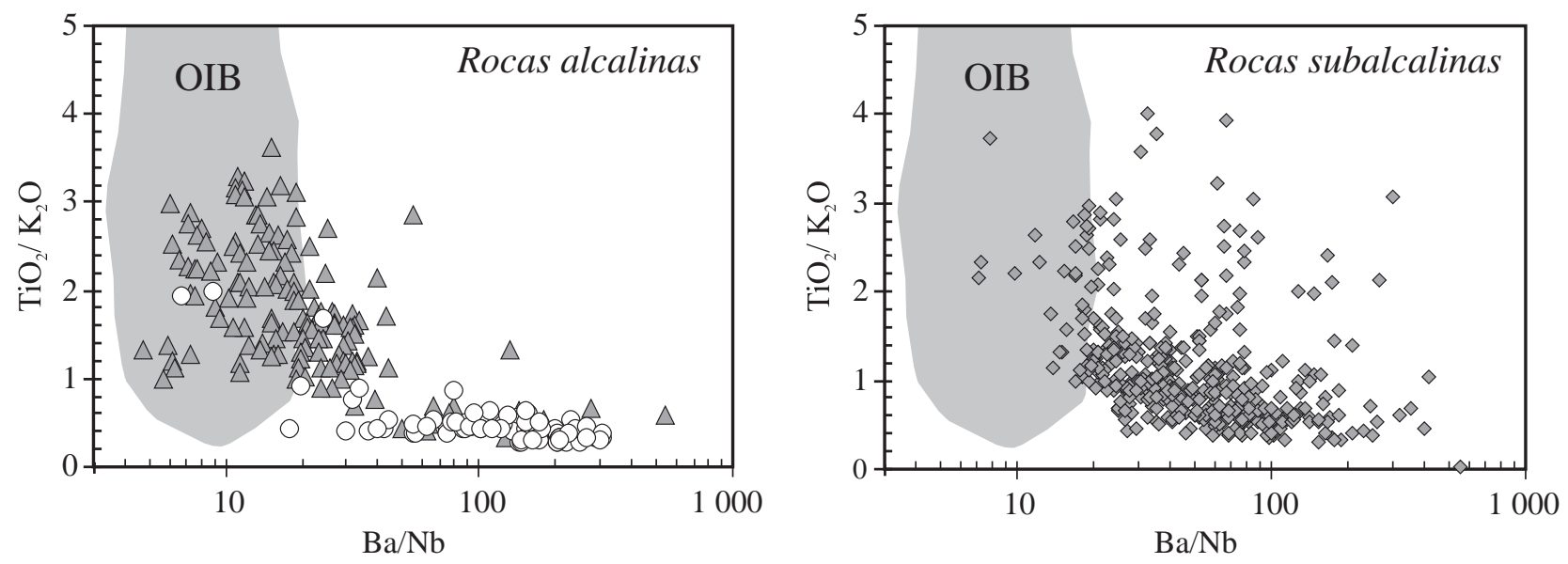

Figura 13. Diagrama de $\mathrm{Ba} / \mathrm{Nb}$ vs. $\mathrm{TiO}_{2} / \mathrm{K}_{2} \mathrm{O}$ para muestras con contenido de $\mathrm{Mgo}>5 \%$ en peso. Rocas alcalinas sódicas: triángulos grises; alcalinas potásicas: círculos blancos; y subalcalinas: rombos grises. El campo de basaltos de islas oceánicas (OIB) se trazó a partir de 992 análisis de la compilación de Georoc (http://georoc.mpch-mainz.gwdg.de/georoc). 


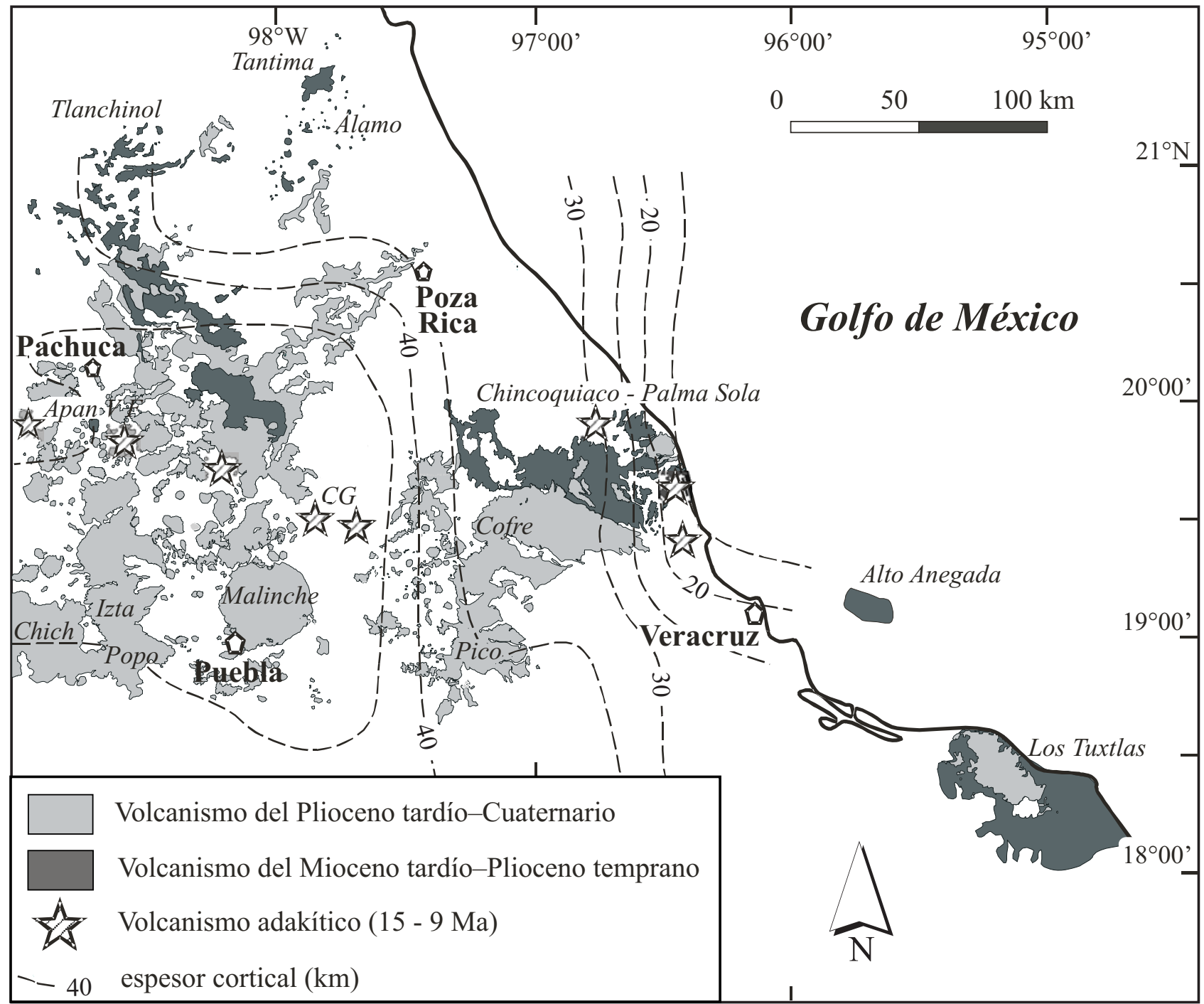

Figura 14. Mapa simplificado del sector oriental de la Faja Volcánica Transmexicana que muestra la relación espacial entre el volcanismo del Mioceno tardío-Plioceno temprano, constituido principalmente por rocas alcalinas sódicas, y el volcanismo del Plioceno tardío-Cuaternario. Se muestra también la ubicación de algunos campos volcánicos del sector oriental: campo volcánico de Apan (Apan), campo volcánico de Cerro Grande (CG), volcanes Popocatépetl (Popo), Iztaccíhuatl (Izta), Sierra Chichinautzin (Chich), Pico de Orizaba (Pico), Cofre de Perote (Cofre). Figura modificada de Ferrari et al. (2005b).

el Plioceno tardío (2.2-1.9 Ma) se emplazaron sobre ese plateau volúmenes menores de lavas alcalinas potásicas de la serie shoshonítica (Ferrari et al., 2005b).

Las lavas alcalinas sódicas son de composición basanítica a mugearítica, y contienen nefelina o hiperstena en la norma (Gómez-Tuena et al., 2003; Ferrari et al., 2005b). Aunque algunos autores reportaron que todas estas lavas tienen firmas geoquímicas de subducción (Negendank et al., 1985; López-Infanzón, 1991), estudios geoquímicos e isotópicos posteriores realizados por Gómez-Tuena $e t$ al. (2003) muestran que en el plateau aparecen interestratificadas lavas con enriquecimiento en $\mathrm{Nb}$ y $\mathrm{Ta}$ y valores bajos de LILE/HFSE, como los observados en magmas de tipo OIB, y lavas con relaciones moderadamente altas de LILE/HFSE y enriquecimiento en $\mathrm{Pb}$ y $\mathrm{Sr}$ que se relacionan con la contribución de los componentes de subducción. Estos autores indican que dichas variaciones no están relacionadas con procesos de contaminación cortical sino que son características derivadas de un manto enriquecido, modificado heterogéneamente por efectos de la subducción. De acuerdo con Gómez-Tuena et al. (2003), la composición de las rocas sin señales de subducción (tipo OIB) indica un origen por fusión parcial en porciones de manto enriquecido relativamente profundas, en el campo de estabilidad de las peridotitas de granate. Las rocas con firma de subducción muestran correlaciones en los diagramas ${ }^{206} \mathrm{~Pb} /{ }^{204} \mathrm{~Pb} v$ s. ${ }^{207} \mathrm{~Pb} /{ }^{204} \mathrm{~Pb}$ y ${ }^{143} \mathrm{Nd} /{ }^{144} \mathrm{Nd} v$ s. Th/Nd que indican un proceso de mezcla entre el manto enriquecido y un magma derivado de la fusión parcial de los sedimentos subducidos. Sin embargo, la presencia de bajos contenidos 
de elementos móviles en fluidos $(\mathrm{Ba}, \mathrm{Pb})$ en comparación con los observados en los sedimentos muestreados en el sitio DSDP 487, indica que los sedimentos sufrieron una notable deshidratación antes de fundirse e incorporarse hacia la cuña del manto. En este modelo la generación de magmas con características geoquímicas tan diferentes, en estrecha asociación espacial y temporal, requiere de un escenario tectónico complejo, en el que el manto funde por una combinación de procesos: (1) pequeñas porciones de la cuña del manto no modificado por subducción funden por descompresión generando magmas tipo OIB; (2) la inyección variable de fundidos de sedimentos subducidos previamente deshidratados promueve la fusión en la cuña del manto generando magmas con características de arco.

El vulcanismo del sector oriental es predominantemente calcialcalino durante el Cuaternario, aunque el vulcanismo alcalino sódico también está presente de manera aislada. Ferrari et al. (2005b) reportan la existencia de flujos masivos de lava máfica que fueron emitidos a través de fisuras en el frente de la Sierra Madre Oriental, al poniente de Poza Rica, Ver., y fluyeron por más de $90 \mathrm{~km}$ hacia la zona costera. Los autores reportan los primeros fechamientos isotópicos en estas rocas (K-Ar, matriz; $1.64 \pm 0.06$ a $1.31 \pm 0.03 \mathrm{Ma}$ ). Las lavas son basaltos alcalinos y hawaiitas normativos en hy o cuarzo (qz), con patrones de elementos traza relativamente empobrecidos que no presentan señales claras de la subducción.

Las rocas cuaternarias en la porción sur del sector oriental, en la región de Palma Sola, son generalmente de carácter calcialcalino, aunque también existen algunas rocas alcalinas sódicas asociadas (Gómez-Tuena et al., 2003 ) con edades muy recientes ( $\sim 870$ años) (Siebert y Carrasco-Núñez, 2002). Las rocas cuaternarias más primitivas presentan señales de subducción muy pequeñas o inexistentes, mientras que las rocas más evolucionadas tienden a mostrar señales de subducción relativamente más pronunciadas y composiciones isotópicas de $\mathrm{Sr}, \mathrm{Nd}$ y $\mathrm{Pb}$ mucho más enriquecidas ${ }^{1}$ que las observadas en las rocas intraplaca. Estas características han sido atribuidas a procesos de contaminación cortical con el basamento local, y no a contribuciones significativas de la placa oceánica subducida (Gómez-Tuena et al., 2003).

En el sector occidental de la FVTM se identifican rocas moderadamente alcalinas con características geoquímicas de tipo intraplaca, similares a las observadas en las

\footnotetext{
"Los términos "empobrecido" y "enriquecido" que se utilizan a lo largo del texto se refieren, sobre todo, a la comparación entre reservorios o componentes cuya composición isotópica es conocida. De esta forma, un reservorio isotópicamente empobrecido, como el que da origen a los basaltos meso-oceánicos (MORB), está empobrecido en elementos incompatibles y por lo tanto tendrá valores bajos de ${ }^{87} \mathrm{Sr} /{ }^{86} \mathrm{Sr},{ }^{206} \mathrm{~Pb} /{ }^{204} \mathrm{~Pb}$, ${ }^{207} \mathrm{~Pb} /{ }^{204} \mathrm{~Pb},{ }^{208} \mathrm{~Pb} /{ }^{204} \mathrm{~Pb}$ y altos de ${ }^{143} \mathrm{Nd} /{ }^{144} \mathrm{Nd}$. En contraste, la corteza superior está generalmente enriquecida en elementos incompatibles y por lo tanto tendrá valores altos de ${ }^{87} \mathrm{Sr} /{ }^{86} \mathrm{Sr},{ }^{206} \mathrm{~Pb} /{ }^{204} \mathrm{~Pb},{ }^{207} \mathrm{~Pb} /{ }^{204} \mathrm{~Pb},{ }^{208} \mathrm{~Pb} /{ }^{204} \mathrm{~Pb}$ y bajos de ${ }^{143} \mathrm{Nd} /{ }^{144} \mathrm{Nd}$.
}

islas oceánicas. Sin embargo, y a diferencia de lo que ocurre en el sector oriental, el emplazamiento de estas rocas mantiene generalmente una estrecha asociación con sistemas de fallas extensionales activos (Demant, 1979; Luhr y Carmichael, 1985a; Ferrari et al., 2000b) (Figura 15). En contraste con lo observado en el sector oriental, el vulcanismo intraplaca del sector occidental inició más tardíamente, durante el Plioceno temprano. La edad más antigua que se ha reportado para rocas alcalinas de intraplaca en el sector occidental corresponde a un basalto de la región de Guadalajara fechado en 4.6 Ma (K-Ar) (Moore et al., 1994). El vulcanismo intraplaca ha continuado de manera intermitente en el área hasta épocas recientes. Los productos de actividad volcánica intraplaca constituyen $\sim 5 \%$ del volumen total de rocas volcánicas emplazadas en el sector (Ferrari et al., 2001). Estas rocas coexisten espacial y temporalmente con rocas calcialcalinas y, en algunas localidades, con rocas alcalinas potásicas (Luhr et al., 1989b; Righter et al., 1995; Righter y Rosas-Elguera, 2001), aunque por lo general tienden a ser más abundantes hacia las porciones más alejadas de la trinchera.

Las localidades de vulcanismo intraplaca que han sido descritas hasta la fecha en el sector occidental (Figura 15) se encuentran en la zona costera de Nayarit, al oeste de Tepic (Righter et al., 1995); en el graben de Tepic-Zacoalco, incluyendo al área del volcán Sangangüey (Nelson y Carmichael, 1984); en el graben San Pedro-Ceboruco (Ferrari et al., 2003b; Petrone et al., 2003), en el graben Plan de Barrancas-Santa Rosa y la región al noreste de Guadalajara (Moore et al., 1994); dentro del bloque Jalisco en el graben Amatlán de Cañas (graben de Atenguillo) (Righter y Carmichael, 1992; Ferrari y Rosas-Elguera, 2000); y finalmente en la región de Ayutla (Righter y Rosas-Elguera, 2001).

La actividad magmática de tipo intraplaca ha formado volcanes escudo, mesetas de lava y numerosos conos cineríticos. Los conos cineríticos se encuentran generalmente alineados dentro de los grábenes, con orientaciones que coinciden con las de estructuras tectónicas en el área. Ejemplo de esto es el alineamiento de cerca de 50 conos que siguen una orientación NW-SE a lo largo $\sim 30 \mathrm{~km}$ cruzando el volcán Sangangüey (Nelson y Carmichael, 1984). En otras áreas, como Tepic y Ayutla, el patrón de distribución del vulcanismo es más difuso y no parece estar asociado con elementos tectónicos bien definidos (Righter et al., 1995; Righter y Rosas-Elguera, 2001).

En todas las localidades descritas se observan comportamientos muy similares de elementos mayores y traza. Las lavas han sido clasificadas como basaltos alcalinos, hawaiitas, mugearitas, benmoreitas y traquitas, que generalmente presentan nefelina o hiperstena en la norma, y muestran características típicas de magmas tipo OIB: altos contenidos de $\mathrm{TiO}_{2}$, Fe total y $\mathrm{Nb}$, y ausencia de enriquecimiento en LILE y LREE con respecto a los HFSE (Nelson y Carmichael, 1984; Righter y Carmichael, 1992; Moore et al., 1994; Righter et al., 1995; Righter y Rosas-Elguera, 
2001; Petrone et al., 2003). Por lo general las rocas no representan magmas primitivos, sino que generalmente se presentan productos más diferenciados, y es únicamente en la región de Ayutla, cercana al frente volcánico, en donde se han identificado magmas que aparentemente pueden ser considerados como primitivos (Righter y Rosas-Elguera, 2001). En el área de Sangangüey, Nelson y Livieres (1986) interpretaron la dispersión observada en los datos geoquímicos como el resultado del ascenso, desde el manto hasta la superficie, de pequeños lotes de magma independientes. Los pequeños lotes de magma en ascenso se diversificaron por procesos de cristalización fraccionada y asimilación de material cortical. Nelson y Carmichael (1984) también observaron que los conos cineríticos del área de Sangangüey que produjeron las rocas más diferenciadas tienden a ser relativamente más antiguos que los que emitieron basaltos alcalinos. Esta evidencia sugiere una diferencia notable en la velocidad de ascenso con el tiempo.

Aunque existe una estrecha relación espacial y temporal entre el emplazamiento de los magmas alcalinos y los subalcalinos, los trabajos publicados sobre este sector de la FVTM coinciden en afirmar que no existe una relación genética directa entre ambas series magmáticas. Esto quiere decir que ambos tipos de rocas deben proceder de magmas parentales distintos, generados en una cuña del manto composicionalmente heterogénea. En ese sentido, el manto debajo del sector occidental debe incluir porciones astenosféricas enriquecidas, que aparentemente no han sido modificadas por efectos de la subducción, y porciones metasomatizadas por los componentes derivados de la placa

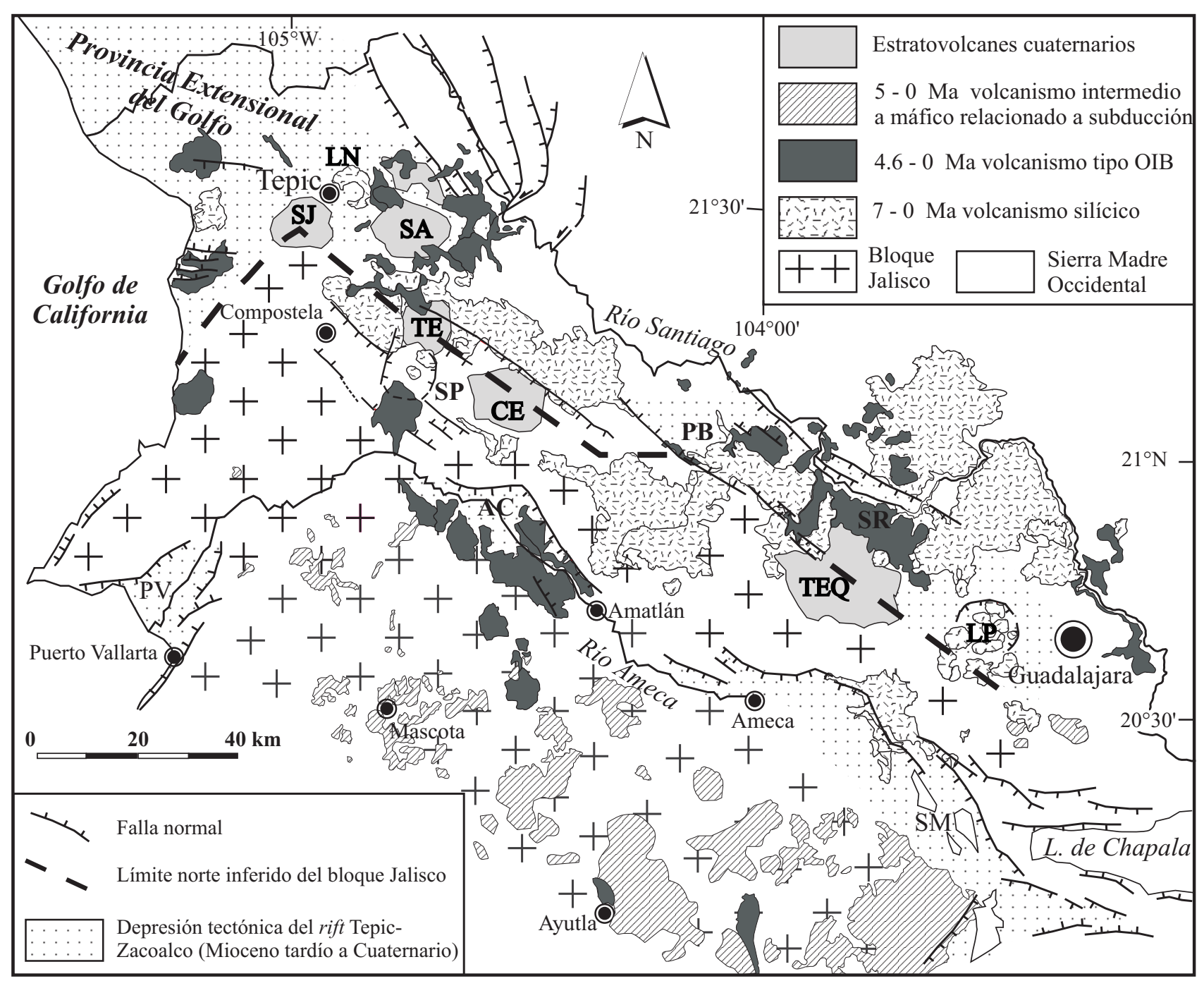

Figura 15. Mapa del sector occidental de la Faja Volcánica Transmexicana que muestra las principales fallas extensionales y la distribución del volcanismo posterior a los 7 Ma. Las estructuras volcánicas principales son: volcán San Juan (SJ), volcán Las Navajas (LN), volcán Sangangüey (SA), volcán Tepeltitic (TE), volcán Ceboruco (CE), volcán Tequila (TEQ), caldera La Primavera (LP). Las principales estructuras tectónicas son: graben de Puerto Vallarta (PV), graben San Pedro-Ceboruco (SP), semigraben de Amatlán de Cañas (AC), graben Plan de Barrancas-Santa Rosa (PB-SR), semigraben de San Marcos (SM). Figura modificada de Ferrari et al. (2003b). 
oceánica subducida. La existencia de un manto heterogéneo ha sido generalmente sustentada con varios argumentos geoquímicos, dado que es evidente la imposibilidad de generar las rocas calcialcalinas a partir de magmas alcalinos mediante procesos de cristalización fraccionada, mezcla de magmas o contaminación cortical (Nelson y Livieres, 1986; Verma y Nelson, 1989; Petrone et al., 2003). Así mismo, se ha reportado que el contenido de agua disuelta en los magmas antes de la erupción es significativamente menor en las rocas alcalinas $(1.5 \%-1.8 \%)$ que en las rocas calcialcalinas $(3 \%-5.8 \%)$, evidencia que sería consistente con un origen en una fuente del manto astenosférico (más seco) para las primeras (Righter et al., 1995). Los cálculos de la fugacidad de oxígeno respecto al buffer redox níquelóxido de níquel $(\triangle \mathrm{NNO})$ para rocas del sector occidental de Righter (2000), arrojan valores de $-1 \mathrm{a}+1$ para las rocas alcalinas de tipo intraplaca, mientras que las rocas calcialcalinas tienen valores más altos $(\triangle \mathrm{NNO}=1-3)$, consistente con un mayor grado de oxidación. Este autor sugiere una relación entre el grado de oxidación de la fuente y el tipo de magmas generados. Las rocas de tipo intraplaca proceden de material más reducido en la astenósfera, mientras que las rocas calcialcalinas proceden de un manto más oxidado.

La mayor parte de los estudios basados en las abundancias de elementos traza supone un manto enriquecido de tipo OIB, no afectado por componentes de subducción, como fuente de los magmas alcalinos sódicos. Los valores bajos en relación $\mathrm{La} / \mathrm{Yb}$ y alto contenido de $\mathrm{Yb}$, así como las relaciones de equilibrio en diagramas de fases indican un origen de los magmas en niveles del manto someros, en el campo de estabilidad de las peridotitas de espinela (Nelson y Livieres, 1986; Righter y Carmichael, 1992; Luhr, 1997a; Righter y Rosas-Elguera, 2001).

Desafortunadamente, los estudios isotópicos de rocas alcalinas sódicas del sector occidental siguen siendo escasos. En un estudio de las relaciones isotópicas de $\mathrm{Sr}$ y $\mathrm{Nd}$ del área de Sangangüey, Verma y Nelson (1989) reportan valores relativamente altos de ${ }^{143} \mathrm{Nd} /{ }^{144} \mathrm{Nd}(0.512843-0.512964)$, mientras que los valores de ${ }^{87} \mathrm{Sr} /{ }^{86} \mathrm{Sr}(0.703003-0.703980)$ son bajos y variables. Los autores interpretan que las rocas alcalinas sódicas de esta área se originaron en un manto tipo OIB y que las variaciones en las relaciones isotópicas se deben a un proceso de asimilación y cristalización fraccionada (AFC, Assimilation and Fractional Crystallization) que puede ser modelado asumiendo la composición de un "contaminante hipotético". En un estudio geoquímico más detallado, que incluye relaciones isotópicas de $\mathrm{Sr}, \mathrm{Nd}$ $\mathrm{y} \mathrm{Pb}$ de rocas del área de San Pedro-Ceboruco, Petrone et al. (2003) encuentran valores de ${ }^{143} \mathrm{Nd} /{ }^{144} \mathrm{Nd}(0.512946-$ $0.512964) \mathrm{y}{ }^{87} \mathrm{Sr} /{ }^{86} \mathrm{Sr}(0.703195-0.703437)$ dentro del rango de los reportados por Verma y Nelson (1989), aunque con menores variaciones, así como valores relativamente altos $\mathrm{de}^{206} \mathrm{~Pb} /{ }^{204} \mathrm{~Pb}$ (18.9011-19.0338) cercanos a los valores del manto enriquecido del tipo EM (Enriched Mantle). Petrone et al. (2003) modelan la composición de las rocas alcalinas sódicas a partir de un manto enriquecido (del tipo EM) que ha sido modificado por una contribución pequeña $(<0.5 \%)$ de componentes de subducción (fluidos y/o fundidos). La relevancia de estos resultados radica en que se identifica y cuantifica por primera vez la contribución, aunque pequeña, de componentes de subducción a los magmas alcalinos sódicos de este sector.

Finalmente, aunque diversos autores han propuesto que en la génesis de las rocas más evolucionadas pudieron haber participado procesos de contaminación cortical o de AFC (Verma y Nelson, 1989; Righter y Rosas-Elguera, 2001; Petrone et al., 2003), la identificación y cuantificación de la contribución de material cortical en los magmas se ve entorpecida por la falta de contraste isotópico entre los materiales provenientes del manto y la corteza continental que conforma el bloque Jalisco.

\subsection{Rocas alcalinas potásicas}

Aunque considerablemente menos abundantes que las típicas rocas calcialcalinas emplazadas a todo lo largo del arco, las rocas alcalinas potásicas de la FVTM han sido el objeto de numerosas investigaciones petrológicas y geoquímicas. Esto se debe no sólo a su inusual presencia con respecto a otros arcos magmáticos, sino también a su estrecha relación con el resto de las secuencias asociadas al arco, tanto en el tiempo como en el espacio.

Las rocas alcalino-potásicas son relativamente más abundantes en el denominado bloque Jalisco que en el resto de la FVTM, pero también es posible encontrar rocas con estas características químicas en volcanes monogenéticos o derrames fisurales del campo volcánico Michoacán Guanajuato (Luhr y Carmichael, 1985b; Hasenaka y Carmichael, 1987), y en el campo volcánico de Valle de Bravo-Zitácuaro (Blatter et al., 2001). También existen algunas rocas con estas características en las secuencias volcánicas del Plioceno tardío del área de Palma Sola que se encuentran comúnmente intercaladas con rocas alcalinassódicas (Negendank et al., 1985; López-Infanzón, 1991; Orozco-Esquivel, 1995; Gómez-Tuena et al., 2003).

La distribución geográfica de las rocas alcalinas potásicas del Plicoceno-Cuaternario marca claramente la existencia de un frente volcánico potásico en la porción occidental y central de la FVTM (Figura 10b), que aparentemente se diluye de forma gradual hacia el oriente del arco (si se excluyen las rocas potásicas pliocénicas de Palma Sola). En efecto, es notable que este tipo de rocas prácticamente desaparezcan al oriente del volcán Nevado de Toluca, y no deja de sorprender su ausencia en el campo volcánico de Chichinautzin, a pesar de la relativa abundancia de magmas máficos y a la presencia de un régimen tectónico distensivo en esta región del arco (Márquez et al., 1999c; Wallace y Carmichael, 1999). En ese sentido, y aunque los trabajos realizados en estas rocas han estado enfocados a tratar de investigar su origen primario en relación al régimen de subducción, hasta la fecha no existe una hipótesis 
que permita explicar su misteriosa ausencia en la porción oriental del arco.

El magmatismo potásico del bloque Jalisco (y de los campos volcánicos Michoacán-Guanajuato y Valle de Bravo Zitácuaro) ha sido en buena medida contemporáneo al magmatismo calcialcalino dominante, al menos desde el Plioceno. Las rocas alcalino-potásicas del bloque Jalisco han sido estudiadas con cierto detalle en varios campos volcánicos: San Sebastián (Lange y Carmichael, 1990; Lange y Carmichael, 1991), Los Volcanes (Wallace y Carmichael, 1989; Wallace y Carmichael, 1992), el graben de Atenguillo (Righter y Carmichael, 1992), los campos volcánicos de Ayutla y Tapalapa (Righter y Rosas-Elguera, 2001), y en el rift de Colima (Luhr y Carmichael, 1981; Luhr y Carmichael, 1982; Allan y Carmichael, 1984), aunque probablemente la mejor estudiada es la serie magmática de Mascota, Jalisco (Carmichael et al., 1996),

Las rocas emplazadas en el campo de Mascota varían en composición desde absarokitas primitivas y minetas, a andesitas y espesartitas. En la serie magmática de Mascota, las rocas con el mayor contenido de $\mathrm{K}_{2} \mathrm{O}$ tienen también el

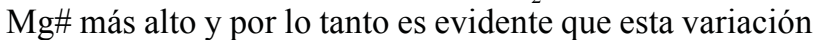
no puede ser el resultado de asimilación cortical y/o cristalización fraccionada, sino que debe reflejar las características geoquímicas de un manto enriquecido metasomáticamente por el proceso de subducción (Carmichael et al., 1996). La cercanía geográfica y la relativa contemporaneidad de las erupciones magmáticas con características alcalinopotásicas y calcialcalinas en Mascota, y en el resto de los campos volcánicos, sugiere claramente la existencia de una estrecha relación genética entre las distintas series magmáticas. Pero cómo ocurre esta relación y cuáles son los mecanismos que gobiernan las diferencias petrológicas, son preguntas que han estado sobre la mesa de discusión por largo tiempo.

El trabajo de Luhr (1997a) presenta tal vez la discusión más completa sobre el origen de las rocas alcalino-potásicas y su relación con el resto de las secuencias magmáticas emplazadas en la porción occidental de la FVTM. Luhr (1997a) fundamenta su discusión en el estudio de magmas primitivos, definiendo como tales a aquellos magmas con $\mathrm{MgO}>6 \%, \mathrm{Mg} \#>62$ en donde el $\mathrm{Fe}^{2+}=0.8 * \mathrm{Fe}^{\text {total }}$. La composición química de las rocas alcalino-potásica del bloque Jalisco se caracteriza por tener altos contenidos de metales alcalinos, especialmente por valores muy altos de $\mathrm{K}_{2} \mathrm{O}$ $\left(\mathrm{K}_{2} \mathrm{O} / \mathrm{Na}_{2} \mathrm{O}>0.5\right)$, pero también por presentar muy altas concentraciones de elementos LILE y de Tierras Raras (REE), así como valores muy altos en las relaciones LILE/HFSE, características geoquímicas que apuntan hacia un origen de subducción. Dadas las altas concentraciones de álcalis, no es de sorprender que la gran mayoría de las rocas alcalinopotásicas presenten nefelina, e incluso leucita, en la norma CIPW. En el diagrama de álcalis totales contra sílice (TAS), las rocas alcalino-potásicas se clasifican principalmente como traquibasaltos y traquiandesitas, y algunas muestras alcanzan incluso el campo de las fonotefritas. En el diagra- ma clásico de $\mathrm{SiO}_{2}$ contra $\mathrm{K}_{2} \mathrm{O}$ (Le Maitre, 1989), las rocas potásicas del bloque Jalisco pertenecerían de hecho a la serie shoshonítica, pero Carmichael et al. (1996) y Luhr (1997a) han enfatizado que las rocas potásicas del bloque Jalisco deben clasificarse como lamprófidos, en concordancia con los ensambles mineralógicos observados en las láminas delgadas. En efecto, la distinción entre shoshonitas y lamprófidos debe hacerse en términos petrográficos y no geoquímicos: las shoshonitas presentan fenocristales de olivino, clinopiroxeno y plagioclasa, mientras que los lamprófidos tienen fenocristales de anfíbol y/o flogopita pero carecen de feldespato. La presencia de mineralogías hidratadas, junto con la ausencia de plagioclasa, es un claro reflejo de los altos contenidos de agua en los magmas, cuyo efecto principal es disminuir la actividad de la sílice en el fundido (Sekine et al., 1979). Por otra parte, es común que los lamprófidos muestren valores altos y variables en la fugacidad de oxígeno cuando se les compara con las otras series magmáticas presentes en el arco.

En términos isotópicos de $\mathrm{Sr}-\mathrm{Nd}-\mathrm{Pb}$ los lamprófidos tienen composiciones muy similares a la observada en las rocas calcialcalinas del bloque Jalisco, sugiriendo que la fuente primigenia que da origen a ambas series magmáticas debe ser similar. Sin embargo, observando la distribución de los datos isotópicos de $\mathrm{Pb}$, Luhr (1997a) sugiere la participación de un componente mantélico enriquecido, similar al observado en montes submarinos del Pacífico (en los llamados Shimada Seamounts), para explicar la presencia de valores muy radiogénicos de $\mathrm{Pb}$ en todas las rocas del bloque Jalisco.

La gran mayoría de los investigadores que han estudiado las rocas potásicas del bloque Jalisco coinciden en afirmar que su origen debe estar relacionado con la fusión parcial de vetas ricas en flogopita, anfíbol, piroxeno y apatita (Carmichael et al., 1996; Luhr, 1997a). Estas vetas estarían distribuidas de manera heterogénea dentro del manto peridotítico, y se ha pensado que el origen de los magmas alcalinos potásicos podría estar asociado a la fusión preferencial de estas vetas a muy bajos grados de fusión parcial. Así mismo, un mayor grado de fusión permitiría la incorporación de mineralogías peridotíticas dentro del fundido.

Aunque la hipótesis de las vetas ricas en flogopita es una de las más favorecidas para explicar el origen de los magmas potásicos en distintos lugares del orbe (Foley, 1992), hasta la fecha no existe un consenso generalizado para explicar cómo y en qué momento ocurrió el metasomatismo potásico que generó las supuestas vetas en el manto mexicano. Algunos autores se han inclinado a pensar que estas vetas ricas en flogopita son de hecho una característica heredada de eventos previos de metasomatismo por subducción, dada la larga historia de convergencia de las placas pacíficas a lo largo del occidente mexicano, especialmente durante el emplazamiento de la Sierra Madre Occidental en el Eoceno-Oligoceno (Lange y Carmichael, 1991; Hochstaedter et al., 1996; Righter y Rosas-Elguera, 
2001). Este manto metasomatizado previamente podría fundirse con facilidad al verse involucrado en el régimen tectónico de subducción y extensión actuales del bloque Jalisco. De hecho, este modelo podría explicar en cierta medida la razón por la cual el magmatismo potásico se diluye hacia la porción oriental del arco mexicano, pues la influencia de la Sierra Madre Occidental se limita a las longitudes de la cuenca de México (Righter y RosasElguera, 2001). Sin embargo, y aunque esta hipótesis podría parecer tectónicamente atractiva, no es capaz de explicar la razón por la cual las rocas alcalino-potásicas y las rocas calcialcalinas del arco tienen prácticamente la misma composición isotópica de Sr. Esta peculiaridad composicional está lejos de ser un fenómeno trivial pues la flogopita, el mineral que aparentemente es el responsable de formar los magmas alcalino-potásicos, acepta con facilidad al $\mathrm{Rb}$ $\left(\mathrm{D}_{\mathrm{Rb}}>1\right)$ pero no incorpora grandes cantidades de $\operatorname{Sr}\left(\mathrm{D}_{\mathrm{Sr}}<1\right)$ (Schmidt et al., 1999). Por lo tanto, si el metasomatismo modal es un fenómeno que ocurrió hace varios millones de años, parecería inevitable que las vetas ricas en flogopita desarrollaran composiciones isotópicas de ${ }^{87} \mathrm{Sr} /{ }^{86} \mathrm{Sr}$ muy enriquecidas en un tiempo relativamente corto, debido a que la relación $\mathrm{Rb} / \mathrm{Sr}$ de la flogopita es mayor que la del manto peridotítico que las engloba.

En contraposición con el modelo del manto con vetas heredadas, Carmichael et al. (1996) y Luhr (1997b) proponen que la formación de estas vetas ricas en flogopita podría ser una consecuencia del régimen de subducción actual y estar asociadas con la desestabilización del anfíbol en la placa oceánica que se subduce a $\sim 80 \mathrm{~km}$ de profundidad, la consecuente liberación de fluidos o fundidos, y su reacción con las peridotitas del manto. Una vez formadas, las vetas y el manto que las engloba se verían arrastradas por acoplamiento viscoso con la placa que se hunde hacia posiciones más profundas. Al alcanzar una profundidad de $\sim 100 \mathrm{~km}$, las vetas ricas en flogopita comenzarán a fundir creando los magmas lamprofídicos ricos en $\mathrm{K}$ que ascienden hacia la superficie. Luhr (1997a) sugiere que los magmas lamprofídicos deberían ser de hecho considerados como la "esencia" geoquímica del magmatismo de subducción, a pesar de que raras veces logran ascender hasta la superficie. En la mayoría de los casos estos magmas poco voluminosos se enfrían y pierden agua durante su ascenso, y por lo tanto se emplazan como diques en el manto superior o en la corteza. Luhr (1997a) propone que es solamente gracias al intrincado ambiente tectónico prevaleciente en el bloque Jalisco, en donde existe un régimen de rifting sobrepuesto al sistema de subducción, que es posible el emplazamiento de este tipo de magmas en la superficie.

Las rocas alcalino-potásicas también han sido objeto de varias investigaciones de petrología experimental, sobre todo enfocadas a definir las condiciones termodinámicas de equilibrio de las fases mineralógicas observadas (Righter y Carmichael, 1996; Moore y Carmichael, 1998). Estos estudios han demostrado que la diversidad mineralógica y la cristalinidad dependen de muchas variables que pueden ser reproducidas experimentalmente: presión, temperatura, composición, fugacidad de oxígeno y, sobre todo, del contenido de agua. Más recientemente, el estudio experimental de Hesse y Grove (2003) intentó reproducir las condiciones de equilibrio de las absarokitas del bloque Jalisco. Estos investigadores utilizan la composición química de una roca absarokítica primitiva de la región de Mascota que debió haberse equilibrado con olivino mantélico al momento de su segregación del manto $\left(\mathrm{Fo}_{90}\right)$. Los resultados de estos experimentos señalan que al menos esta absarokita fue segregada a partir de un manto lherzolítico empobrecido, o incluso harzburgítico, localizado a una presión de 1.6 a $1.7 \mathrm{GPa}(48-51 \mathrm{~km}$ de profundidad) y con una temperatura de 1400 a $1300{ }^{\circ} \mathrm{C}$, en donde las variaciones en $\mathrm{P}$ y $\mathrm{T}$ dependen del contenido original de agua en el magma original (1.7\% a 5.1\%). Es notable, sin embargo, que los resultados de estos experimentos no predicen la existencia de mineralogías no peridotíticas en el manto a la $\mathrm{P}$ y $\mathrm{T}$ de último equilibrio, sugiriendo en todo caso que las supuestas vetas ricas en flogopita y anfíbol deben estar localizadas en zonas más profundas. En ese sentido, Hesse y Grove (2003) proponen un modelo para explicar la petrogénesis de las rocas potásicas del bloque Jalisco que involucra la inyección de fluidos desde la placa oceánica hacia la cuña del manto y la formación de minerales hidratados que son arrastrados hacia zonas más profundas por efecto de la convección inducida por la placa subducida. Los minerales hidratados se vuelven inestables en zonas más profundas, y por lo tanto se descomponen liberando fluidos que migran hacia el interior de la cuña del manto, promoviendo su fusión parcial y generando un magma rico en $\mathrm{K}_{2} \mathrm{O}$. Una vez formado, este magma asciende y se reequilibra continuamente con el manto astenosférico al disolver minerales peridotíticos. La última fase de reequilibrio con el manto registrada en los experimentos ocurre a $\sim 50 \mathrm{~km}$ de profundidad y, aparentemente, el magma no vuelve a sufrir ninguna modificación adicional durante el resto de su camino hacia la superficie.

\subsection{Rocas calcialcalinas}

Las rocas con afinidad calcialcalina se encuentran ampliamente distribuidas a todo lo largo y ancho del arco mexicano, y se han emplazado durante todos sus periodos de actividad (Figura 10c). Rocas de este tipo han sido extravasadas a partir de una gran diversidad de estructuras volcánicas: conos cineríticos, volcanes escudo, domos, estratovolcanes, maares, calderas, y también a través de fisuras y derrames de lava que no parecen estar asociados a una estructura volcánica central. Sin embargo, y aunque las composiciones de las rocas derivadas de las distintas estructuras volcánicas son a grandes rasgos similares, las rocas basálticas más primitivas están siempre asociadas a conos cineríticos monogenéticos y derrames fisurales, mientras que los estratovolcanes y las estructuras caldéricas 
presentan rocas mucho más evolucionadas.

En este trabajo hemos dividido a las rocas calcialcalinas en dos grandes grupos representativos: campos monogenéticos y estratovolcanes. Ésta es una división arbitraria que responde a efectos de claridad y conveniencia, y trata de dar un seguimiento concreto a los estudios petrológicos y geoquímicos del arco que tradicionalmente han estado enfocados al estudio de campos volcánicos específicos. Dentro de los campos monogenéticos, nos abocaremos a revisar las características de los campos volcánicos de MichoacánGuanajuato (CVMG) y de Chichinautzin (CVC) porque son los que han recibido mayor atención en las investigaciones y porque, en su conjunto, engloban prácticamente toda la diversidad petrológica del arco.

Sorprendentemente los grandes estratovolcanes mexicanos han recibido una menor atención en las investigaciones petrológicas y geoquímicas recientes. Valiosas excepciones serían los volcanes de Colima, Popocatépetl e Iztaccíhuatl, pero desafortunadamente aún son escasas las publicaciones recientes sobre la petrología y geoquímica de la Malinche, Pico de Orizaba y Tancítaro. Esta falta de información está siendo gradualmente revertida gracias a que en la actualidad existen varios grupos de investigadores dedicados a su estudio.

\subsubsection{Campos volcánicos monogenéticos}

El campo volcánico Michoacán-Guanajuato (CVMG). Este campo volcánico está constituido por más de 1000 centros eruptivos de edad cuaternaria distribuidos en una superficie de $40000 \mathrm{~km}^{2}$, y por lo tanto es una de las zonas con mayor concentración de volcanes monogenéticos del planeta. A diferencia de lo que ocurre en los grandes estratovolcanes del arco mexicano, la vida media de los centros eruptivos del CVMG es relativamente corta $(<15$ años) y raras veces logran reactivarse después de finalizar su actividad eruptiva. Estas características indican que la tasa de abastecimiento de magma es tan baja que no permite la formación de cámaras magmáticas someras de larga duración (Hasenaka y Carmichael, 1985). Por este motivo, los procesos de diferenciación y mezcla a gran escala que han sido documentados ampliamente en los estratovolcanes mexicanos se ven relativamente atenuados en los sistemas magmáticos monogenéticos.

Los primeros estudios petrológicos del CVMG estuvieron sobre todo enfocados a la caracterización y evolución del volcán más famoso del campo: El volcán Parícutin (1943-1952) (Wilcox, 1954; Eggler, 1972). El nacimiento de este volcán en una zona pintoresca y de fácil acceso atrajo la atención de un gran número de investigadores de todo el mundo que, en poco tiempo, convertieron al Parícutin en uno de los volcanes mejor estudiados del planeta, y el objeto de estudio de un buen número de trabajos petrológicos clásicos. Gracias a que el registro eruptivo del Parícutin estuvo extraordinariamente bien registrado desde su nacimiento (Foshag y González, 1954), Wilcox (1954) pudo establecer una evolución composicional sistemática de los productos volcánicos. En este trabajo se reconoció que las primeras etapas eruptivas del Parícutin tienen una composición basáltico-andesítica con fenocristales de olivino $\left(55 \% \mathrm{SiO}_{2}\right)$, mientras que las fases culminantes son andesitas de hiperstena $\left(60 \% \mathrm{SiO}_{2}\right)$. Esta tendencia de diferenciación fue sorpresiva para los investigadores de aquellos años pues contrastaba con la observada en otros volcanes (i. e., Arenal, Kilauea), y era también muy distinta al modelo clásico de evolución de una cámara magmática zonificada a baja presión. Haciendo alusión a las observaciones e hipótesis de Bowen (1928), Wilcox (1954) reconoce que la evolución petrológica del Parícutin no estuvo controlada únicamente por un proceso simple de cristalización fraccionada, sino que era necesario asumir la asimilación de un componente adicional proveniente del basamento cortical local. Más tarde Reid (1983) y McBirney et al. (1987), echando mano de estudios más modernos que incluían las variaciones en la composición isotópica, encuentran evidencias más concretas de ese proceso de asimilación que acompaña a la cristalización. Estos trabajos documentaron lo que hoy en día es mundialmente conocido como un ejemplo clásico del proceso de asimilación y cristalización fraccionada que fuera enunciado matemáticamente por DePaolo (1981).

El estudio más completo realizado hasta la fecha en el CVMG es el trabajo doctoral de Toshiaki Hasenaka de la Universidad de Berkeley, EUA, (Hasenaka, 1986) y las publicaciones formales que de él se derivaron (Hasenaka y Carmichael, 1985; Hasenaka y Carmichael, 1987; Hasenaka, 1994). Hasenaka compiló un inventario de prácticamente todos los centros eruptivos del CVMG y realizó un análisis exhaustivo de la morfología, edad relativa, petrografía y composición química de más de 200 muestras de roca. Gracias a la gran densidad de muestras analizadas, Hasenaka y Carmichael (1987) encuentran tres asociaciones petrológicas principales en el CVMG: rocas calcialcalinas con características típicas de arco magmático, rocas alcalinas ricas en $\mathrm{K}_{2} \mathrm{O}$ con concentraciones altas de $\mathrm{MgO}$, y rocas alcalinas ricas en $\mathrm{TiO}_{2}$ con concentraciones bajas de $\mathrm{MgO}$ (Figura 16). Un importante número de rocas del CVMG también pueden ser clasificadas como transicionales, debido a que se ubican en un campo intermedio entre rocas netamente alcalinas y calcialcalinas. Hasenaka nota que las diferencias composicionales de las distintas series magmáticas no pueden ser el resultado de una línea de evolución común a partir de un mismo líquido primitivo, sino que deben representar la conjunción de procesos petrogenéticos distintos y mucho más complejos. No obstante, el autor encuentra una cierta sistemática espacial y temporal para las distintas series magmáticas. Hasenaka observa que prácticamente todos los centros eruptivos con edades menores que 40000 años se encuentran localizados en la porción sur del campo volcánico (entre 200 y $300 \mathrm{~km}$ desde la trinchera), son calcialcalinos, y muestran un ligero enriquecimiento en sílice con respecto a los conos más antiguos. En cambio, 

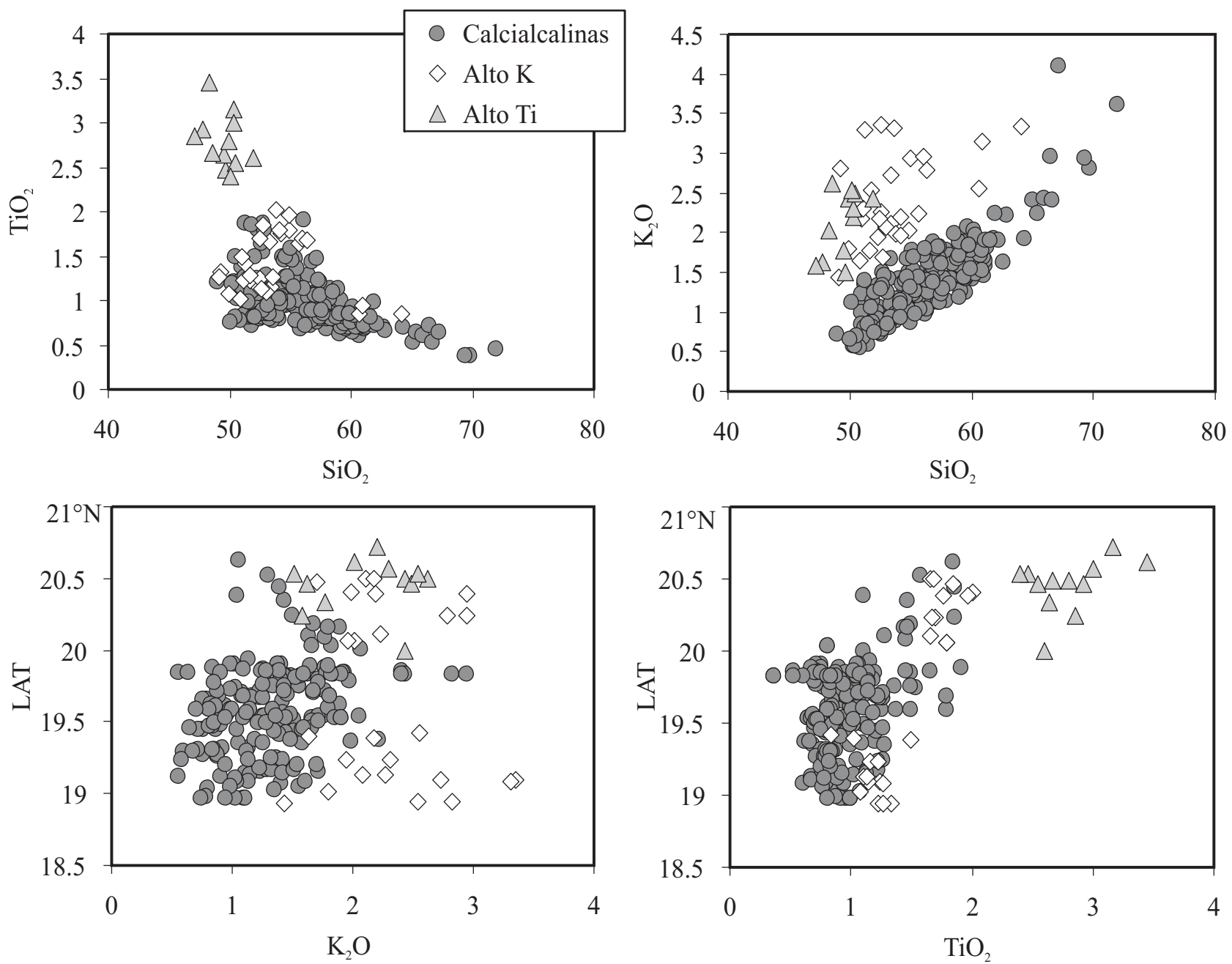

Figura 16. Las variaciones composicionales observadas en el campo volcánico Michoacán-Guanajuato permite la identificación de tres grandes grupos de rocas: calcialcalinas, alcalinas ricas en Ti y alcalinas ricas en K (Hasenaka, 1986; Hasenaka y Carmichael, 1987). Nótese la inexistencia de un incremento gradual en la concentración de $\mathrm{K}_{2} \mathrm{O}$ conforme se incrementa la distancia desde la trinchera (latitud). Sin embargo, las rocas ricas en Ti se encuentran ubicadas invariablemente en las porciones más alejadas de la trinchera.

los volcanes con afinidades alcalinas son morfológicamente más antiguos, aunque su edad específica y su rango de actividad no han sido todavía determinados con precisión. Es notable también que los conos alcalinos de bajo $\mathrm{MgO}$ y alto $\mathrm{TiO}_{2}$ se encuentren emplazados en la porción norte del campo (entre 350 y $400 \mathrm{~km}$ desde la trinchera), mientras

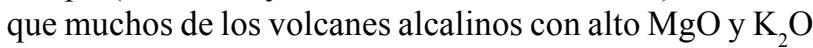
se encuentran próximos a la trinchera (entre 200 y $270 \mathrm{~km}$ desde la trinchera). En ese sentido, los conos del CVMG despliegan una tendencia a disminuir el contenido de $\mathrm{MgO}$ (y de elementos compatibles como $\mathrm{Ni}, \mathrm{Cr}$ ) e incrementar en $\mathrm{TiO}_{2}$ conforme se alejan de la trinchera (Figura 16). Estas características, junto con las inferencias de estabilidad mineralógica de las fases observadas, indican que los magmas en el sur tienden a emplazarse en la superficie de una forma mucho más rápida y eficiente, sufriendo por consiguiente un menor grado de diferenciación a presiones mayores, que los magmas emplazados en el norte que parecen estacionarse por un periodo de tiempo mayor a niveles corticales mucho más someros. Curiosamente, y en contraposición a lo que se observa en un gran número de arcos magmáticos, en el CVMG no parece existir una sistemática composicional clara entre la concentración de elementos incompatibles y la distancia desde la trinchera. Por ejemplo, mientras que en muchos arcos se observa un incremento en el contenido de $\mathrm{K}_{2} \mathrm{O}$ (y de elementos incompatibles) conforme se incrementa la distancia desde la trinchera (i.e., profundidad de la placa subducida) (Dickinson y Hatherton, 1967), en el CVMG esta relación no es evidente y sólo llega a observarse si se excluyen las rocas alcalinas de alto $\mathrm{MgO}$, cuyos contenidos de $\mathrm{K}_{2} \mathrm{O}$ son muy altos, y se encuentran ubicadas hacia el frente volcánico (Figura 16). En otras palabras, el CVMG, y en general el arco mexicano, rompe una vez más con los paradigmas del magmatismo de arco establecidos en otros márgenes convergentes del orbe.

La evolución petrológica del volcán Jorullo, el otro cono monogenético con actividad histórica del CVMG, también 
ha recibido cierta atención en las investigaciones geoquímicas y petrológicas. El trabajo de Luhr y Carmichael (1985b), y más recientemente el trabajo experimental de Barclay y Carmichael (2004), documentan y discuten las variaciones composicionales de este volcán y de un pequeño cono ligeramente más antiguo, localizado inmediatamente al sur del Jorullo, que se conoce con el nombre de Cerro La Pilita. De forma semejante a lo que se observó en el Parícutin, las lavas del Jorullo se volvieron paulatinamente más silícicas con el tiempo, evolucionando desde basaltos $\left(52 \% \mathrm{SiO}_{2}\right)$ hasta andesitas basálticas $\left(55 \% \mathrm{SiO}_{2}\right)$. Pero a diferencia del Parícutin, la evolución petrológica del Jorullo no puede ser explicada con un mecanismo simple de cristalización fraccionada, con o sin contaminación cortical, a pesar de que algunas de las lavas contengan abundantes enclaves graníticos del basamento local. En efecto, Luhr y Carmichael (1985b) notan que no obstante las variaciones observadas en los elementos mayores podrían ser explicadas mediante un proceso de cristalización de olivino, augita, plagioclasa y un poco de espinela, a presiones del manto superior o la corteza continental inferior, las concentraciones de elementos traza más incompatibles, y las Tierras Raras pesadas, están anómalamente enriquecidas y empobrecidas, respectivamente, en las lavas más evolucionadas. Los autores reconocen que debió ocurrir otro proceso petrológico que actuó de forma conjunta con la cristalización fraccionada, pero desafortunadamente no les fue posible resolver su origen.

La composición del Cerro La Pilita, emplazado a escasos tres kilómetros de distancia del Jorullo, es diametralmente diferente. La Pilita extravasó traquibasaltos primitivos con fenocristales de hornblenda, apatita, olivino, espinela y augita, presentando además nefelina normativa y muy altos contenidos de $\mathrm{K}_{2} \mathrm{O}, \mathrm{P}_{2} \mathrm{O}_{5}, \mathrm{Ba}$ y $\mathrm{Sr}$ (Luhr y Carmichael, 1985b). Los autores muestran que los magmas del Jorullo y del Cerro la Pilita no están relacionados entre sí a un proceso de diferenciación simple, con o sin contaminación cortical, sino que deben representar dos procesos petrogenéticos distintos que, aparentemente, actúan de forma casi simultánea en el frente magmático del arco. En ese sentido, el trabajo de Barclay y Carmichael (2004) documenta que la asociación mineralógica de las lavas del Cerro La Pilita puede ser reproducida experimentalmente si el magma cristalizó entre $1040{ }^{\circ} \mathrm{C}$ y 970 ${ }^{\circ} \mathrm{C}$ con un contenido de agua variable entre 2.5 y $4.5 \%$ a 50-150 MPa. Los experimentos realizados a distintas presiones y temperaturas demuestran que la cristalización de hornblenda a partir de magmas basálticos produce un aumento en la cristalinidad del magma de hasta el $40 \%$ en volumen, lo que produce un incremento considerable en su viscosidad y, por lo tanto, una disminución en su capacidad de ascender hacia la superficie. Utilizando estas evidencias, los autores razonan que la relativa escasez de magmas basálticos con hornblenda en arcos magmáticos se debe a que generalmente éstos se quedan atrapados en la interfaz manto-corteza.
Recientemente, Verma y Hasenaka (2004) reportaron datos isotópicos de $\mathrm{Sr}, \mathrm{Nd}$ y $\mathrm{Pb}$, y de elementos mayores y traza, en una selección de muestras del CVMG que en buena medida cubren el espectro petrológico descrito previamente por Hasenaka (1986). Utilizando estos datos, los autores también desestiman un mecanismo petrogenético simple de diferenciación para explicar la diversidad petrológica del CVMG, y tampoco consideran viable que esta diversidad esté controlada por los efectos químicos de la placa que se subduce. En cambio, y siguiendo la hipótesis planteada por Sheth et al. (2000), los autores proponen que el manto debajo del CVMG debe ser composcionalmente heterogéneo, y que probablemente estas heterogeneidades se distribuyan en forma de vetas enriquecidas cuyo origen podría ser metasomático. Para estos investigadores, el origen primario de estas vetas tampoco estaría relacionado con el proceso de subducción actual, sino con un complejo proceso metasomático debajo de una supuesta sutura cortical en la proto-FVTM. En ese sentido, los autores retoman la hipótesis planteada por von Humboldt (1808) en donde se asume que la FVTM estaría controlada por una fractura cortical de primer orden.

Diferenciar los efectos químicos de la subducción de aquellos derivados de la corteza continental ha sido una tarea difícil de lograr utilizando los datos geoquímicos tradicionales. No obstante, en los últimos años se han desarrollado y aplicado algunas técnicas isotópicas que hasta hace poco tiempo permanecían solamente en el ámbito teórico, pues simplemente no existían los instrumentos capaces de determinarlas de manera precisa y rutinaria. Tal es el caso del sistema isotópico de Re-Os y su aplicación en estudios petrogenéticos de rocas de arco. El Re es un elemento relativamente incompatible durante los procesos de fusión parcial del manto, mientras que el Os se comporta como un elemento altamente compatible. Por lo tanto la corteza continental tendrá relaciones de $\mathrm{Re} / \mathrm{Os}$ mucho mayores que las del manto, y evolucionará hacia composiciones isotópicas extremadamente radiogénicas en la relación ${ }^{187} \mathrm{Os} /{ }^{188} \mathrm{Os}$ (Shirey y Walker, 1998). Estas características hacen que la composición isotópica de Os observada en las rocas volcánicas sea un trazador extraordinario para observar las contribuciones del manto y la corteza continental en la petrogénesis ígnea.

Las rocas del CVMG han sido el objeto de unos de los pocos estudios que existen en el mundo sobre la isotopía de Os en arcos magmáticos (Lassiter y Luhr, 2001; Chesley et al., 2002). Estos estudios han confirmado la participación de la corteza continental en la composición isotópica de Os de algunas rocas del CVMG, pero también han demostrado que una buena parte de las rocas que muestran señales de subducción evidentes (i.e., valores altos en las relaciones LILE/HFSE) tienen valores isotópicos de Os bajos y semejantes a los del manto. Estas observaciones tienen implicaciones importantes para nuestra forma de entender el magmatismo en el arco mexicano, poniendo en evidencia que no todos los magmas del arco están 
contaminados con la corteza continental y, por ende, que la señal de subducción que se observa en ellos debe ser en gran medida heredada de su fuente mantélica.

El campo volcánico de Chichinautzin (CVC). Este campo volcánico ocupa una superficie aproximada de $2500 \mathrm{~km}^{2}$ y está ubicado en la porción central de la FVTM, formando una sierra alongada de dirección E-W que se extiende entre los flancos de los volcanes Popocatépetl y Nevado Toluca (Lámina 1). Aunque menos extenso que el CVMG, el CVC tiene una de las mayores concentraciones de vulcanismo monogenético de la FVTM, incluyendo al menos a 220 conos cineríticos y volcanes escudo (Bloomfield, 1975; Martín-Del Pozzo, 1982). Varios estudios paleomagnéticos, junto con los fechamientos isotópicos disponibles hasta el momento, han demostrado que la mayor parte del vulcanismo del CVC tiene edades menores que $\sim 0.78 \mathrm{Ma}$ (Bloomfield, 1973; Mooser et al., 1974; Herrero y Pal, 1978; Siebe et al., 2004a). Aunque no existen reportes de erupciones históricas en el área, es notable que las lavas del volcán Xitle cubrieron y destruyeron el asentamiento prehispánico de Cuicuilco, ubicado al sur de la Ciudad de México, en una erupción ocurrida hace 2000 o 1670 años (Siebe, 2000 y referencias incluidas). En ese sentido, el estudio detallado del CVC adquiere una relevancia adicional, pues su eventual actividad puede afectar directamente a una de las regiones más pobladas del país y del mundo: la Ciudad de México.

Un gran número de autores han reportado análisis petrográficos y geoquímicos en las rocas del CVC, y el área también ha recibido una atención especial en los estudios de tectónica y de vulcanología física [ver Velasco-Tapia y Verma (2001) para una revisión más extensa]. Sin embargo, y a pesar del abultado número de publicaciones, las discusiones sobre el origen del CVC siguen teniendo aún serias discrepancias.
Según el estudio de Wallace y Carmichael (1999), la mayor parte de las rocas del CVC son de composición andesítica y dacítica de afinidad calcialcalina con características típicas de magmatismo de arco. Sin embargo, es particularmente notable que las erupciones netamente basálticas tengan afinidades alcalinas (Figura 17). Los basaltos alcalinos no son particularmente abundantes en el área, pero sí representan unos de los magmas más primitivos del arco, y su sola presencia ha sido motivo de múltiples discusiones entre la comunidad científica. Wallace y Carmichael (1999) también notan que las rocas menos diferenciadas (alcalinas y calcialcalinas) se localizan hacia el centro del campo volcánico, formando una franja que sigue una dirección aproximada N-S a lo largo de la latitud $99.2^{\circ} \mathrm{W}$. En cambio, las rocas emplazadas hacia los flancos de los estratovolcanes tienden hacia composiciones más diferenciadas y tienden a ser químicamente muy similares a ellos.

La mineralogía de las rocas más primitivas del CVC está generalmente compuesta por olivino y plagioclasa, mientras que el piroxeno y la hornblenda aparecen en las rocas más diferenciadas. Un gran número de muestras contienen también xenocristales y xenolitos de cuarzo y plagioclasa sódica que se encuentran en claro desequilibrio químico con el magma que los engloba. Wallace y Carmichael (1999) asumen que las rocas calcialcalinas menos diferenciadas del CVC podrían representar líquidos casi primitivos que, al ser comparadas con otros magmas basálticos estudiados en el arco, podrían derivarse de muy bajos grados de fusión parcial $(3.3 \%-7.7 \%)$ de una fuente mantélica empobrecida en elementos incompatibles que ha sido enriquecida en agua y en elementos móviles en fluidos por influencia de la placa subducida. En cambio, los magmas basálticos alcalinos deben provenir de una fuente mantélica mucho más heterogénea, aunque enriquecida y similar a la que da origen
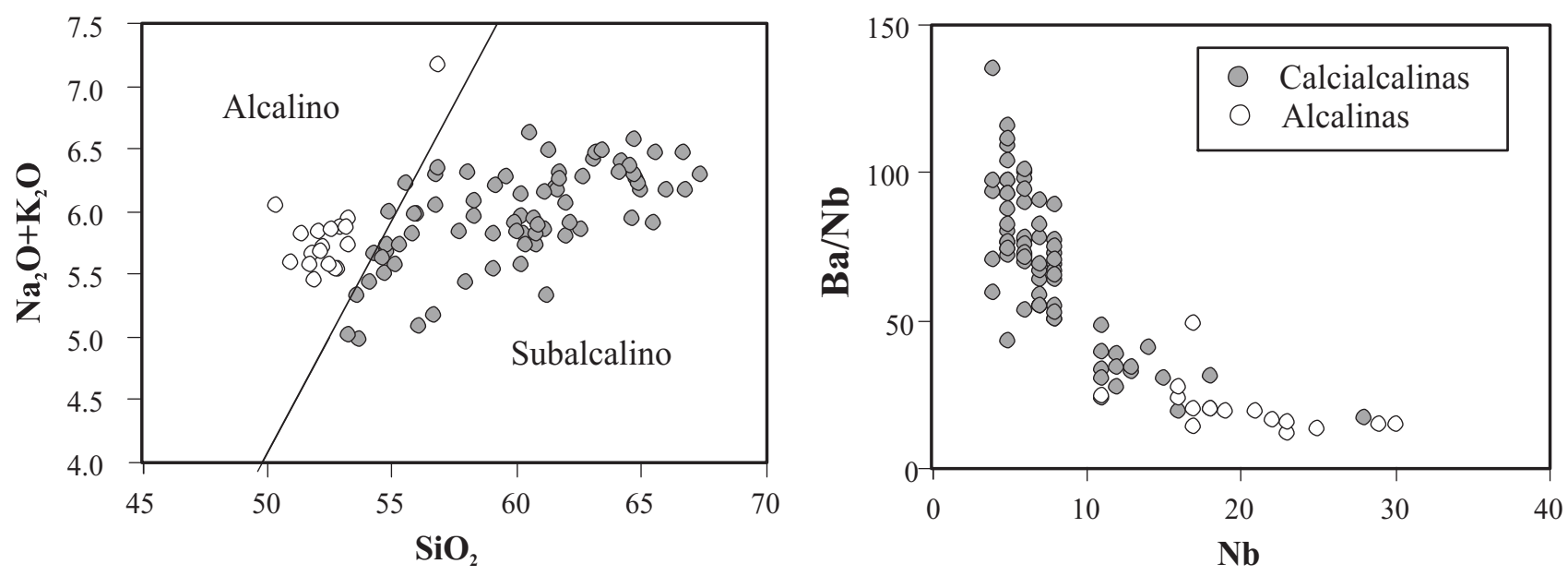

Figura 17. Variaciones composicionales de las rocas del campo volcánico de Chichinautzin (Wallace y Carmichael, 1999). Nótese que las rocas netamente basálticas tienen afinidades alcalinas, altas concentraciones de $\mathrm{Nb}$ y señales de subducción muy bajas (i. e., Ba/ $\mathrm{Nb}$ ). La línea divisoria entre los campos alcalinos y subalcalinos es de McDonald y Katsura (1964). 
al magmatismo intraplaca del Basin and Range mexicano (Luhr et al., 1989a; Pier et al., 1992; Luhr, 1997a), que se funde en condiciones prácticamente anhidras, y que ha sido transferida hacia el frente del arco por la convección inducida del manto dentro del régimen tectónico convergente. Las diferencias en el grado de hidratación del manto genera magmas con distintas concentraciones de agua y relaciones LILE/HFSE y confirman la complejidad del proceso petrogenético del CVC (Cervantes y Wallace, 2003a; Cervantes y Wallace, 2003b)

Los trabajos de Verma $(1999,2000 a)$ ponen en entredicho las conclusiones de Wallace y Carmichael (1999) al reconocer que las rocas más primitivas del CVC, con afinidades alcalinas, carecen de las características geoquímicas típicas asociadas a un proceso de subducción, y en cambio tienen una mayor semejanza con rocas asociadas a islas oceánicas. Verma nota que las rocas calcialcalinas más diferenciadas presentan concentraciones menores de elementos incompatibles (HFSE y HREE) que las rocas alcalinas más primitivas (Figura 17), y argumenta la dificultad que existe para explicar esta tendencia con un simple proceso de cristalización fraccionada o contaminación cortical. Las rocas primitivas y diferenciadas tienen composiciones isotópicas de $\mathrm{Nd}$ y $\mathrm{Pb}$ muy parecidas, y sólo las rocas más evolucionadas presentan valores más radiogénicos de $\mathrm{Sr}$ (Figura 18). Verma señala que el arreglo isotópico de los datos no puede ser relacionado con contribuciones de la placa oceánica, debido a que se aleja considerablemente de un modelo de mezcla entre los componentes basálticos y sedimentarios de la placa subducida. En cambio, el autor propone que las rocas más diferenciadas tienen su origen en la fusión parcial de la corteza continental inferior, y que los magmas de composición intermedia serían el producto de una mezcla simple entre los magmas basálticos y los evolucionados.

Las observaciones y argumentos geoquímicos de Verma (1999, 2000a) fueron retomados por Márquez et al. (1999a) quienes propusieron que el origen primario de los magmas primitivos de tipo OIB podría estar asociado a una pluma del manto actuando en un complejo esquema de extensión y rifting que se propagó paulatinamente hacia el oriente de México desde el Mioceno tardío. Siguiendo la misma línea de pensamiento, Sheth et al. (2000) modifica el modelo de pluma y argumenta en cambio la presencia de un sistema de rifting y la formación de magmas primitivos por descompresión adiabática sin influencia alguna de los efectos químicos de la subducción.

Construyendo sobre la hipótesis de pluma-rift en el CVC, Márquez y De Ignacio (2002) reportan un análisis más completo de la mineralogía y geoquímica de las rocas de Chichinautzin y, al igual que Wallace y Carmichael (1999), reconocen la presencia de dos tipos de fuentes mantélicas para las rocas máficas: un manto esencialmente anhidro y geoquímicamente enriquecido que daría origen a las rocas de tipo OIB o intraplaca, y un manto hidratado y metasomatizado que daría origen a las rocas calcialca-

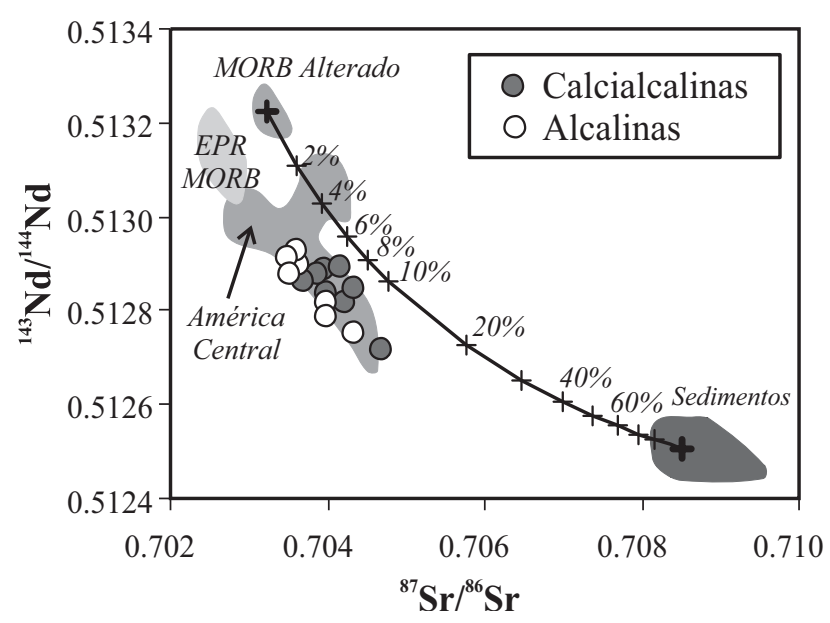

Figura 18. Composición isotópica de $\mathrm{Sr}$ y $\mathrm{Nd}$ de las rocas del campo volcánico de Chichinautzin y de la corteza oceánica muestreada en el sitio DSDP 487 (Verma, 1999; Verma, 2000a). Nótese que un modelo de mezcla entre los dos componentes de la loza oceánica (MORB alterado y sedimentos) no es capaz de reproducir los datos de Chichinautzin. Esta característica ha sido tomada por Verma como una evidencia para desestimar la participación de la placa oceánica en la petrogénesis de Chichinautzin (y de otras zonas del arco). Se incluye también el campo de variación isotópica de las rocas del arco Centroamericano (Feigenson y Carr, 1986; Feigenson et al., 2004).

linas máficas con señales geoquímicas de subducción. La intrusión de estos magmas máficos en la corteza inferior induciría su fusión parcial en condiciones distintas de fugacidad de oxígeno, generando magmas diferenciados con distintas composiciones. En ese sentido, el espectro de composiciones encontrado en las rocas del CVC representaría mezclas entre esta gran variedad de magmas mantélicos y corticales. A diferencia de Wallace y Carmichael (1999), Márquez y De Ignacio (2002) no encuentran evidencias suficientes para asegurar que el manto hidratado debajo del CVC esté relacionado con el proceso de subducción actual, sino que consideran también probable que el metasomatismo del manto litosférico haya estado inducido por el efecto de una pluma "desenraizada".

Recientemente, Siebe et al. (2004b) realizaron una caracterización geoquímica y petrográfica detallada de tres centros volcánicos del CVC (Pelado, Guespalapa y Chichinautzin), documentando nuevamente la heterogeneidad geoquímica e isotópica de las rocas máficas del campo volcánico como un reflejo de la diversidad composicional del manto debajo del arco. Así mismo, y utilizando una variedad de argumentos tectónicos, termodinámicos y petrológicos, los autores refutan el modelo de pluma del manto o de rift continental para explicar la heterogeneidad de composiciones, y en cambio brindan soporte al modelo postulado por Wallace y Carmichael (1999). De forma parecida a lo que ocurre en los volcanes Parícutin y Jorullo del CVMG, las rocas de estos centros volcánicos se vuelven gradualmente más silícicas con el tiempo, y también muestran la muy documentada tendencia a disminuir las concentraciones de HFSE y HREE conforme el contenido 
de $\mathrm{SiO}_{2}$ se incrementa. Sin embargo, y a diferencia de otros autores, Siebe et al. (2004a) consideran que estas tendencias podrían estar controladas por un proceso de cristalización fraccionada de minerales accesorios, como la apatita, el zircón, la hornblenda y otros minerales titaníferos (Ti-magnetita, ilmenita férrica, esfena). En este modelo, la cristalización de estas fases mineralógicas probablemente actuaría de forma polibárica y en conjunción con un proceso de asimilación cortical, y su efecto se vería reflejado en la composición de los magmas más diferenciados.

En resumen, aunque todos los autores coinciden en afirmar que las rocas máficas del CVC muestran una heterogeneidad composicional extrema que debe relacionarse con variaciones significativas en la composición de la fuente mantélica, existen también serias discrepancias con respecto al origen primario de estas heterogeneidades: plumas del manto, migración de un manto enriquecido del trasarco por efecto de la convección inducida por el régimen convergente, metasomatismo inducido por la subducción o de un manto litosférico metasomatizado previamente. Por otra parte, el origen de las rocas diferenciadas tampoco parece encontrar consenso pues aunque todos los autores coinciden en afirmar que un proceso simple de cristalización fraccionada de las fases mineralógicas mayores no es capaz de explicar las tendencias geoquímicas, también es cierto que los modelos de fusión cortical, contaminación y/o cristalización fraccionada han sido difíciles de demostrar con argumentos térmicos o geoquímicos convincentes. En ese sentido, aunque probablemente no sería aventurado afirmar que el CVC es el campo volcánico mejor estudiado de México, es evidente también la necesidad que existe de plantear un modelo global que reconcilie las múltiples evidencias petrológicas, estructurales y tectónicas que han sido vertidas a lo largo de los años.

\subsubsection{Estratovolcanes}

México es un país de volcanes y su expresión más conspicua está fielmente representada por la presencia de grandes estratovolcanes que se levantan de costa a costa en el centro del país (Lámina 1). La observación directa de su actividad se remonta a las culturas del México prehispánico, cuyas representaciones en códices y estelas aportaron información valiosa que aún ahora es utilizada para establecer su historia eruptiva. Por eso, no debería sorprendernos que los nombres que reciben los estratovolcanes mexicanos hagan alusión a su persistente actividad (Popocatépetl significa "montaña que humea", mientras que Colima era el nombre que recibía el "dios del fuego que domina"). Los grandes volcanes eran considerados como verdaderas deidades por las culturas del México antiguo y fueron motivo de numerosas ofrendas y ritos que hoy en día siguen representándose matizados con la cultura mestiza. Los mexicas consideraban que los volcanes habían surgido después de que los mares invadieron la tierra; en la edad del predominio del fuego, o el Tletonatiuh de la mitología nahua, época en que brotaron las enormes corrientes de lava y los cráteres encendidos. Cuenta la leyenda que como sólo las aves eran capaces de escapar del gran incendio, todos los hombres se convirtieron en pájaros, a excepción de uno que, con su mujer, se salvó en el interior de una caverna. Ésta y algunas otras leyendas fueron compiladas por Yarza de la Torre (1992) en su libro Volcanes de México.

Al llegar los españoles a la Nueva España, su asombro ante la majestuosidad de las montañas mexicanas se vio plasmado en las numerosas referencias de los cronistas de la conquista. Fray Bernardino de Sahagún (1499-1590), en su libro Historia General de las Cosas de la Nueva España (Sahagún, 1992), nos narra:

"Hay un monte que se llama Poyauhtécatl', está cerca de Auillizapán y de Tecamachalco, ha pocos años que comenzó a arder la cumbre de él y yo le ví muchos años que tenía la cumbre cubierta de nieve, y despúes vi cuando comenzó a arder y las llamas parecían de noche y de día de más de veinte leguas y ahora como el fuego ha gastado mucha parte de lo interior del monte ya no se parece el fuego aunque siempre arde."

Las primeras observaciones científicas de los estratovolcanes mexicanos se atribuyen generalmente al gran naturalista alemán Alexander von Humboldt (von Humboldt, 1808). Humboldt sospechó que el alineamiento tan perfecto de volcanes a lo largo del paralelo $19^{\circ} \mathrm{N}$ obedecía a una fractura terrestre de primer orden. Aunque la presencia de esta gran falla ha sido difícil de confirmar, esta hipótesis fue muy popular por un largo periodo de tiempo (Mooser, 1972) y ha sido incluso rescatada en algunos trabajos más recientes (Verma y Hasenaka, 2004).

Aunque los estudios petrológicos y geoquímicos sistemáticos de los estratovolcanes mexicanos no son particularmente abundantes, es francamente alentador percibir un cierto nivel de consenso en las explicaciones sobre su origen. En efecto, la gran mayoría de los investigadores han reconocido que la variedad petrológica de los estratovolcanes refleja una suerte de mezcla entre distintos componentes magmáticos cuya residencia en cámaras magmáticas de larga duración permiten una efectiva homogeneización, y el consecuente emplazamiento de rocas volcánicas con composiciones relativamente monótonas (Nelson, 1980; Luhr y Carmichael, 1982; Nixon, 1988a; Nixon, 1988b; Robin et al., 1991; Straub y Martín-Del Pozzo, 2001; Schaaf et al., 2005). Las evidencias más contundentes que demuestran la existencia de estas mezclas se ven fehacientemente plasmadas en la textura y mineralogía de los productos volcánicos. Ha sido ampliamente documentado que la mayor parte de las rocas extravasadas por los estratovolcanes presentan mineralogías antagónicas (por ejemplo, olivino y cuarzo) que evidentemente no puede haberse derivado de un proceso de cristalización en equilibrio a partir de un mismo magma máfico. Además, muchos de los minerales

\footnotetext{
${ }^{2}$ Antiguo nombre náhuatl que recibía Pico de Orizaba o Citlaltépetl.
} 
presentes en estas rocas muestran texturas complejas de corrosión-reacción y zoneamiento que demuestran un tránsito complejo, lejos del equilibrio, dentro del sistema magmático. En términos geoquímicos, las correlaciones lineales observadas en los diagramas de variación de los elementos mayores son también típicas de un proceso de mezcla, pues no presentan las inflexiones y/o curvaturas características de un proceso de cristalización fraccionada simple. No obstante, y a pesar de que el mecanismo de mezcla parece ser un proceso común en la evolución petrológica de los estratovolcanes, las características específicas de los componentes involucrados, su origen primario, y los mecanismos físicos que la facilitan siguen siendo todavía difíciles de comprender.

Uno de los trabajos petrológicos más completos que documenta el proceso de mezcla fue el realizado por Nixon (1988a, 1988b) en el volcán Iztaccíhuatl (Izta). Nixon explica que la evolución petrológica del sistema magmático en el Izta está controlada por una vigorosa mezcla de magmas acompañada de un proceso de cristalización fraccionada. De hecho, Nixon demuestra que las variaciones petrológicas y geoquímicas encontradas en el Izta exhiben aspectos clave para entender los modelos teóricos desarrollados por O’Hara (1977) y O’Hara y Mathews (1981), quienes explicaron el comportamiento geoquímico de cámaras magmáticas como sistemas termodinámicos abiertos en donde existe una periodicidad entre la alimentación de magma profundo, cristalización fraccionada, y un eventual drenado de material magmático durante las erupciones. Nixon denominó a este proceso como fraccionamiento dinámico, pues los modelos simples de mezcla de magmas y cristalización fraccionada, por sí solos, no permiten explicar la complejidad mineralógica y geoquímica de las rocas volcánicas. Para Nixon, las lavas del Izta, cuya composición varía entre andesitas y dacitas (58-66\% de $\left.\mathrm{SiO}_{2}\right)$, representan siempre un producto híbrido de un proceso continuo y repetitivo en donde existe una inyección de magma basáltico que se mezcla en distintas proporciones con un magma dacítico residente en una cámara magmática de larga duración. Nixon considera que los magmas primarios que alimentan al sistema magmático del Izta tienen una composición basáltica o basáltico-andesítica, relativamente rica en sílice, pero con contenidos de $\mathrm{MgO}$ y $\mathrm{Ni}$ semejantes a los de magmas primitivos. Sin embargo, la composición de estos magmas basálticos muestra variaciones considerables en $\mathrm{Ba}, \mathrm{Sr}$, y en la relación ${ }^{87} \mathrm{Sr} /{ }^{86} \mathrm{Sr}$. Los cálculos de Nixon consideran que el espectro de magmas primarios alimentando al Izta puede ir desde basaltos calcialcalinos con hiperstena normativa hasta basaltos alcalinos con nefelina normativa, con composiciones semejantes a las encontradas en los basaltos del campo volcánico de Chichinautzin y en el Valle de México. Estas aseveraciones ponen una vez más en evidencia el carácter heterogéneo de la cuña del manto bajo la FVTM. El componente magmático más evolucionado, de composición dacítica, es mucho más homogéneo pues encarna la última etapa evolutiva del proceso de cristalización dinámica, que en última instancia debe converger hacia el equilibrio.

El volcán mejor estudiado de México es sin duda el volcán de Colima (conocido también como volcán de Fuego, o volcán de Fuego de Colima), el estratovolcán más activo de México y Norteamérica (Luhr y Carmichael, 1980; Luhr y Carmichael, 1981; Luhr y Carmichael, 1982; Luhr y Carmichael, 1990; Robin et al., 1991; Moore y Carmichael, 1998; Luhr, 2002; Mora et al., 2002). Las lavas del volcán de Colima tienen una composición andesítica relativamente monótona, y presentan ensambles mineralógicos compuestos por plagioclasa \pm ortopiroxeno \pm clinopiroxeno \pm titanomagnetita \pm hornblenda en una matriz compuesta por vidrio y microlitos de los mismos minerales a excepción de hornblenda. Como sucede en otros estratovolcanes, es posible encontrar fenocristales de olivino con coronas de reacción y abundantes texturas de desequilibrio.

Desde los primeros estudios, Luhr y Carmichael (1980) reconocieron la existencia de cierta ciclicidad eruptiva que quedó registrada en las variaciones petrológicas y geoquímicas de los productos volcánicos. Más tarde, Luhr y Carmichael, (1990) y Luhr (2002) confirman que durante la segunda mitad de la historia eruptiva del Colima se han repetido dos ciclos vulcanológicos con características similares (1818-1913 y 1913-presente): (1) la existencia de un cráter abierto producto de una erupción explosiva que marca la culminación de cada ciclo; (2) crecimiento de un domo de lava dentro del conducto; (3) arribo del domo al borde del cráter y la generación de derrames de lava en bloques y flujos de bloques y ceniza; (4) periodos breves de actividad explosiva que se conjugan con los fenómenos de la etapa $3 ;$ (5) culminación del ciclo con la generación de una gran erupción explosiva que produce depósitos de caída de tefra y flujos piroclásticos. Los autores reconocen que en la actualidad nos encontramos cerca del cierre de un ciclo eruptivo, y vaticinan que una erupción explosiva de grandes dimensiones es un hecho inminente que ocurrirá en algún momento dentro de este siglo (Luhr y Carmichael, 1980). Para estos autores los ciclos eruptivos tienen una duración de aproximadamente un siglo y parecen reflejar el tránsito de cuerpos magmáticos discretos y zonificados (enriquecidos en $\mathrm{SiO}_{2}$ hacia la superfice). En este modelo, el punto culminante del ciclo eruptivo estaría representado por el emplazamiento de magmas andesíticos, aunque ligeramente más primitivos que los emplazados en las etapas precedentes.

Como ocurre en el volcán Iztaccíhuatl, la evolución del sistema magmático de Colima no parece estar relacionada con un proceso de diferenciación simple, ni tampoco con un mecanismo de mezcla entre dos componentes. Las características geoquímicas y mineralógicas indican más bien un mecanismo híbrido de mezcla que acompaña a la cristalización en una cámara magmática abierta (Luhr y Carmichael, 1980). No obstante, los estudios experimentales de equilibrio de fases en los magmas andesíticos del Colima y los lamprófidos del bloque Jalisco parecen 
definir una estrecha relación genética entre ellos (Moore y Carmichael, 1998; Carmichael, 2002). La Figura 19 muestra el campo de estabilidad de las distintas fases mineralógicas observadas en las rocas de Colima y en las del bloque Jalisco, y reproducidas por los experimentos con distintos contenidos de agua. El sombreado gris oscuro representa la estabilidad del ensamble mineralógico del volcán de Colima, mientras que el sombreado gris claro define la zona en donde únicamente la hornblenda es estable. Los autores documentan que la abundancia y composición mineralógica de estas rocas son un reflejo de la cantidad de agua disuelta en los magmas. La típica roca andesítica rica en fenocristales de plagioclasa que emana del volcán de Colima es en realidad el resultado de una profunda desgasificación que ocurre durante el ascenso hacia la superficie de un magma rico en agua. El magma primario que alimenta al sistema del volcán de Colima podría ser, de hecho, un lamprófido de hornblenda con al menos $6 \%$ de agua disuelta que se pierde casi por completo durante la descompresión, y cuyo efecto directo es disparar el proceso cristalización. En ese sentido, Carmichael (2002) nota que las rocas basálticas y basáltico-andesíticas del arco poseen casi siempre una cristalinidad menor; y que la plagioclasa, cuyo campo de estabilidad está fuertemente controlado por la cantidad de agua disuelta, no es tan abundante como en las andesitas que emanan de los estratovolcanes.

El volcán Popocatépetl (Popo) también ha sido el objeto de algunas investigaciones petrológicas y geoquímicas relativamente detalladas (Boudal y Robin, 1987; Straub y Martín-Del Pozzo, 2001; Schaaf et al., 2005). De manera

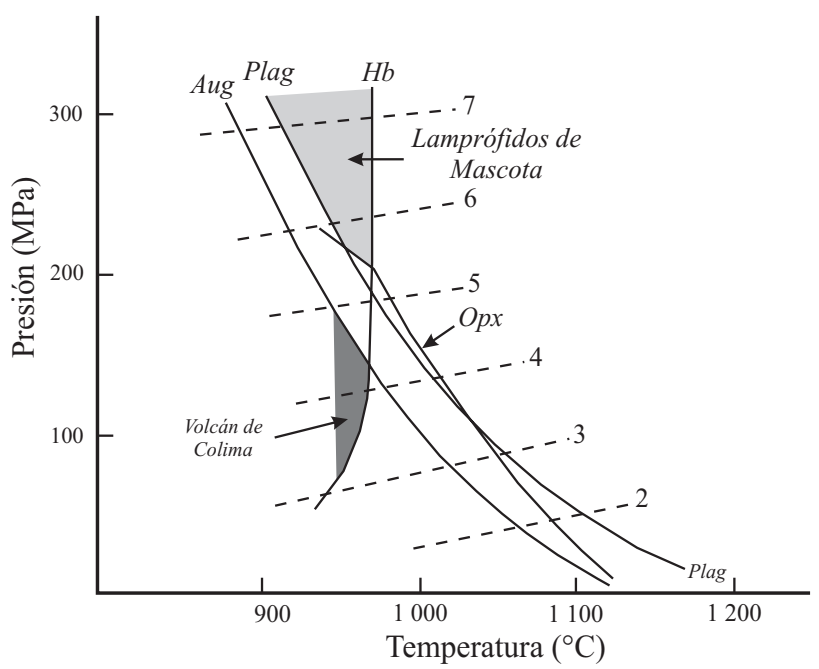

Figura 19. Diagrama de estabilidad de fases para rocas andesíticas del volcán de Colima y espesartíticas del campo volcánico de Mascota, en condiciones de saturación con agua (Moore y Carmichael, 1998). Las líneas subhorizonatles representan isopletas del contenido de agua (\% en peso). El campo gris oscuro representa el campo de estabilidad del ensamble mineralógico típico del volcán de Colima. El campo gris claro representa el campo de estabilidad mineralógica de las rocas lamprofídicas del campo volcánico de Mascota, caracterizadas por la presencia de fenocristales de hornblenda y la ausencia de plagioclasa y piroxeno. similar a lo que ocurre con el resto de los estratovolcanes, el Popo muestra todos los rasgos típicos de mezcla de magmas mencionados anteriormente $y$, aunque sus periodos de actividad y reposo son relativamente más prolongados que los del volcán de Colima, también es posible inferir una cierta recurrencia y ciclicidad en su actividad eruptiva (Siebe et al., 1996).

El trabajo de Schaaf et al. (2005) reporta datos geoquímicos e isotópicos de distintas fases eruptivas del Popocatépetl, así como de varios centros monogenéticos emplazados en la vecindad del estratovolcán. Siguiendo un argumento similar al planteado por Siebe et al. (2004a), los autores indican que las variaciones composicionales asociadas a los volcanes monogenéticos están relacionadas con un proceso de cristalización fraccionada polibárica que ocurre en sistemas magmáticos de corta duración. En cambio, los productos del Popocatépetl son mucho más homogéneos y resultan de la mezcla, o mingling, de un componente dacítico y un magma basáltico primitivo que ocurre en una cámara magmática de larga duración. Las rocas del Popo también suelen mostrar evidencias tangibles de interacción magmática con las rocas del basamento en forma de xenolitos y xenocristales, que aparentemente se ve reflejada también en la composición isotópica de los productos volcánicos. Las rocas del Popo muestran valores mayores en la relación ${ }^{87} \mathrm{Sr} /{ }^{86} \mathrm{Sr}$ que los observados en los conos cineríticos a valores equivalentes de $\varepsilon \mathrm{Nd}$. Los autores sugieren que estas diferencias son el resultado de la interacción del magma con las calizas cretácicas del basamento local.

Los estudios petrológicos de Straub y Martín-Del Pozzo (2001) sugieren, en cambio, que las andesitas del

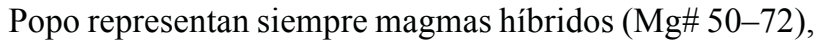
producto de la mezcla entre un componente máfico $(\mathrm{Mg \#}$ 68-86) y un componente evolucionado ( $\mathrm{Mg \#} \mathrm{35-40).} \mathrm{El}$ componente máfico se encuentra considerablemente hidratado y está saturado en olivino y espinela a una temperatura de $1170-1085^{\circ} \mathrm{C}$ y a una presión $>12 \mathrm{kbar}$. El componente máfico cristaliza clinopiroxeno durante su ascenso a través de la corteza, y se mezcla vigorosamente con el componente evolucionado que reside a 3-4 kbar con una temperatura de $\sim 950{ }^{\circ} \mathrm{C}$. Utilizando cálculos de balance de masa y argumentos termodinámicos simples, Straub y Martín-Del Pozzo (2001) desestiman que las lavas del Popo puedan ser el resultado de mezclas entre basaltos primitivos de Chichinautzin con un magma evolucionado derivado de la fusión de la corteza continental o de un grado avanzado de cristalización. En cambio, las investigadoras consideran que el componente máfico está representado por una andesita $\left(\mathrm{SiO}_{2}\right.$ 55-62 \% en peso) rica en $\mathrm{MgO}$ con características petrológicas cercanas a un magma primario. De esta forma, el componente evolucionado podría formarse por grados moderados de cristalización fraccionada, aunque no descartan la posibilidad de que una pequeña cantidad de corteza continental haya sido asimilada.

Por su parte Wallace y Carmichael (1994) tampoco en- 
cuentran evidencias de que el magma primario que alimenta al volcán Tequila tenga una composición basáltica, sino que se trata de un magma andesítico que interactúa con un magma dacítico residente. Wallace y Carmichael (1994) notan la imposibilidad de formar el magma evolucionado a partir del magma primitivo mediante cristalización, pues la concentración de algunos elementos incompatibles disminuye al aumentar el contenido de sílice. Por esto, los autores proponen la existencia de distintos magmas parentales cuya evolución parece ser independiente, y no descartan la posibilidad de que exista algún grado de contaminación cortical durante su petrogénesis.

La posibilidad de que el magma primario que alimenta a los estratovolcanes sea una andesita rica en magnesio y no un basalto ofrece una perspectiva importante para nuestra forma de entender el magmatismo de arco en México y en el mundo. En efecto, aunque esta hipótesis había sido planteada desde hace largo tiempo (Gill, 1981), las evidencias petrológicas y geoquímicas parecen restringirla a condiciones extremas, cercanas al límite de saturación con agua, que aún ahora siguen siendo difíciles de reproducir en los laboratorios experimentales más sofisticados (Parman y Grove, 2004). Sin embargo, Blatter y Carmichael (1998a) documentan la presencia de nódulos lherzolíticos con hornblenda incluidos en una roca andesítica del campo volcánico de Zitácuaro, cuyo entrampamiento no pudo ocurrir más que durante su ascenso a través del manto. Los investigadores utilizan esta evidencia, junto con los estudios experimentales de equilibrio de fases en este tipo de rocas (Blatter y Carmichael, 2001), para sugerir la posibilidad de que algunas rocas andesíticas ricas en magnesio $\left(62 \% \mathrm{SiO}_{2}\right.$ y $5.6 \% \mathrm{MgO}$ ) puedan derivarse directamente de la fusión parcial del manto en condiciones de saturación de agua, en concordancia con algunos estudios experimentales (Hirose, 1997). Estas composiciones no están muy alejadas de lo que se observa en los estratovolcanes, y podrían explicar la razón por la cual no existen magmas basálticos primitivos emanando de estos sistemas.

Recientemente se han presentado una serie de evidencias y argumentos que intentan explicar la evolución petrogenética del arco de una forma alternativa (Luhr, 2000; Gómez-Tuena et al., 2003; Martínez-Serrano et al., 2004). Estos estudios han mostrado que algunas de las rocas de composición intermedia emplazadas en los estratovolcanes y en algunos conos cineríticos, tanto miocénicos como cuaternarios, muestran características geoquímicas similares a las de los magmas derivados de la fusión parcial de la corteza oceánica, incluyendo a su componente sedimentaria (Figura 20). Aunque en su conjunto estas rocas muestran una composición variable (andesitas-dacitas), también presentan altas concentraciones de Sr y muy bajas concentraciones de Y y HREE, cuyo origen es difícil de explicar mediante un proceso de diferenciación simple a partir de un magma basáltico (Defant y Drummond, 1990). Estas rocas muestran también composiciones isotópicas cercanas a las de los MORB, poniendo en evidencia la participación de

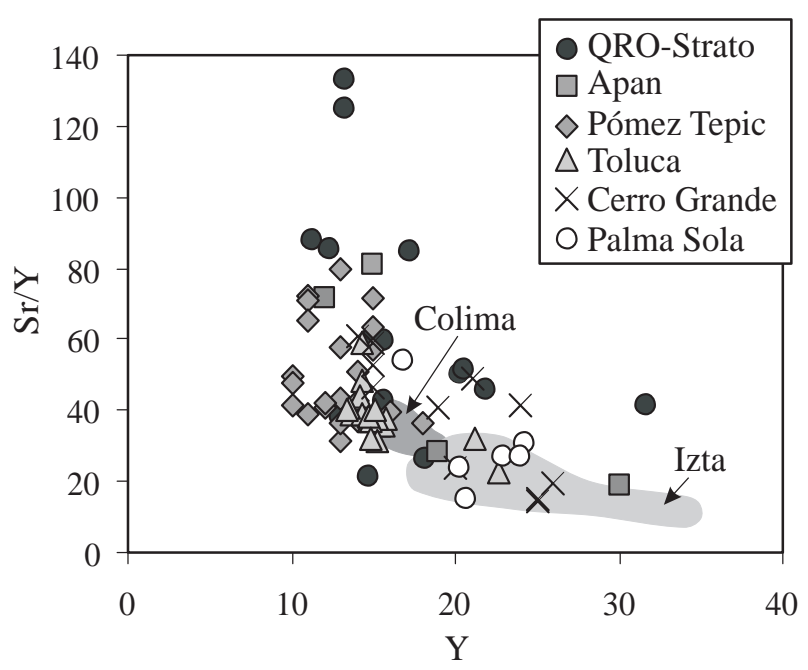

Figura 20. Diagrama de variación de $\mathrm{Sr} / \mathrm{Y}$ contra $\mathrm{Y}$ en andesitas y dacitas de algunos campos volcánicos de la FVTM. La señales adakíticas se verifican en los volcanes cuaternarios de San Juan (Luhr, 2000) y en el Nevado de Toluca (Martínez-Serrano et al., 2004), y en los campos volcánicos miocénicos de Apan (García-Palomo et al., 2002), Cerro Grande (Gómez-Tuena y Carrasco-Núñez, 2000), Palma Sola y Palo Huérfano-La Joya-Zamorano (PH-LJ-Z, Gómez-Tuena et al., 2003). Como comparación se muestran los campos que ocuparían los datos del volcán de Colima (Luhr, 2002) y del volcán Iztaccíhuatl (Nixon, 1988b), en donde la señal adakítica no está presente.

este componente en su petrogénesis e invalidando un origen asociado a la fusión parcial de la corteza continental. La posibilidad de que la corteza oceánica se funda debajo del arco permite visualizar la generación de rocas de composición andesítica y dacítica ricas en $\mathrm{MgO}$ por medio de la interacción de magmas silícicos, derivados de la fusión de la losa oceánica, con las peridotitas del manto (Kelemen et al., 2003). Por lo tanto, si esta hipótesis se confirma, entonces no sería necesario invocar la fusión parcial del manto en condiciones extraordinariamente hidratadas para la generación de andesitas primitivas, pues los altos contenidos de $\mathrm{SiO}_{2}$ observados en las rocas podrían ser una característica heredada de los magmas derivados de la fusión parcial de la corteza oceánica (Rapp y Watson, 1995).

\subsection{Magmatismo silícico}

En un trabajo de revisión sobre el volcanismo riolítico de la Faja Volcánica Transmexicana, Ferriz y Mahood (1986) mencionan la existencia de cinco centros volcánicos riolíticos y algunas otras manifestaciones aisladas. Trabajos posteriores han reconocido y estudiado un número creciente de centros riolíticos a todo lo largo de la FVTM. Sin embargo, gran parte de los estudios han estado enfocados a establecer las relaciones estratigráficas y los procesos eruptivos asociados, mientras que los estudios petrológicos y geoquímicos siguen siendo relativamente escasos. Con base en la distribución geográfica y estratigráfica, así como 
en las características petrográficas, geoquímicas y el modo de emplazamiento magmático, hemos distinguido tres episodios de volcanismo silícico asociado a la evolución de la FVTM: (1) Mioceno tardío, (2) Plioceno temprano, y (3) Plioceno tardío-Cuaternario.

Tanto en el sector occidental como en el sector central las primeras manifestaciones de vulcanismo riolítico aparecen durante el Mioceno tardío, a los $\sim 7 \mathrm{Ma}$ (Figura 2c) (Aguirre-Díaz y López-Martínez, 2001; Ferrari et al., 2001; Rossotti et al., 2002). En el sector occidental, al NW y NE de Guadalajara, se emplazaron algunos domos y flujos piroclásticos entre los 7.15 y los $5.2 \mathrm{Ma}$ (Gilbert et al., 1985) formando el denominado Grupo Guadalajara, con un volumen estimado de $212 \mathrm{~km}^{3}$ (Rossotti et al., 2002). Estas rocas son predominantemente riolitas peraluminosas $\left(\mathrm{Al}_{2} \mathrm{O}_{3} / \mathrm{CaO}+\mathrm{Na}_{2} \mathrm{O}+\mathrm{K}_{2} \mathrm{O}\right.$ molar $\left.>1\right)$, con corindón normativo, alto sílice y valores altos de $\mathrm{K}_{2} \mathrm{O}$ (datos no publicados de L. Ferrari) (Figura 21). En el sector central se emplaza la caldera de Amazcala, ubicada al NE de la ciudad de Querétaro, cuyo periodo de actividad abarca de 7.3 a 6.6 Ma. Las rocas de esta caldera están caracterizadas por pómez de caída, ignimbritas, domos y flujos de lava con composiciones riolíticas y alto contenido de $\mathrm{K}_{2} \mathrm{O}$ (AguirreDíaz y López-Martínez, 2001). Al sur de Querétaro se presentan también grandes complejos de domos riolíticos, para los cuales sólo se han reportado dos edades [ $\sim 6 \mathrm{Ma}$ (Aguirre-Díaz y López-Martínez, 2001) y 5.4 Ma (Ferrari et al., 1991)]. Al oriente de la caldera de Amazcala también afloran algunos domos riolíticos que han sido fechados en 7.49 Ma (Jacobo-Albarrán, 1986). En ambos sectores, el episodio riolítico del Mioceno tardío se manifiesta hacia la porción norte de la FVTM, en la zona más alejada a la trinchera, y es inmediatamente posterior al evento máfico del Mioceno tardío (Figura 2b-c).

Se ha considerado que la tasa de extrusión magmática disminuyó de manera considerable durante el emplazamiento del episodio riolítico del Mioceno tardío del sector occidental. Esta disminución ha sido atribuida al decremento en la tasa de convergencia entre las placas de Rivera y de Norteamérica para ese periodo. El episodio silícico también coincide con el inicio de la migración del arco magmático hacia la trinchera, que comúnmente ha sido relacionado con un aumento en el ángulo de subducción que comenzó a desarrollarse a partir de los 8.5 Ma (Ferrari et al., 2000a; Ferrari et al., 2001). Estas evidencias podrían indicar que la dinámica de placas ha controlado el estilo y la composición del vulcanismo en la FVTM, pero desafortunadamente hasta la fecha no existen datos geoquímicos ni petrológicos adicionales que arrojen información sobre los procesos de generación de magmas silícicos y su relación con la dinámica de placas.

A partir del Plioceno temprano las rocas riolíticas coexisten con rocas máficas e intermedias, y el volumen de rocas piroclásticas se vuelve proporcionalmente más importante. Varios autores han observado que los depósitos ignimbríticos presentan un vidrio de color oscuro con composición de andesita-basáltica a traquítica que coexiste con un vidrio incoloro de composición riolítica a riolítica de alto sílice, desplegando una textura de mezcla inhomogénea o mingling (Gilbert et al., 1985; Aguirre-Díaz, 2001; Rossotti et al., 2002). En el área de Guadalajara, este fenómeno se observó en depósitos con edades comprendidas entre 4.8

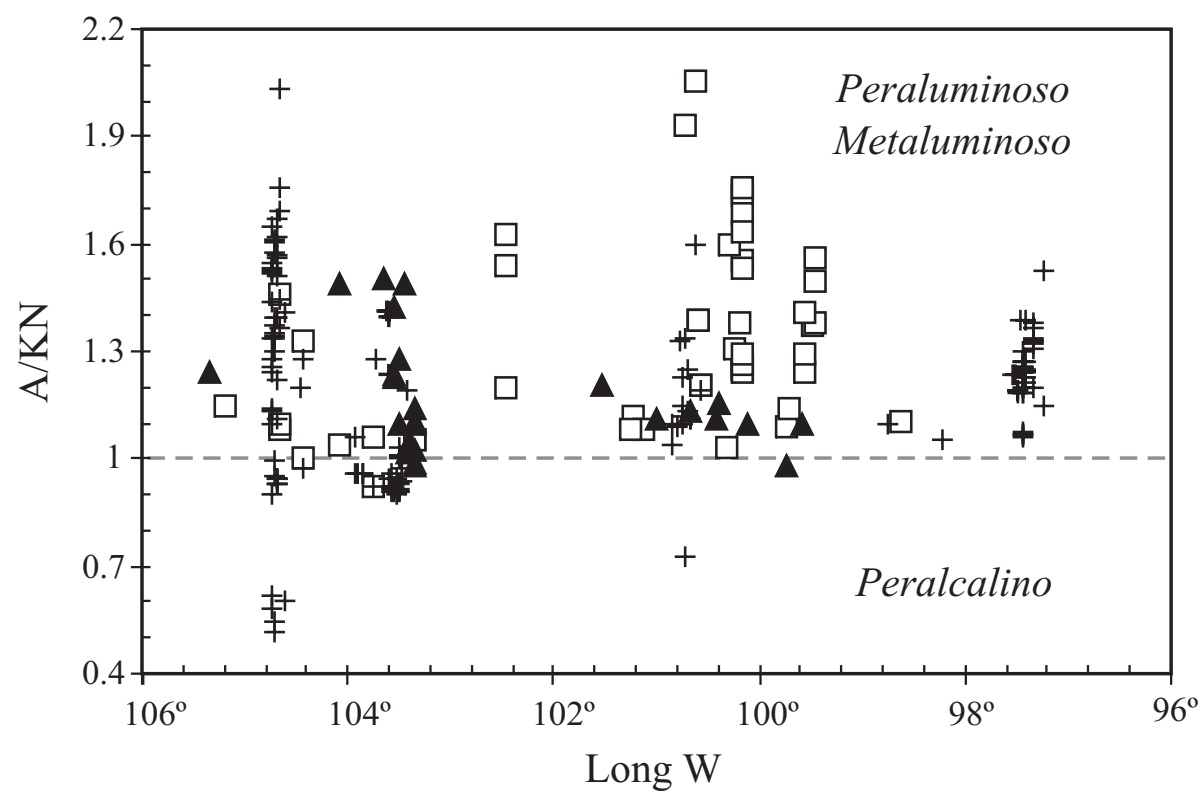

Figura 21. Variación espacial y temporal en el grado de saturación de alúmina para las rocas riolíticas de la FVTM. En el eje de las ordenadas se representan las relaciones molares de $\mathrm{A} / \mathrm{KN}=$ molar $\mathrm{Al}_{2} \mathrm{O}_{3} / \mathrm{Na}_{2} \mathrm{O}+\mathrm{K}_{2} \mathrm{O}$. La línea punteada divide el campo peraluminoso-metaluminoso del peralcalino. Triángulos: Mioceno tardío; cuadros: Plioceno temprano; cruces: Plioceno tardío-Cuaternario. 
y $3.07 \mathrm{Ma}$, en las Ignimbritas San Gaspar y Guadalajara (Gilbert et al., 1985), y en depósitos piroclásticos incluidos en el Grupo Cerro Chicharrón (Rossotti et al., 2002). La persistencia de volcanismo riolítico del área de Guadalajara, que inicia en el Mioceno tardío y migra hacia el sur durante el Pleistoceno, ha sido relacionada también con la existencia de una cámara magmática somera de larga vida que se establece a $\sim 7 \mathrm{Ma}$. Algunos autores han propuesto que, al iniciar el volcanismo alcalino máfico de tipo intraplaca en el área, hacia los 4.6 Ma (Moore et al., 1994), la inyección de magmas máficos dentro de la cámara silícica suministró la energía necesaria para desencadenar los eventos explosivos y generar la notable mezcla de magmas (Rosas-Elguera $e t$ al., 1997; Rossotti et al., 2002).

En el sector central, el volcanismo riolítico del Plioceno temprano se asocia a grandes calderas: Los Azufres, Amealco y Huichapan (Lámina 1). Estas calderas se caracterizan por la alternancia de eventos de composición máfica a intermedia y eventos de composición félsica, siendo evidente un aumento en la emisión de productos menos diferenciados en comparación con el episodio del Mioceno tardío. Como ejemplo, en la caldera de Amealco, el $95 \%$ del volumen de magma emitido es de composición intermedia y sólo el 5\% del volúmen presenta una composición riolítica (Aguirre-Díaz, 1996).

El intenso fallamiento y los vastos depósitos volcánicos sucesivos han dificultado la definición de los eventos asociados a la formación de la caldera de Los Azufres. Sin embargo, Ferrari et al. (1991) la interpretan como una caldera que ha sufrido colapsos múltiples (caldera anidada) durante el Mioceno tardío y el Plioceno, mientras que Pradal y Robin (1994) la definen como una caldera construida a $<3.4$ Ma sobre un complejo andesítico del Mioceno-Plioceno. Los productos volcánicos más recientes relacionados con la caldera han sido fechados en $26.5 \mathrm{ka}$. De acuerdo con los escasos datos geoquímicos que han sido publicados, en Los Azufres se presenta de manera alternada volcanismo félsico y máfico. Las rocas félsicas son dacitas, riolitas y riolitas de alto sílice con un carácter peraluminoso, que pertenecen a la serie calcialcalina de alto potasio (Cathalieau et al., 1987; Pradal y Robin, 1994). Aquí también han sido reportadas evidencias geoquímicas y mineralógicas de una mezcla entre magmas riolíticos y basálticos que generaron lavas dacíticas (Cathalieau et al., 1987). Las variaciones en la composición de los magmas emitidos han sido relacionadas con el muestreo progresivo de una cámara magmática zonificada que se ve reabastecida periódicamente por magmas máficos (Pradal y Robin, 1994). La variación en la relación ${ }^{87} \mathrm{Sr} /{ }^{86} \mathrm{Sr}$ de una andesita de $0.6 \mathrm{Ma}(0.70357)$, una riolita de $0.026 \mathrm{Ma}(0.70553)$, y un cono basáltico más reciente $(0.70367)$ parecen confirmar esta hipótesis (Pradal y Robin, 1994), aunque los autores no discuten los procesos por los cuales la roca más diferenciada alcanza la composición más radiogénica. Por su parte, Ferrari et al. (1991) asocian la generación de las rocas más evolucionadas a un pulso compresivo que permitió el estacionamiento y diferenciación de magma en cámaras magmáticas. Este episodio fue reemplazado por una fase transtensiva que permitió la recarga de la cámara magmática con magmas máficos que propiciaron un proceso de mezcla de magmas y el emplazamiento de grandes volúmenes de lava basáltica a lo largo de fallas extensionales localizadas en el exterior de la caldera.

Los primeros productos de la caldera de Amealco (la llamada Toba Amealco), emplazados a los 4.7 Ma, también tienen características de mingling (Aguirre-Díaz, 1996; Aguirre-Díaz, 2001). En este caso la mezcla de magmas ha sido relacionada con la repetitiva inyección de magma menos diferenciado y más caliente en una cámara magmática zonificada (Aguirre-Díaz, 2001). Al finalizar los eventos iniciales que generaron la Toba Amealco y el emplazamiento de domos y lavas andesíticas a dacíticas, se emplazaron dentro de la caldera cinco domos, fechados en 3.9 Ma, con composición de riolita de bajo sílice (Aguirre-Díaz, 1996). Además, en la periferia de la caldera también existen domos riolíticos perluminosos a metaluminosos con alto sílice que han sido fechados en 4.7 y 2.9 Ma (Aguirre-Díaz, 1996).

En la caldera de Huichapan, localizada en el límite entre el sector central y el sector oriental, las ignimbritas de la fase inicial han sido fechadas en 4.8 y 4.4 Ma (Aguirre-Díaz et al., 1997). En este centro volcánico se presentan eventos alternantes de composición silícica (dacitas, traquitas y riolitas) y máfica (basalto andesítico a andesita) pero, a diferencia de la caldera de Amealco, el volcanismo explosivo inicial es de composición silícica (Verma, 2001b). Los análisis químicos (Verma, 2001b) indican que en los eventos más diferenciados las rocas son calcialcalinas de alto potasio y predominan las rocas de carácter peraluminoso (corindón normativo; $\mathrm{A} / \mathrm{CKN}$ molar $>1$ ).

Los estudios isotópicos realizados por Verma et al. (1991, 2001b) en las calderas de Amealco y Huichapan muestran que los productos volcánicos tienden a valores más enriquecidos en las relaciones isotópicas de $\mathrm{Sr}, \mathrm{Pb}$ y $\mathrm{Nd}$ al aumentar el contenido de $\mathrm{SiO}_{2}$. Como era de esperarse, esta característica ha sido tomada como una evidencia de asimilación cortical. La composición de las rocas de Huichapan puede ser modelada por un proceso de asimilación y cristalización fraccionada (AFC), empleando como componentes un basalto miocénico y un asimilante hipotético derivado de la composición de una riolita muy enriquecida isotópicamente, la cual se considera originada por fusión cortical durante un evento volcánico previo (Verma, 2001b). De manera similar a lo que ocurre en la caldera de Los Azufres, la recarga cíclica de magmas más primitivos hacia una cámara magmática evolucionada también ha jugado un papel importante en la evolución petrológica de los magmas de Huichapan. Curiosamente, las rocas riolíticas de la caldera de Amealco están sólo ligeramente más enriquecidas en ${ }^{87} \mathrm{Sr} /{ }^{86} \mathrm{Sr}(0.70419-0.70424)$ y $\varepsilon \mathrm{Nd}(1.8-2.5)$ que las rocas intermedias emplazadas previamente $\left({ }^{87} \mathrm{Sr} r{ }^{86} \mathrm{Sr}=0.70396-0.70419 ; \varepsilon \mathrm{Nd}=2.1-2.6\right)$. En este sentido, Verma et al. (1991) proponen que durante la 
evolución a composiciones intermedias, los magmas derivados del manto asimilaron material cortical $(\sim 1 \mathrm{a} \sim 10 \%)$ en niveles profundos de la corteza, o durante las etapas tempranas de diferenciación en una cámara magmática somera, pero que la asimilación fue insignificante durante la evolución de composiciones intermedias a riolíticas.

En el sector oriental, en una extensa área comprendida entre Tenango de Doria y Tlanchinol, al NE de Pachuca, Hidalgo (Lámina 1), afloran depósitos de piroclásticos y lavas riolíticas vítreas intercalados con emisiones fisurales de lavas máficas moderadamente alcalinas o transicionales (Robin, 1976b; Robin, 1982). Las rocas riolíticas tienen edades de 4.3 y 4.4 Ma (Cantagrel y Robin, 1979). El origen del volcanismo riolítico en esta suite bimodal fue estudiado muy someramente por Robin (1982), quien reporta promedios de análisis para dos grupos de muestras que tienen composición de riolita peraluminosa. La composición de estas rocas se grafica cercano al mínimo granítico en el diagrama Ab-Or-Q sugiriendo un origen anatéctico (Robin, 1982). La presencia de volcanismo alcalino sódico que evoluciona a una suite bimodal, llevó a este autor a proponer que las emisiones se relacionan a una "subprovincia del borde del Altiplano" asociada a procesos extensionales y sin relación con el sistema de subducción del sur de México. Sin embargo, este modelo ha sido reevaluado en trabajos recientes que consideran a estas rocas como parte de la FVTM (Ferrari et al., 2005b).

El volcanismo riolítico del Plioceno tardío-Cuaternario de la FVTM se distingue de los episodios anteriores por la emisión de volúmenes significativos de magmas peralcalinos $\left(\mathrm{Al}_{2} \mathrm{O}_{3} / \mathrm{Na}_{2} \mathrm{O}+\mathrm{K}_{2} \mathrm{O}\right.$ molar $<1$; acmita normativa) (Figura 21). Las rocas peralcalinas generalmente se asocian a ambientes anorogénicos y su presencia en los extremos occidental y oriental de la FVTM, donde ha ocurrido volcanismo alcalino sódico de intraplaca (graben TepicZacoalco, noreste del estado de Hidalgo), parece indicar una relación genética entre ambos tipos de magma. Cabe señalar que durante este periodo son dominantes las rocas riolíticas metaluminosas y peraluminosas en todo el arco, mientras que las rocas peralcalinas se presentan en volúmenes más pequeños y con una distribución restringida.

En el sector occidental han sido descritas rocas peralcalinas en el volcán Las Navajas, en Nayarit, en el complejo de domos Magdalena y en la sierra de La Primavera, Jalisco. El volcán Las Navajas (con un edad menor que 4 Ma y mayor que $200 \mathrm{ka}$; Nelson y Carmichael, 1984), localizado en el extremo occidental del graben Tepic-Zacoalco, es la única localidad de la FVTM donde han sido reportadas rocas riolíticas fuertemente peralcalinas (panteleritas), aunque también se presentan rocas moderadamente peralcalinas (comenditas). Las lavas y depósitos piroclásticos peralcalinos presentan la mineralogía característica de este tipo de rocas con fenocristales de cuarzo y feldespato alcalino así como cantidades menores de olivino fayalítico, riebeckita y enigmatita en las comenditas o ferrohedembergita, arfvedsonita, enigmatita y riebeckita en las panteleritas (Nelson y Hegre, 1990). Las panteleritas tienen contenidos bajos de $\mathrm{Al}_{2} \mathrm{O}_{3}(8.2-9.4 \%$ en peso) y alto de $\mathrm{Zr}$ (8392049 ppm), indicando que estas rocas evolucionaron por cristalización fraccionada extrema en una cámara magmática somera a partir de basaltos moderadamente alcalinos (Nelson y Hegre, 1990). Estas evidencias indican que un volumen considerable de magma máfico alcalino se estacionó en la corteza donde pudo diferenciarse, pero también ponen de manifiesto un contraste con el típico mecanismo de emplazamiento observado en la mayoría de los magmas alcalinos que generalmente ascienden con rapidez a través de fallas y fracturas.

El complejo de domos de Magdalena está constituido por doce domos y flujos riolíticos $\left(\mathrm{SiO}_{2}: 70-76.5 \%\right)$ que rodean al volcán Tequila y que han sido fechados entre 1.12-0.24 Ma (Harris, 1986; Lewis-Kenedi et al., 2005). En este complejo se presentan rocas moderadamente peralcalinas, metaluminosas y peraluminosas, que contienen fenocristales de sanidino, plagioclasa y un poco de hornblenda (Demant, 1979; Harris, 1986). Estas lavas se emplazaron antes del evento que formó el edificio principal andesítico del volcán Tequila $(<0.2 \mathrm{Ma})$ y coexisten con basaltos de alto Ti, por lo que Lewis-Kenedi et al. (2005) las consideran parte de una suite bimodal formada entre 1 y 0.2 Ma. En este modelo, los magmas riolíticos se habrían generado durante episodios de fusión de la corteza superior promovidos por el emplazamiento episódico de magmas basálticos, los cuales en parte ascendieron hasta la superficie a través de fracturas y fallas que siguen una dirección NW-SE.

La Sierra La Primavera, localizada al W de Guadalajara, ha sido más estudiada (Mahood, 1981a; Mahood, 1981b; Mahood y Halliday, 1988). Las rocas de La Primavera son domos, flujos de lava y depósitos piroclásticos con composición riolítica con alto contenido de sílice ( $>75 \%$ $\mathrm{SiO}_{2}$ ) que se emplazaron entre los 145000 y 30000 a. Los depósitos contienen fenocristales de sanidino sódico y cuarzo, y pueden contener cantidades menores ( $<3 \%$ vol.) de ferrohedembergita, fayalita e ilmenita. Su composición varía desde comenditas peralcalinas hasta riolitas metaluminosas. Los primeros productos son más diferenciados y están enriquecidos en F, Rb, Na, Y, Zr, HREE, Hf, Ta, Pb, Th, U con respecto a los más tardíos que, en cambio, están enriquecidos en Ca, LREE, Ti, y Al. Esta evolución magmática está aparentemente relacionada con el muestreo de porciones cada vez más profundas y menos diferenciadas de una cámara magmática zonificada (Mahood, 1981a, 1981b; Mahood y Halliday, 1988). Los autores sugieren que las variaciones en la temperatura, el contenido de volátiles y la peralcalinidad con respecto a la profundidad pudieron influir en el tipo y cantidad de fases que fraccionan, dando lugar a las variaciones geoquímicas observadas. Es notable también que las rocas de La Primavera presentan valores relativamente primitivos y constantes de ${ }^{87} \mathrm{Sr} /{ }^{86} \mathrm{Sr}(0.704-$ $0.7048), \varepsilon N d(4.5-5.8)$ y $\delta^{18} \mathrm{O}(\sim 6.6 \%$, en sanidino $)$, cuyo 
origen sería consistente con un proceso de cristalización fraccionada a partir de magmas basálticos con contribuciones mínimas o nulas de material cortical. Sin embargo, la ausencia de rocas máficas a intermedias y la observación de que la mayor parte de los campos riolíticos de México muestran señales geoquímicas consistentes con fusión cortical, hace que los autores sugieran la participación de fundidos derivados del basamento mesozoico local (terreno Guerrero) que, aparentemente, tiene una composición isotópica muy parecida a la de los productos provenientes del manto.

Un volumen significativo de lavas silícicas se emplazó en el sector oriental durante el Plioceno tardío-Cuaternario (Lámina 1). Los centros más importantes son las calderas de Los Humeros y Acoculco, los domos de la cuenca de Serdán-Oriental, y manifestaciones aisladas de menor volumen como el volcanismo peralcalino de la Sierra de Las Navajas, Hidalgo (Geyne et al., 1963; Nelson y Lighthart, 1997) y el complejo de domos de la Sierra de Los Pitos del Plioceno tardío (Zamorano-Orozco et al., 2002).

En la caldera de Acoculco se emplazaron una serie de domos y flujos piroclásticos riolíticos y dacíticos con edades comprendidas entre 3 y $1.26 \mathrm{Ma}$, y en la última fase de actividad fueron emitidas lavas basálticas que han sido fechadas en 0.24 Ma (López-Hernández y CastilloHernández, 1997). El análisis de una muestra indica una composición de riolita metaluminosa de alto sílice y alto contenido de potasio (Verma, 2001a).

En la caldera de los Humeros, los magmas emplazados presentan también una evolución en el tiempo a composiciones más máficas. Los primeros productos son riolitas de alto sílice a riodacitas emplazadas entre $\sim 0.47 \mathrm{Ma} \mathrm{y} \sim 0.22$ $\mathrm{Ma}$, seguidos por el emplazamiento de rocas andesíticas a riodacíticas entre 0.24 y $0.02 \mathrm{Ma}$, y finalmente basaltos de olivino emplazados a $<0.02 \mathrm{Ma}$. En esta secuencia, los magmas riolíticos de alto sílice dominan volumétricamente sobre los otros tipos de magma. Las rocas más diferenciadas pertenecen a la serie calcialcalina de alto potasio y son de carácter metaluminoso, presentando algunas de ellas cristales de biotita o hiperstena y raras veces hornblenda (Ferriz y Mahood, 1984; Ferriz y Mahood, 1987).

Siguiendo una lógica similar a la aplicada para el estudio de las calderas de Amealco y Huichapan, Verma (2000b, 2001a) proponen que los magmas parentales se originan por fusión parcial en el manto litosférico (con características geoquímicas enriquecidas y similares a las que dan origen a los OIB) y evolucionaron a composiciones intermedias por un proceso de asimilación cortical. El autor modela los datos usando una composición hipotética para el componente cortical, y asumiendo que la evolución de composiciones intermedias a riolíticas estaría dominada únicamente por cristalización fraccionada. Por otra parte, Ferriz y Mahood (1987) proponen un modelo complejo de evolución en una cámara magmática estratificada, donde la inyección periódica de magma basáltico derivado del manto en la zona basal suministró calor al reservorio y dio lugar a procesos de mezcla. La mezcla entre magma basáltico con magma andesítico de alto sílice habría generado andesitas basálticas a partir de las cuales se originan las riodacitas y riolitas por cristalización fraccionada o AFC. En este modelo, el zonamiento inverso observado en los depósitos piroclásticos individuales representaría el muestreo de zonas cada vez más profundas de la cámara magmática. Los magmas más evolucionados de Los Humeros tienen composiciones isotópicas más enriquecidas $\left({ }^{87} \mathrm{Sr} /{ }^{86} \mathrm{Sr}=0.70414-0.70444\right.$; $\varepsilon \mathrm{Nd}=1.4 ; \delta^{18} \mathrm{O}=6.4-7.2 \%$ ) que los magmas más primitivos emplazados en las últimas fases de actividad $\left({ }^{87} \mathrm{Sr} /{ }^{86} \mathrm{Sr}=\right.$ $0.70386, \varepsilon \mathrm{Nd}=4.1$ y $\delta^{18} \mathrm{O}=5.8 \%$ ), sugiriendo un proceso de mezcla y/o asimilación cortical. Ferriz y Mahood (1987) relacionan la evolución global a composiciones más máficas en la historia de Los Humeros con un aumento en la tasa de extracción y un descenso en la tasa de recarga, que impediría el reestablecimiento del reservorio zonificado original.

En la cuenca de Serdán-Oriental, al sur de Los Humeros, se localiza un grupo de domos riolíticos emplazados en un área restringida con una burda alineación N-S: Las Derrumbadas, Cerro Águila, Cerro Pinto y Cerro Pizarro (Ferriz y Mahood, 1986). Riggs y Carrasco-Núñez (2004) reportan una edad de 220000 años para el Cerro Pizarro y Yañez-García y Casique (1980) fecharon el domo Las Derrumbadas en 0.32 Ma, aunque Siebe y Verma (1988) estimaron una edad menor que 40000 años para este último con base en la morfología. En el área también se reporta un extenso depósito de caída de pómez formado por una erupción pliniana ocurrida hace 20000 años cuya fuente se localiza al oriente de Las Derrumbadas: la llamada Pómez Quetzalapa (Rodríguez-Elizarrarás et al., 2002). Este depósito está conformado por fragmentos de pómez riolítica $\left(\mathrm{SiO}_{2}: 68.5-75.5 \%\right.$ en peso) peraluminosa, con fenocristales de biotita y cantidades menores de hornblenda.

Los domos de la cuenca de Serdán-Oriental son generalemente peraluminosos y contienen cristales de plagioclasa, sanidino, cuarzo, biotita, magnetita e ilmenita, y es notable que el domo de Las Derrumbadas presente también granate (Ferriz y Mahood, 1986). Aún cuando todos los domos tienen contenidos de sílice similares, y se emplazaron en un área y tiempo restringidos, existen entre ellos variaciones importantes en el contenido de elementos traza y en las relaciones isotópicas que sugieren orígenes diversos. Los datos geoquímicos obtenidos por diversos autores (Negendank et al., 1985; Ferriz y Mahood, 1986; Ferriz y Mahood, 1987; Besch et al., 1988; Besch et al., 1995; Riggs y Carrasco-Núñez, 2004) indican que las rocas de Las Derrumbadas están muy empobrecidas en Tierras Raras medias y pesadas, muestran una anomalía negativa de Eu muy pequeña, tienen contenidos moderados de $\mathrm{Ba}$ (770-889 ppm) y Sr (138-275 ppm) y la composición isotópica más enriquecida $\left({ }^{87} \mathrm{Sr} r{ }^{86} \mathrm{Sr}=0.70511 ; \varepsilon \mathrm{Nd}=-2.8\right)$. Las rocas del Cerro Pinto tienen patrones de Tierras Raras relativamente planos (bajo LREE/HREE), una marcada anomalía negativa en Eu, están muy empobrecidas en 
$\mathrm{Ba}(30-50 \mathrm{ppm})$ y $\mathrm{Sr}(21-22 \mathrm{ppm})$, y tienen relaciones isotópicas ligeramente menos enriquecidas que las de Las Derrumbadas $\left({ }^{87} \mathrm{Sr} /{ }^{86} \mathrm{Sr}=0.70506 ; \varepsilon \mathrm{Nd}=-1.6\right)$. Los domos Cerro Águila y Cerro Pizarro tienen contenidos de LREE similares a los de Las Derrumbadas, pero no muestran el marcado empobrecimiento en HREE y tienen una anomalía negativa de Eu moderada. En el Cerro Pizarro los contenidos de $\mathrm{Ba}$ (1658-1776 ppm) son los más elevados, los valores de $\mathrm{Sr}$ son relativamente altos (176-205 ppm), y las relaciones isotópicas son las menos enriquecidas de todos los domos estudiados $\left({ }^{87} \mathrm{Sr} /{ }^{86} \mathrm{Sr}=0.70481, \varepsilon_{\mathrm{Nd}}=-1.4\right)$. Aunque hasta la fecha no existen estudios petrogenéticos detallados para estas rocas, Ferriz y Mahood $(1986,1987)$ proponen que los domos representan pequeños volúmenes de magma generados por fusión parcial de la corteza, y que las variaciones en la composición isotópica y de tierras raras reflejan las variaciones en la litología de las fuentes corticales. En este mismo sentido, Besch et al. (1988) interpretan una mineralogía residual con granate, anfíbol y plagioclasa para los magmas de Las Derrumbadas, y con ortopiroxeno, clinopiroxeno y plagioclasa para el Cerro Pinto. Por otra parte, y con base en la composición isotópica de $\mathrm{Sr}$ y $\mathrm{Nd}$ de las rocas y su correlación con el contenido de sílice, se ha propuesto de manera muy general un origen para los magmas de Las Derrumbadas y Pinto por asimilación y cristalización fraccionada a partir de magmas basálticos provenientes del manto (Siebe y Verma, 1988; Besch et al., 1995), pero en estos trabajos no se discuten las notorias variaciones en los contenidos de elementos traza.

En resumen, las principales características del volcanis- mo silícico de la FVTM se pueden sintetizar de la siguiente manera: (1) En el Mioceno tardío ocurre un episodio exclusivamente riolítico y predominantemente efusivo en el sector occidental y central, en el área norte de la FVTM (Lámina 1). Las lavas son predominantemente peraluminosas (Figura 21). (2) En el Plioceno temprano, las rocas riolíticas coexisten con rocas más máficas. Se emplazan rocas piroclásticas con evidencia de mezcla inhomogénea de magmas (mingling) y suites bimodales. El volcanismo explosivo se vuelve más importante y dominan las composiciones metaluminosas y peraluminosas (Figura 21). (3) En el Plioceno tardío(?)-Cuaternario se generan magmas peralcalinos asociados a volcanismo máfico alcalino-sódico en los extremos oriental y occidental, en este último coexiste con volcanismo metaluminoso y peraluminoso. En el sector central y oriental el volumen mayoritario es de carácter peraluminoso (Figura 21). El volcanismo riolítico aparentemente está más localizado: graben Tepic-Zacoalco en el sector occidental, un área reducida en el sector central (Los Azufres), y la extensa área comprendida por Los Humeros-cuenca de Sedán-Oriental, así como otras manifestaciones menores al NW de ésta (Lámina 1). (4) Entre el Mioceno tardío y el Cuaternario, el volcanismo riolítico del sector occidental se ha concentrado en el área del graben Tepic-Zacoalco, en la zona más alejada a la trinchera. En el área de Guadalajara (sector occidental) y en los sectores central y oriental se observa una migración en el tiempo hacia la trinchera (Lámina 1). (5) Los procesos de asimilación cortical o anatexis han sido importantes en el sector central y oriental, como lo indican las composicio-

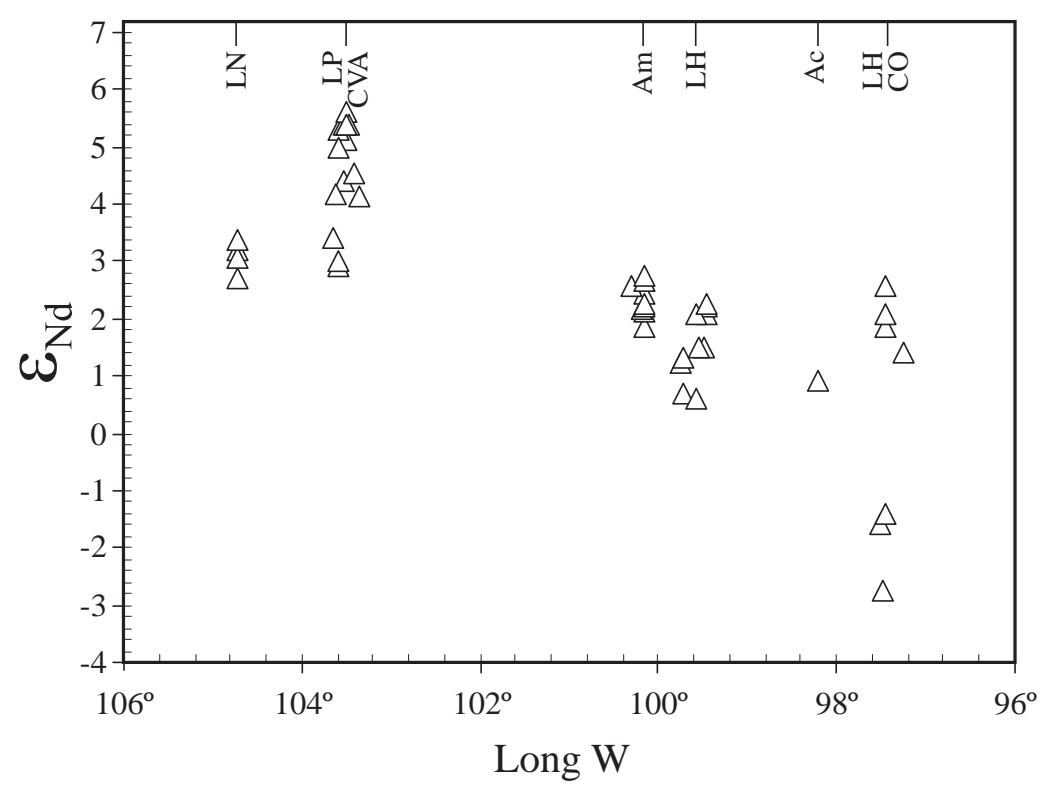

Figura 22. Variación espacial de la composición isotópica de Nd para rocas de los centros riolíticos de la Faja Volcánica Transmexicana. Datos isotópicos de Mahood y Halliday (1988); Verma y Nelson (1989); Verma et al. (1991); Besch et al. (1995); Verma (2000b, 2001a, 2001b, 2001c); MaldonadoSánchez y Schaaf (2005). LN: Las Navajas, LP: La Primavera, CVA: campo volcánico de Acatlán, Am: caldera de Amealco, Hu: caldera de Huichapan, Ac: caldera de Acoculco, LH: caldera de Los Humeros, CO: cuenca de Oriental. 
nes isotópicas más radiogénicas (Figura 22), pero no han sido claramente demostrados en el sector occidental. Esto podría deberse al poco contraste isotópico entre las rocas del manto y del basamento cortical en este sector dominado por las secuencias del terreno Guerrero.

\section{Modelos tectónico-petrogenéticos}

La diversidad composicional de un arco magmático depende de un gran número de componentes y procesos cuya interacción e importancia relativa es, con frecuencia, difícil de reconocer y evaluar. En efecto, las evidencias petrológicas y geológicas con las que contamos en la actualidad indican que, en el escenario más complejo, los magmas emplazados en la superficie pueden representar mezclas entre una gran variedad de materiales geológicos: (1) magmas derivados de la fusión parcial del manto litosférico y/o astenosférico cuya composición original puede ser heterogénea; (2) fluidos provenientes de la deshidratación de la placa oceánica y/o de los sedimentos subducidos; (3) magmas provenientes de la fusión parcial de los sedimentos y/o de la placa oceánica; (4) magmas derivados de la fusión parcial de la corteza continental, cuya composición puede ser extremadamente variable. Esta diversidad de componentes puede producir una plétora de composiciones en los magmas resultantes. Sin embargo, la importancia relativa de cada uno de ellos dependerá estrechamente de las condiciones geológicas y tectónicas que gobiernan la estructura térmica y el régimen de esfuerzos en el arco; y cuyas variaciones controlan la generación, el ascenso y el emplazamiento de los magmas en la superficie. De hecho, factores como la edad de la placa subducida, la velocidad de convergencia, el ángulo de subducción, el espesor de la corteza continental, y el régimen tectónico que opera en la placa superior, son los factores responsables de que cada uno de los componentes disponibles participe en mayor o menor medida en la petrogénesis magmática. En otras palabras: aunque la mayor parte de los investigadores consideran que el magmatismo de arco involucra una suerte de reciclaje de materiales derivados del manto, de la placa que se subduce, y de la placa cabalgante, cada arco magmático presenta peculiaridades geoquímicas únicas que deben ser atribuidas a variaciones, a veces notables, a veces sutiles, de los factores y componentes mencionados anteriormente.

La FVTM, y por lo tanto la zona de subducción mexicana, ha sido vista y descrita por largo tiempo como una extravagancia dentro del espectro petrológico de los arcos magmáticos del planeta. En realidad no podía ser de otra forma. A nuestro juicio no existe ningún otro arco magmático activo en donde exista tal variabilidad de factores tectónicos, geológicos y estructurales operando de forma simultánea. La zona de subducción mexicana está controlada por dos placas oceánicas independientes que varían en edad, composición, velocidad y ángulo de subducción a lo largo de la trinchera mesoamericana, y cuya individualización estuvo ligada a un complejo proceso de fragmentación de la antigua placa de Farallón. En ese sentido, todas las condiciones que gobiernan la estructura térmica de la zona de subducción mexicana, la historia metamórfica de las placas subducidas, y por lo tanto las características de los agentes químicos derivados de la subducción, deben verse modificadas de forma paulatina a lo largo de la trinchera. Más aún, y como se mencionó anteriormente, el arco magmático se encuentra emplazado sobre una corteza continental que varía en edad, composición y espesor; y cada sector del arco se encuentra gobernado por un régimen estructural complejo que involucra fallamientos normales y laterales que han actuado en conjunto con el magmatismo gracias a la acción de un complejo régimen de esfuerzos. Por si fuera poco, el régimen tectónico convergente, y en consecuencia el arco magmático, no parecen haber evolucionado de forma homogénea y constante a lo largo de su historia. Gracias a que la resolución estratigráfica ha mejorado año con año es claro que el magmatismo de arco ha sufrido modificaciones notables en su geometría y composición a lo largo de su historia. Estas variaciones han dado lugar a migraciones del frente volcánico, y a que distintos componentes en subducción hayan sido transferidos a las rocas volcánicas en las distintas etapas evolutivas.

Debido a la multiplicidad de componentes y procesos involucrados no es de sorprender que el origen y la evolución petrológica de la Faja Volcánica Transmexicana hayan estado bajo discusión por más de un siglo, de manera particularmente intensa durante la segunda mitad del siglo $\mathrm{XX}$, y que las controversias se extiendan hasta nuestros días. Las teorías que han sido propuestas para explicar el origen del magmatismo están todavía lejos de encontrar consenso, y por lo tanto deben ser vistas como un reflejo tangible de la complejidad a la que se han enfrentado los investigadores a lo largo de los años.

Las primeras observaciones e interpretaciones científicas de los volcanes mexicanos fueron realizadas por el gran naturalista alemán Alexander von Humboldt (von Humboldt, 1808). Humboldt describió la alineación de los grandes volcanes mexicanos, a lo largo del paralelo $19^{\circ} \mathrm{N}$, como el producto de una zona de debilidad cortical que atravesaba el continente de oriente a occidente. Aunque los avances en los estudios tectónicos y estratigráficos más recientes no han encontrado evidencias claras de esta gran discontinuidad tectónica, la hipótesis de Humboldt fue muy popular por un largo periodo de tiempo: fue recogida, adaptada y extendida por diversos autores durante la década de los cincuenta, y siguió cosechando adeptos hasta mediados de los años setenta. Por esos años, algunos autores consideraron al Eje Neovolcánico (nombre que solía recibir la FVTM durante la primera mitad del siglo XX) como la prolongación de la zona de fractura de Clarion del Pacífico oriental (Menard, 1955; Mooser y Maldonado-Koerdell, 1961). Estos autores asumían que las islas Revillagigedo representaban la expresión volcánica más occidental del 
arco. Más tarde, Mooser (1972) consideró la existencia de una gran "geosutura" pre-Paleozoica debajo del arco que estaría dividiendo a dos grandes bloques cratónicos, y que habría sido reactivada por el proceso de subducción a lo largo de la margen pacífica. En este modelo, el magmatismo estaría relacionado con un calentamiento diferencial debajo de esta gran "geosutura". Por su parte, Gastil y Jensky (1973) consideraron también la existencia de una falla dextral bajo la FVTM como una continuación natural del sistema transcurrente del Golfo de California.

Con el advenimiento y la aceptación de la tectónica de placas como el principal paradigma de la geología moderna, y a partir de la segunda mitad de la década de 1970, la gran mayoría de los investigadores consideraron que el magmatismo en la FVTM debía estar de alguna manera relacionado con la subducción de las placas de Cocos y de Rivera debajo de la placa de Norteamérica (UrrutiaFucugauchi y del Castillo, 1977; Urrutia-Fucugauchi y Böhnel, 1987; Pardo y Suárez, 1993; Pardo y Suárez, 1995). En la actualidad, la mayor parte de la comunidad científica acepta que la falta de paralelismo del arco magmático con respecto a la trinchera se debe a la variación en la geometría de las placas subducidas (Menard, 1978; Nixon, 1982; Urrutia-Fucugauchi y Böhnel, 1987; Pardo y Suárez, 1993; Pardo y Suárez, 1995). Sin embargo, diversos autores han reconocido que una importante proporción de las rocas emplazadas a todo lo largo del arco no muestran las características petrológicas que se esperaría encontrar en un ambiente tectónico convergente. Destaca sobre todo la presencia de rocas alcalinas y transicionales con patrones de elementos traza que no muestran las características típicas de la subducción, sino que son más semejantes a las observadas en zonas de vulcanismo intraplaca (islas oceánicas y rifts continentales). Se ha notado también que las rocas alcalinas de tipo intraplaca no se encuentran aisladas, o formando campos volcánicos independientes, sino que están invariablemente asociadas, tanto en el tiempo como en el espacio, a rocas calcialcalinas y alcalinas con características geoquímicas típicas de magmas de arco. Varias líneas de pensamiento han sido utilizadas para explicar el origen y la relación genética entre esta peculiar diversidad petrológica y, hasta la fecha, no parece existir un consenso general que unifique satisfactoriamente las hipótesis planteadas.

Por un lado, los trabajos de Luhr y Carmichael (1985a), Luhr (1997b), Wallace y Carmichael (1999) y Ferrari et al. (2001) sugieren una estrecha relación entre el proceso de subducción y la tectónica local para explicar el origen de ambas secuencias petrológicas. En estos modelos, los magmas con valores altos de LILE/HFSE se relacionan con un manto composicionalmente heterogéneo, aunque empobrecido y similar al manto de tipo MORB, que ha sido modificado metasomáticamente por efecto de fluidos derivados de la deshidratación de las placas de Cocos y de Rivera durante el proceso de subducción. Las rocas con valores bajos de LILE/HFSE estarían, en contraste, asociadas a la migración de un manto astenosférico enriquecido (tipo OIB), que no ha sufrido modificaciones significativas por el proceso de subducción, y que probablemente se funde gracias a un régimen tectónico extensional que opera en las inmediaciones del arco. Este manto enriquecido podría provenir de la zona del trasarco (Luhr, 1997b; Wallace y Carmichael, 1999), pues las rocas volcánicas alcalinas emplazadas en la FVTM tienen composiciones semejantes a las emplazadas en la provincia de Cuencas y Sierras de México (Luhr et al., 1989a). Estos modelos sugieren la existencia de al menos dos mantos composicionalmente diferentes debajo del arco mexicano que probablemente se funden gracias a la acción conjunta de dos mecanismos distintos (descompresión adiabática y metasomatismo asociado a la subducción).

Por el contrario, otros autores han sugerido la existencia de un manto isotópicamente heterogéneo, aunque enriquecido y similar al que da origen a los OIB, cuya fusión por descompresión adiabática genera magmas primitivos sin señales apreciables de subducción (Márquez et al., 1999a; Verma, 1999; Sheth et al., 2000; Verma, 2000a; Verma, 2000b; Verma, 2002). En estos modelos, las rocas más evolucionadas, que invariablemente presentan características geoquímicas de arco magmático, tendrían su origen en un proceso de contaminación y/o fusión cortical y por lo tanto no reflejan las contribuciones de la placa oceánica que se subduce. Algunos autores han planteado incluso que el proceso de fusión de este manto enriquecido podría estar asociado a una pluma del manto (Moore et al., 1994; Márquez et al., 1999a). Mientras que Moore et al. (1994) restringen la presencia de una pluma al bloque Jalisco, el modelo de Márquez et al. (1999b) sugiere que todo el arco podría estar influenciado por la presencia de una pluma del manto y la acción conjunta de un sistema de rift que se ha propagado paulatinamente hacia el oriente desde el Mioceno. Estos modelos han sido criticados por Ferrari y Rosas-Elguera (1999) y Ferrari et al. (2001) quiénes señalaron que la mayoría de las supuestas rocas de tipo OIB del occidente de México presentan las anomalías negativas de $\mathrm{Nb}$ típicas de magmas de arco, que no parece existir una progresión en la edad del vulcanismo de tipo OIB hacia el oriente de México, ni tampoco se verifica un levantamiento topográfico tan notable como el que se esperaría encontrar con la influencia de una pluma del manto. En su réplica Márquez et al. (1999a) defienden su modelo argumentando que las anomalías negativas de $\mathrm{Nb}$ no necesariamente reflejan un ambiente en subducción, y que la ausencia de un levantamiento topográfico notable se debe a que la pluma se ha expandido lateralmente.

Aunque el modelo de pluma no parece haber conseguido muchos adeptos [por ejemplo ver las discusiones planteadas por Siebe et al. (2004a)], algunos autores encuentran todavía difícil explicar la variedad petrológica de la FVTM dentro de un simple sistema de arco magmático. Destacan sobre todo los estudios geoquímicos detallados que Verma y colaboradores han realizado en diversos campos volcánicos 
a lo largo y ancho de la FVTM, desde el Mioceno hasta el Cuaternario (Verma y Aguilar y Vargas, 1988; Verma et al., 1991; Verma, 1999; Verma, 2000a; Verma, 2000b; Verma, 2001a; Verma, 2001b; Verma, 2001c; Verma, 2002; Verma y Carrasco-Núñez, 2003; Verma y Hasenaka, 2004). En la mayor parte de estas publicaciones, Verma y colaboradores han seguido una línea de pensamiento semejante para desestimar la influencia de la placa subducida en el magmatismo. La desaparición de los hipocentros a una profundidad de $\sim 70 \mathrm{~km}$, y la consecuente inexistencia de una zona de Wadati-Benioff bien definida debajo del arco, han sido interpretados por estos autores como evidencias de que el vulcanismo de la FVTM no está asociado a la placa oceánica en subducción. De hecho, se ha mencionado que las extrapolaciones de la placa de Cocos hacia profundidades de $\sim 100$ km sugeridas por Pardo y Suárez (1995) son, por lo menos, especulativas, si no es que completamente erróneas (Verma, 2001a). Verma (2002) ha argumentado que si la placa permanece a baja profundidad hasta las inmediaciones del arco, sería difícil que alcanzara las condiciones térmicas necesarias para influenciar la producción de magmas en la FVTM. Sin embargo, el vulcanismo en el centro de México es claramente activo y prolífico, y además está asociado con un flujo calorífico elevado. Verma también nota que la composición química de las rocas volcánicas más primitivas del arco no presenta señales apreciables de subducción, y son de hecho muy distintas a las observadas en rocas volcánicas primitivas de arcos magmáticos maduros y bien desarrollados (Verma, 2000a; 2002). En efecto, cuando se compara la composición de las rocas volcánicas de la FVTM con las rocas de América Central, por ejemplo, es evidente que ambos arcos divergen considerablemente en las relaciones LILE/HFSE, a pesar de que es la misma placa de Cocos la que subduce a ambos segmentos de la trinchera mesoamericana (Verma, 2002). Pero tal vez el argumento más usado por Verma y colaboradores resulta al comparar las composiciones isotópicas de $\mathrm{Sr}, \mathrm{Nd} \mathrm{y} \mathrm{Pb}$ de las rocas mexicanas con lo que se debería esperar en una mezcla simple entre la corteza oceánica alterada y los sedimentos que la sobreyacen, muestreados ambos en el sitio DSDP 487 (Figura 18). La figura muestra que mientras las rocas del frente volcánico de América Central despliegan una tendencia hacia esta mezcla binaria (Feigenson y Carr, 1986; Feigenson et al., 2004), las rocas mexicanas tienen valores menores de ${ }^{87} \mathrm{Sr} /{ }^{86} \mathrm{Sr}$ a valores semejantes de ${ }^{143} \mathrm{Nd} /{ }^{144} \mathrm{Nd}$, se grafican alejadas del modelo de mezcla entre esos dos componentes, y en general se sobreponen a los valores observados en las rocas del trasarco centroamericano. Esta característica ha sido tomada por Verma (1999, 2000a, 2002) como un argumento contundente para desestimar la participación de la placa oceánica en la petrogénesis de la FVTM, y aunque algunos autores han cuestionado la representatividad de la corteza oceánica alterada muestreada en el sitio DSDP 487 (Gómez-Tuena et al., 2003), también hay que decir que esta divergencia representa todavía una importante dificultad para aquellos que pretenden encontrar las contribuciones isotópicas de la subducción en el arco mexicano.

De cualquier forma es claro que para Verma y colaboradores la FVTM no es un arco magmático continental ya que, bajo su punto de vista, no presenta ni las características tectónicas ni las composiciones geoquímicas que se deberían observar en un régimen convergente. En cambio, Verma y colaboradores sugieren que el magmatismo en la FVTM es el producto directo de un sistema activo de rift continental que opera en el centro de México, cuya expresión tectónica está representada por una notable extensión intra-arco y el consecuente fallamiento normal, y en donde la expresión magmática primitiva estaría íntimamente relacionada con fusión directa del manto durante su ascenso y descompresión adiabática (Verma y Aguilar y Vargas, 1988; Verma et al., 1991; Verma, 1999; Verma, 2000a; Verma, 2000b; Verma, 2001a; Verma, 2001b; Verma, 2001c; Verma, 2002; Verma y Carrasco-Núñez, 2003; Verma y Hasenaka, 2004). La composición de algunos de los magmas más primitivos es, de hecho, semejante a la que se observa en sistemas magmáticos intraplaca (rifts continentales e islas oceánicas). En estos modelos, las rocas más evolucionadas (con señales geoquímicas típicas de arco magmático) estarían fuertemente influenciadas por procesos de contaminación o fusión cortical y no tendrían la influencia de la placa oceánica (Verma, 1999; Verma, 2002).

Aunque los trabajos de Verma y colaboradores representan una contribución importante a nuestra forma de entender el magmatismo de la FVTM, también es cierto que el modelo de rift continental ha cobrado muy pocos partidarios (Ferrari y Rosas-Elguera, 1999; Siebe et al., 2004a). La gran mayoría de los autores que se han dedicado a la petrología y geoquímica de las rocas volcánicas en el arco mexicano se inclinan a pensar que la FVTM debe estar influenciada, en mayor o menor medida, por las placas oceánicas en subducción. Por supuesto, integrar todas las peculiaridades tectónicas y petrológicas de la FVTM dentro de un modelo clásico y simple de arco magmático (como si fuera, por ejemplo, un arco insular del Pacíico occidental) está irremediablemente condenado al fracaso, porque en realidad no existe ninguna condición geológica que los haga semejantes, a no ser, evidentemente, la existencia de una zona de subducción. Por este motivo también hay que decir que las interpretaciones que se han inclinado hacia un origen primario de subducción tampoco están exentas de limitaciones y controversias.

Los estudios petrológicos realizados por el grupo de la Universidad de Berkeley han sido, tal vez, los portadores de las evidencias más contundentes para explicar el origen de las secuencias magmáticas dentro de un contexto de arco magmático. Los trabajos de este grupo, resumidos extraordinariamente en una de las contribuciones más completas sobre el magmatismo andesítico de la FVTM (Carmichael, 2002), muestran que la diversidad mineralógica y la cristalinidad observada en las rocas volcánicas es un reflejo directo de la cantidad de agua disuelta en los 
magmas. Diversas evidencias confirman que una buena parte del agua incorporada en estos magmas debe provenir de su fuente en el manto. Por ejemplo, Blatter y Carmichael (1998a) reportan la presencia de rocas andesíticas ricas en agua que traen consigo nódulos de peridotita con hornblenda, indicando claramente que al menos una porción del manto debajo del arco debe encontrarse considerablemente hidratado. La presencia de agua y otros compuestos volátiles $\left(\mathrm{CO}_{2}, \mathrm{~S}, \mathrm{Cl}\right)$ en la fuente mantélica de algunos magmas basálticos del arco ha sido confirmada con estudios geoquímicos recientes realizados en inclusiones vítreas de olivinos primitivos $\left(\mathrm{Fo}_{85-90}\right)$ (Cervantes y Wallace, 2003a; Cervantes y Wallace, 2003b). Estas inclusiones (pequeñas muestras de magma basáltico que quedó atrapado dentro de los olivinos al momento de su cristalización) presentan concentraciones de agua que varían entre $1.3 \%$ y $5.2 \%$ e incorporan también contenidos apreciables de elementos móviles en fluidos acuosos, desplegando los típicos valores altos en las relaciones LILE/HFSE de los magmas de arco. La presencia de agua, y la incorporación de cantidades apreciables de LILE y otros volátiles en las inclusiones más primitivas, es atribuida por estos investigadores a la deshidratación de la placa subducida y al reciclaje de elementos volátiles hacia el manto.

En su conjunto, las evidencias vertidas por los autores citados parecen confirmar la presencia de un manto parcialmente hidratado que da origen a rocas igualmente ricas en agua y otros volátiles. Estas evidencias, aunadas a varios años de estudios experimentales en las rocas mexicanas, han llevado a algunos investigadores a sugerir la posibilidad de que ciertos magmas andesíticos ricos en agua puedan provenir, incluso, de la fusión parcial directa del manto en condiciones de hidratación cercanas al límite de saturación con agua $(\sim 16 \%)$ a $1 \mathrm{GPa}$ (Blatter y Carmichael, 2001). Aunque a primera vista estas interpretaciones parecerían discretas, en realidad tienen implicaciones importantes para nuestra forma de entender a la FVTM, y al magmatismo de arco en general, pues indican que la fusión parcial del manto no necesariamente produce magmas basálticos, como generalmente se asume, sino que es posible también generar rocas mucho más ricas en $\mathrm{SiO}_{2}$, siempre y cuando exista una gran cantidad de agua disponible en la fuente mantélica. Tal vez no sería redundante mencionar que el único lugar en donde el manto puede encontrarse tan hidratado es en un régimen tectónico convergente. Por lo tanto, si estas hipótesis son correctas, entonces la estrategia que se ha seguido tradicionalmente para confirmar las evidencias geoquímicas de la subducción en las rocas del arco mexicano, es decir, analizar los basaltos más primitivos, sólo nos ha permitido ver una parte pequeñísima del problema y hacer interpretaciones que son, por lo menos, incompletas.

La participación de la corteza continental como parte esencial del magmatismo en la FVTM ha sido tradicionalmente mencionada y documentada desde los estudios clásicos de Wilcox (1954). En efecto, la presencia de xe- nolitos y xenocristales en claro desequilibrio químico con el magma que los contiene (Blatter y Carmichael, 1998b), y la evolución temporal de algunos magmas primitivos hacia composiciones más diferenciadas e isotópicamente enriquecidas (McBirney et al., 1987), son evidencias inapelables de que los magmas en ascenso interactúan con los niveles superiores de la corteza. Sin embargo, todavía es incierto qué tanto influye esta contribución en la composición química del arco en general, y en qué medida la corteza continental es capaz de enmascarar las posibles contribuciones de la placa oceánica. En efecto, aunque localmente ha sido posible observar correlaciones directas entre el enriquecimiento isotópico y el grado de diferenciación magmática (McBirney et al., 1987; Chesley et al., 2002), lo cierto es que este tipo correlaciones no siempre se observan, y en muy contadas ocasiones ha sido posible identificar el origen y la composición del componente que supuestamente está siendo asimilado por los magmas. Esto ha propiciado que muchas veces la composición del contaminante cortical haya tenido que ser inferida, y que los modelos hayan tenido que ser adaptados para coincidir con un proceso de asimilación (Verma, 1999; Verma, 2000b; Verma, 2001a). Por otro lado, otros autores han simplemente desestimado que las rocas más evolucionadas del arco puedan tener su origen en un proceso de asimilación y cristalización fraccionada. Por ejemplo, Straub y MartínDel Pozzo (2001) observaron que la evolución magmática del Popocatépetl (como la de todos los grandes estratovolcanes mexicanos) es a través de un proceso de mezcla de magmas, y haciendo uso de cálculos termodinámicos simples, llegan a la conclusión de que se requeriría invocar la presencia de un volumen de cúmulos máficos similar al de todo el estratovolcán para explicar el origen de las rocas más evolucionadas por medio de contaminación cortical. Por estos motivos, y aunque los estudios realizados hasta la fecha indican que la interacción de los magmas con la corteza continental parece ser en gran medida un fenómeno inevitable, también es cierto que sigue siendo muy difícil reconocer su contribución específica, dado que todavía no conocemos con certeza las características del basamento que subyace al arco, los niveles corticales en donde ocurre esta asimilación, y todavía desconocemos mucho sobre el mecanismo fisicoquímico específico que gobierna esa supuesta contaminación.

Algunos estudios geoquímicos más modernos no solamente han buscado determinar las contribuciones relativas derivadas de la subducción y de la corteza continental, sino que también han intentado determinar y cuantificar los componentes geológicos específicos involucrados, e inferir los mecanismos físicos que actúan como agentes de reciclaje geoquímico. La cuantificación certera de estos procesos requiere hoy en día de datos geoquímicos abundantes y precisos, en secuencias volcánicas bien caracterizadas, pues gracias a ellos es posible hacer algunas inferencias directas sobre los procesos tectónicos que gobiernan las variaciones composicionales del arco en el 
tiempo y en el espacio. En un estudio sobre el magmatismo de la porción más oriental de la FVTM, en el área de Palma Sola, Gómez-Tuena et al. (2003) encuentran variaciones temporales en las características geoquímicas de los componentes provenientes de la placa oceánica que han sido inyectados hacia el manto desde el Mioceno medio hasta el Cuaternario. Estos autores señalan que las manifestaciones más tempranas de vulcanismo asociado a la FVTM estuvieron influenciadas por magmas derivados de la fusión parcial de la corteza oceánica subducida. Varias secuencias volcánicas del Mioceno medio y tardío presentan características geoquímicas semejantes a las denominadas adakitas (Figura 20), para las cuales se ha inferido un proceso de fusión parcial de la placa oceánica (Kay, 1978; Defant y Drummond, 1990). Gómez-Tuena et al. (2003) reconocen también que las etapas subsecuentes de vulcanismo en la región de Palma Sola provienen de una zona relativamente más profunda y enriquecida del manto, pero que la señal de arco tiene todavía una influencia muy clara de fusión de los sedimentos subducidos. En cambio, en las etapas más recientes, el magmatismo no presenta contribuciones importantes de la subducción, y en cambio parece estar fuertemente influenciado por un proceso de contaminación con la corteza superior local. Para explicar estas diferencias, los autores proponen un cambio gradual en las condiciones geométricas de la placa oceánica en subducción: las etapas más tempranas estarían asociadas a una subducción subhorizontal, o de muy bajo ángulo, que paulatinamente ha ido hundiéndose hasta ubicarse en su posición actual. La variación en el ángulo permite variaciones en el comportamiento térmico y metamórfico de la placa subducida, que se reflejan en la transferencia de distintos componentes de subducción hacia el manto, y cuya expresión geológica se vería manifestada en una migración del vulcanismo de arco hacia posiciones más cercanas a la trinchera.

La diversidad petrológica del arco magmático ha propiciado la generación de modelos más complejos que involucran no solamente las evidencias geoquímicas y petrológicas, sino también la evolución geológica y tectónica del régimen convergente. En ese sentido, el estudio de Ferrari (2004) propone una hipótesis novedosa que, de confirmarse, vendría a reconciliar muchas de las controversias que han sido planteadas a lo largo de los años. Haciendo un análisis detallado de la geología y estratigrafía volcánica de la FVTM, y gracias a la gran cantidad de fechamientos reportados en varias décadas de investigaciones, Ferrari (2004) descubre la existencia de un importante pulso magmático máfico, que migra desde el occidente hacia el oriente entre los $\sim 11.5$ y los $\sim 6 \mathrm{Ma}$, y que geográficamente se ubica hacia el límite septentrional del arco magmático (Figura 2b). El autor interpreta este pulso máfico como la expresión volcánica de un fenómeno de rompimiento de la losa oceánica (slab detachment), que comenzó a desarrollarse en la boca del Golfo de California durante el Mioceno tardío, en el momento de que la Dorsal del Pacífico Oriental colisionó contra la placa de Norteamérica, y cuya traza se propagó gradualmente hacia el oriente. El rompimiento de la placa oceánica, y la consecuente introducción de manto astenosférico para rellenar el espacio que repentinamente quedó libre, debieron fomentar un calentamiento transitorio del manto superior y promover su fusión parcial. En ese sentido (Ferrari, 2004) atribuye la notable aparición de rocas con características intraplaca a la infiltración de manto astenoférico, químicamente enriquecido, 3-5 Ma después del paso de la ventana tectónica debajo del arco. De esta forma, el manto debajo del arco mexicano actual estaría conformado por dominios químicamente enriquecidos (fuente de los magmas intraplaca) y empobrecidos (fuente de los magmas de arco) que pueden fundirse de forma simultánea.

\section{Algunas perspectivas de investigación}

A lo largo de este trabajo hemos tratado de mostrar la mayor parte de las evidencias que, a nuestro juicio, son relevantes para comprender el origen de la FVTM de una manera integral. Hemos intentado reunir la información geológica y estratigráfica con las evidencias geofísicas y geoquímicas, pero también reconocemos la existencia de un cierto sesgo al destacar aquellas evidencias con las que estamos más familiarizados: la geoquímica y la geología de campo. El comentario está encaminado a subrayar la relevancia que podría tener el estudio de una región tan compleja como la FVTM si lográramos acercarnos a ella de una forma verdaderamente interdisciplinaria. Las publicaciones que hemos revisado aquí muestran un elevado nivel de especialización, pero todavía son muy pocos los investigadores que logran trascender el campo de su especialidad y acercarse a colaborar con académicos de otras disciplinas. Por estos motivos creemos que la perspectiva más alentadora y fructífera para el estudio del arco mexicano, y probablemente también para el resto del planeta, aparecerá cuando geólogos, geofísicos y geoquímicos trabajen en conjunto y aborden los cuestionamientos que por sí solos no han sido capaces de resolver. Basten aquí solamente algunos ejemplos que podrían encaminar las investigaciones futuras.

Las señales geoquímicas que observamos en los magmas de arco dependen fuertemente de la estabilidad mineralógica de la placa oceánica que subduce y del manto que la rodea. Esta estabilidad de fases está a su vez controlada por la presión y la temperatura que logren alcanzar la placa y el manto en la zona de subducción. El registro sísmico de la placa de Cocos se desvanece antes de llegar a las inmediaciones de la porción central y oriental del arco, y hasta el momento no conocemos con certeza si la placa se hunde hasta los supuestos $\sim 100$ kilómetros de profundidad (Figura 4), si continúa con su trayectoria subhorizontal, o si se encuentra truncada debajo del arco. Por este motivo un ejercicio de tomografía sísmica detallada es un requerimiento 
indispensable para el centro de México. Pero también es necesario que en la reducción y el modelado numérico de los datos se tenga un enfoque geológico y geoquímico que permita reconciliar las observaciones experimentales y de campo con los resultados geofísicos.

Distinguir de manera certera las contribuciones de la placa oceánica de aquellas derivadas de la corteza continental requiere que conozcamos con precisión las características de los componentes involucrados en la petrogénesis magmática. Sin embargo, nuestro conocimiento sobre la composición y espesor de la loza oceánica que está siendo subducida se restringe hoy en día a una sola perforación profunda (sitio DSDP 487), y a unos cuantos perfiles sísmicos y gravimétricos. La edad de las placas y el espesor de la cobertura sedimentaria muestran variaciones considerables a lo largo de la trinchera, y hasta el momento desconocemos las contribuciones específicas de estos componentes a la zona de subducción. De manera similar, la corteza continental sobre la cual está emplazado el arco también sufre modificaciones notables en su estructura y composición, y la falta de información certera en parámetros tan importantes como el espesor cortical o la geología del basamento hacen que los modelados petrogenéticos sigan siendo demasiado especulativos. La conjunción de geólogos, geoquímicos y geofísicos es evidentemente indispensable para poder resolver estas incertidumbres.

El reconocimiento de que la variedad química de las rocas ígneas emplazadas en el arco es un reflejo de un manto composicionalmente heterogéneo ha sido un tema por demás recurrente en las investigaciones del arco. Sin embargo, el origen de estas heterogeneidades y la forma en que han sido reconocidas no están exentos de limitaciones y controversias. Por ejemplo, es tradición asumir que las diferencias en los elementos mayores de las rocas más primitivas, así como las concentraciones y relaciones entre elementos insolubles en fluidos acuosos (por ejemplo, los HFSE), deben ser un reflejo de las heterogeneidades de la fuente mantélica. Las variaciones en la composición isotópica de las rocas primitivas también han sido utilizadas con esta perspectiva. Sin embargo, hoy en día se reconoce que los elementos mayores varían en función de una gran cantidad de parámetros que son difíciles de modelar y cuantificar, que los HFSE pueden movilizarse en un régimen de subducción si el mecanismo de transporte no es un fluido sino un magma derivado de la fusión parcial de la loza oceánica basáltica y/o de los sedimentos que la cubren, y que la composición isotópica de $\mathrm{Sr}, \mathrm{Nd}$ y $\mathrm{Pb}$ es particularmente sensible a las contribuciones provenientes de la placa oceánica y de la corteza continental. Por esta razón, no es del todo claro que las herramientas geoquímicas tradicionales reflejen en efecto una heterogeneidad inherente al manto ya que también podrían estar influenciadas por el régimen de subducción, el manto sublitosférico o la placa continental. Más aún, la posibilidad de que al menos algunas de las rocas más evolucionadas puedan tener un origen mantélico primario ofrece una perspectiva que merece ser explorada con mayor detalle. Resolver estas ambigüedades está lejos de ser un hecho trivial. Baste mencionar que la gran mayoría de las hipótesis tectónicas planteadas para explicar el origen de la heterogeneidad del manto (i. e., rift continental, pluma del manto, convección del trasarco, truncamiento de la placa, etc.) dependen de que su caracterización sea acertada.

La caracterización de la composición química y mineralógica de las rocas del arco mexicano ha tenido un avance notable en las últimas décadas. Hoy en día conocemos con bastante precisión el comportamiento de los elementos mayores en el arco, estamos al tanto de sus ensambles mineralógicos más comunes, y tenemos una visión más o menos certera del comportamiento de algunos de los elementos traza más importantes. También hemos avanzado mucho en la caracterización de los sistemas isotópicos más notables ( $\mathrm{Sr}, \mathrm{Nd}$ y $\mathrm{Pb}$ ). Utilizando estos datos hemos reconocido que las rocas del arco mexicano rompen con los paradigmas establecidos en otros arcos magmáticos del planeta, pero también nos hemos dado cuenta que para explicar satisfactoriamente estas discrepancias debemos echar mano de herramientas más modernas y sofisticadas. En efecto, hoy más que nunca debemos ser capaces de elaborar hipótesis y modelos más complejos que tengan como base los avances geológicos y petrológicos obtenidos en los últimos años, pero que también aprovechen las posibilidades que brindan las nuevas tecnologías. En ese sentido, debemos profundizar en la caracterización precisa de los elementos traza, incluyendo aquellos cuya determinación se veía obstaculizada por los altos límites de detección de los instrumentos o por las dificultades en la preparación de las muestras (por ejemplo, Li, Be, B, Tl, $\mathrm{Ta}, \mathrm{Hf}, \mathrm{Sb}$ ). También requerimos más y mejores datos de los sistemas isotópicos tradicionales, especialmente $\mathrm{Pb}$, cuyo potencial está apenas comenzando a ser reconocido; pero al mismo tiempo necesitamos explorar otros sistemas isotópicos cuya utilidad está siendo demostrada en otros arcos magmáticos del mundo. Por ejemplo, el estudio de las series de decaimiento del $\mathrm{U}$ y Th es una herramienta invaluable para determinar los tiempos de residencia y transporte magmático. El fraccionamiento natural de los isótopos estables de $\mathrm{O}, \mathrm{Li}, \mathrm{Cl}$ y $\mathrm{B}$ nos ofrecerían una perspectiva sobre el mecanismo físico de transferencia de los elementos químicos. La geoquímica isotópica del Hf nos ofrecería una perspectiva distinta para reconocer las heterogeneidades mantélicas. Pero como en todas las ciencias, nuestra tarea debe ir mucho más allá de la simple recolección de nuevos datos y observaciones. Los notables avances en la petrología experimental, y los modelos matemáticos que describen el comportamiento de los elementos químicos durante los procesos magmáticos, ofrecen las herramientas conceptuales para modelar cuantitativamente las observaciones geoquímicas. En ese sentido, el ejercicio de cuantificar las contribuciones específicas al magmatismo debería emplearse con mucha mayor frecuencia para validar nuestras hipótesis. 


\section{Agradecimientos}

Deseamos agradecer a Tania Norato Cortez y Carolina Muñoz Torres, quienes contribuyeron en la elaboración, compilación y revisión de la base de datos geoquímicos. También agradecemos a Susanne Straub por habernos dado acceso a su base de datos de rocas cuaternarias con la que complementamos la base de datos que aparece aquí. Agradecemos los acertados comentarios y la minuciosa revisión de Álvaro Márquez, Ángel Nieto-Samaniego y Peter Schaaf. L. Ferrari y T. Orozco-Esquivel contaron con el apoyo de dos proyectos de cooperación bilateral CONACyT-Consiglio Nazionale delle Ricerche (CNR, Italia) para la realización de este trabajo. A. Gómez-Tuena agradece el apoyo de CONACyT (proyecto 39785) para el estudio del magmatismo en la FVTM.

\section{Referencias}

Aguirre-Díaz, G., 1996, Volcanic stratigraphy of the Amealco caldera and vicinity, central Mexican Volcanic Belt: Revista Mexicana de Ciencias Geológicas, 13, 10-51.

Aguirre-Díaz, G., 2001, Recurrent magma mingling in succesive ignimbrites from Amealco caldera, central Mexico: Bulletin of Volcanology, 63, 238-251.

Aguirre-Díaz, G., López-Martínez, M., 2001, The Amazcala caldera, Querétaro, central Mexican Volcanic Belt, México. Geology and geochronology: Journal of Volcanology and Geothermal Research, 111, 203-218.

Aguirre-Díaz, G., McDowell, F., 2000, Volcanic evolution of the Amealco caldera, central Mexico, en Delgado-Granados, H., Stock, J., Aguirre-Díaz, G. (eds.), Cenozoic tectonics and volcanism of Mexico: Boulder, CO, Geological Society of America, Special Paper, 334, 167-178.

Aguirre-Díaz, G., Nelson, S., Ferrari, L., López, M., 1997, Ignimbrites of the central Mexican Volcanic Belt, Amealco and Huichapan calderas (Querétaro-Hidalgo), en Aguirre-Díaz, G., Aranda-Gómez, J., Carrasco-Núñez, G., Ferrari, L. (eds.), Magmatism and tectonics in the central and northwestern Mexico-a selection of the 1997 IAVCEI General Assembly excursions: México, DF, Universidad Nacional Autónoma de México, Instituto de Geología, Excursión 1, 1-39.

Aguirre-Díaz, G., Dubois, M., Laureyns, J., Schaaf, P., 2002, Nature and $\mathrm{P}-\mathrm{T}$ conditions of the crust beneath the central Mexican Volcanic Belt based on a Precambrian crustal xenolith: International Geology Review, 44, 222-242.

Alaniz-Álvarez, S. A., Nieto-Samaniego, Á. F., 2005, El sistema de fallas Taxco-San Miguel de Allende y la Faja Volcánica Transmexicana, dos fronteras tectónicas del centro de México activas durante el Cenozoico: Boletín de la Sociedad Geológica Mexicana, 57(1), 63-80.

Alaniz-Álvarez, S. A., Nieto-Samaniego, Á. F., Ferrari, L., 1998, Effects of strain rate in the distribution of monogenetic and polygenetic volcanism in the Transmexican volcanic belt: Geology, 26(7), 591-594.

Alaniz-Álvarez, S. A., Nieto-Samaniego, Á. F., Ferrari, L., 1999, Effects of strain rate in the distribution of monogenetic and polygenetic volcanism in the Transmexican volcanic belt: Reply: Geology, 26(7), 591-594.

Alaniz-Álvarez, S. A., Nieto-Samaniego, Á. F., Morán-Zenteno, D., AlbaAldave, L., 2002a, Rhyolitic volcanism in extension zone associated with strike-slip tectonics in the Taxco region, southern México: Journal of Volcanology and Geothermal Research, 118, 1-14.

Alaniz-Álvarez, S. A., Nieto-Samaniego, Á. F., Orozco-Esquivel, M. T., Vasallo-Morales, L., Xu, S., 2002b, El Sistema de fallas Taxco-San
Miguel de Allende: implicaciones en la deformación post-Eocénica del centro de México: Boletín de la Sociedad Geológica Mexicana, $55,12-29$.

Allan, J., 1986, Geology of the Colima and Zacoalco grabens, SW Mexico: late Cenozoic rifting in the Mexican Volcanic Belt: Geological Society of America Bulletin, 97, 473-485.

Allan, J., Carmichael, I., 1984, Lamprophyric lavas in the Colima Graben, SW Mexico: Contributions to Mineralogy and Petrology, 88, 203216.

Allan, J., Nelson, S., Luhr, J., Carmichael, I., Wopat, M., Wallace, P., 1991, Pliocene-Recent rifting in SW Mexico and associated volcanism: an exotic terrain in the making, en Dauphin, J., Simoneit, B. (eds.), The gulf and peninsular province of the Californias: Tulsa, Oklahoma, American Association of Petroleum Geologists, Memoir, $47,425-445$.

Alvarez, R., 2002, Banderas rift zone: a plausible NW limit of the Jalisco Block: Geophysical Research Letters, 29(20), 1994 doi:10.1029/ 2002GL016089, 55-1-55-4.

Alva-Valdivia, L., Goguitchaichvili, A., Rosas-Elguera, J., UrrutiaFucugauchi, J., Ferrari, L., Zamorano, J., 2000, Paleomagnetic data from the trans-Mexican Volcanic Belt: implications for tectonics and volcanic stratigraphy: Earth, Planets and Space, 52, 467-478.

Atwater, T., 1970, Implications of plate tectonics for the Cenozoic tectonic evolution of western North America: Geological Society of America Bulletin, 81, 3513-3536.

Atwater, T., 1989, Plate tectonic history of the northeast Pacific and western North America, en Winterer, E., Hussong, D., Decker, R. (eds.), The northeastern Pacific Ocean and Hawaii: Boulder, CO, Geological Society of America, The geology of North America, N, 21-72.

Atwater, T., Stock, J., 1998, Pacific-North America plate tectonics of the Neogene southwestern United States: International Geology Review, 8, 375-402.

Ban, M., Hasenaka, T., Delgado-Granados, H., Takaoka, N., 1992, K-Ar ages of lavas from shield volcanoes in the Michoacán-Guanajuato volcanic field, Mexico: Geofísica Internacional, 31, 467-473.

Barclay, J., Carmichael, I., 2004, A hornblende basalt from western Mexico: water-saturated phase relations constrain a pressure temperature window of eruptibility: Journal of Petrology, 45(3), 485-506.

Barrier, E., Borgois, J., Michaud, F., 1990, Le systeme de rift actifs du point triple de Jalisco: vers un proto-golfe de Jalisco: Comptes Rendus de l'Academie des Science, Paris, 310, 1513-1520.

Besch, T., Negendank, J., Emmermann, R., 1988, Geochemical constraints on the origin of the calc-alkaline and alkaline magmas of the eastern Trans-Mexican Volcanic Belt: Geofísica Internacional, 27, 641-663.

Besch, T., Verma, S., Kramm, U., Negendank, J., Tobschall, H., Emmermann, R., 1995, Assimilation of silaic crustal material by volcanics of the easternmost extension of the Trans-Mexican Volcanic Belt-Evidence from $\mathrm{Sr}$ and Nd isotopes: Geofísica Internacional, 34, 263-281.

Blatter, D., Carmichael, I., 1998a, Hornblende peridotite xenoliths from central Mexico reveal the highly oxidized nature of subarc upper mantle: Geology, 26, 1035-1038.

Blatter, D., Carmichael, I., 1998b, Plagioclase-free andesites from Zitácuaro (Michoacán), México: petrology and experimental constraints: Contributions to Mineralogy and Petrology, 132, 121-138.

Blatter, D., Carmichael, I., 2001, Hydrous phase equilibria of a Mexican high-lilica andesite: a candidate for mantle origin?: Geochimica et Cosmochimica Acta, 65, 4043-4065.

Blatter, D., Carmichael, I., Deino, A., Renne, P., 2001, Neogene volcanism at the front of the central Mexican volcanic belt: basaltic andesites to dacites, with contemporaneous shoshonites and high- $\mathrm{TiO}_{2}$ lava: Geological Society of America Bulletin, 113(10), 1324-1342.

Bloomfield, K., 1973, The age and significance of the Tenango basalt: Bulletin of Volcanology, 37, 586-595.

Bloomfield, K., 1975, A late-Quaternary monogenetic volcano field in central Mexico: Geologische Rundschau, 64, 476-497.

Boudal, C., Robin, C., 1987, Relation entre dynamismes éruptifs et réalimentations magmatiques d'origine profonde au Popocatepelt: Canadian Journal of Earth Sciences, 25, 955-971. 
Bourgois, J., Michaud, F., 1991, Active fragmentation of the North America plate at the Mexican triple junction area off Manzanillo: Geo-Marine Letters, 11, 59-65.

Bowen, N. L., 1928, The evolution of igneous rocks: Princeton, New Jersey, Princeton University Press, 334 p.

Cabral-Cano, E., Lang, H., Harrison, C., 2000a, Stratigraphic assessment of the Arcelia-Teloloapan area, southern Mexico: implications for southern Mexico's post-Neocomian tectonic evolution: Journal of South American Earth Sciences, 13, 443-457.

Cabral-Cano, E., Draper, G., Lang, H., Harrison, C., 2000b, Constraining the late Mesozoic and early Tertiary tectonic evolution of southern Mexico: structure and deformation history of the Tierra Caliente region, southern Mexico: Journal of Geology, 108, 427-446.

Campa, M. F., Coney, P. J., 1983, Tectono-stratigraphic terranes and mineral resource distributions in Mexico: Canadian Journal of Earth Sciences, 20, 1040-1051.

Campillo, M., Singh, S., Shapiro, N., Pacheco, J., Herrmann, R., 1996, Crustal structure south of the Mexican volcanic belt, based on group velocity dispersion: Geofísica Internacional, 35(4), 361-370.

Campos-Enríquez, J., Sánchez-Zamora, O., 2000, Crustal structure across southern Mexico inferred from gravity data: Journal of South American Earth Sciences, 13, 479-489.

Campos-Enríquez, J., Arroyo-Esquivel, M., Urrutia-Fucugauchi, J., 1990 Basement, curie isotherm and shallow-crustal structure of the TransMexican Volcanic Belt, from aeromagnetic data: Tectonophysics, $172,77-90$

Cantagrel, J., Robin, C., 1979, K-Ar dating on eastern Mexican Volcanic rocks-relations between the andesitic and the alkaline provinces: Journal of Volcanology and Geothermal Research, 5, 99-114.

Capra, L., Macías, J., Garduño, V., 1997, The Zitácuaro Volcanic Complex, Michoacán, México: magmatic and eruptive history of a resurgent caldera: Geofísica Internacional, 36(3), 161-179.

Carmichael, I., 2002, The andesite aqueduct: perspectives on the evolution of intermediate magmatism in west-central $\left(105^{\circ}-99^{\circ} \mathrm{W}\right)$ Mexico: Contributions to Mineralogy and Petrology, 143, 641-663.

Carmichael, I., Lange, R., Luhr, J., 1996, Quaternary minettes and associated volcanic rocks of Mascota, western Mexico: a consequence of plate extension above a subduction modified mantle wedge: Contributions to Mineralogy and Petrology, 124, 302-333.

Carr, M., Feigenson, M., Patino, L., Walker, J., 2003, Volcanism and Geochemistry in Central America: Progress and Problems, en Eiler, J. (eds.), Inside the subduction factory: Washington, D.C., American Geophysical Union, Geophysical Monograph, 138, 153-179.

Carrasco-Núñez, G., Ban, M., 1994, Geologic map and structure sections of the summit area of Citlaltépetl volcano, México with summary of the geology of the Citlàtepetl volcano summit area: Mexico D. F. Universidad Nacional Autónoma de México, Instituto de Geología, Cartas Geológicas y Mineras, (9), 1 mapa, texto explicativo.

Carrasco-Núñez, G., Milán, M., Verma, S., 1989, Geología del volcán El Zamorano, estado de Querétaro: Revista Instituto de Geología, Universidad Nacional Autónoma de México, 8, 194-201.

Carrasco-Núñez, G., Gómez-Tuena, A., Lozano-Velázquez, L., 1997, Geologic map of Cerro Grande volcano and surrounding area central Mexico: Boulder, CO, Geological Society of America, Map and Chart Serie MCH081, 1 mapa, texto $10 \mathrm{p}$.

Cathalieau, M., Oliver, R., Nieva, D., 1987, Geochemistry of volcanic series of the Los Azufres geothermal field (Mexico): Geofísica Internacional, 26(2), 273-290.

Centeno-García, E., Ruíz, J., Coney, P. J., Patchett, P. J., Ortega-Gutiérrez, F., 1993, Guerrero terrane of Mexico: its role in the Southern Cordillera from new geochemical data: Geology, 21, 419-422.

Cervantes, P., Wallace, P., 2003a, Role of $\mathrm{H}_{2} \mathrm{O}$ in subduction-zone magmatism: new insights from melt inclusions in high-Mg basalts from central Mexico: Geology, 31(3), 235-238.

Cervantes, P., Wallace, P., 2003b, Magma degassing and basaltic eruption styles: a case study of V2000 year BP Xitle volcano in central Mexico: Journal of Volcanology and Geothermal Research, 120, 249-270.

Chesley, J., Ruiz, J., Righter, K., Ferrari, L., Gómez-Tuena, A., 2002, Source contamination versus assimilation: an example from the
Trans-Mexican Volcanic Arc: Earth and Planetary Science Letters, 195, 211-221.

Connor, C., 1990, Cinder cone clustering in the Trans-Mexican volcanic belt: implications for structural and petrologic models: Journal of Geophysical Research, 95, 19395-19405.

Contreras, J., Gómez-Tuena, A., 1999, Effect of strain rate in the distribution of monogenetic and polygenetic volcanism in the Transmexican volcanic belt. Comment: Geology, 27, 571-572.

Currie, C., Hyndman, R., Wang, K., Kostoglodov, V., 2002, Thermal models of the Mexico subduction zone: Implications for the megathrust seismogenic zone: Journal of Geophysical Research, 107 (B12), doi:10.1029/2001JB000886, 15-1-15-13.

De Cserna, Z., 1958, Notes on the tectonics of Southern Mexico: American Association of Petroleum Geologists, 86, 523-532.

De la Fuente, M., Aitken, C., Mena, M., 1994, Cartas gravimétricas de la República Mexicana, Carta de anomalía de Bouguer, en Atlas nacional de México: México, D. F., Universidad Nacional Autónoma de México, Instituto de Geografía., v. 3.

Defant, M., Drummond, M., 1990, Derivation of some modern arc magmas by melting of young subducted lithosphere: Nature, 347, 662-665.

Delgado-Granados, H., Urrutia-Fucugauchi, J., Hasenaka, T., Masso, B., 1995, Southwestward volcanic migration in the western Transmexican Volcanic Belt during the last $2 \mathrm{Ma}$ : Geofísica Internacional, 34, 341-352.

Demant, A., 1978, Características del Eje Neovolcánico Transmexicano y sus problemas de interpretación: Revista Instituto de Geología, 2, 172-187.

Demant, A., 1979, Vulcanologia y petrografia del sector occidental del Eje Neovolcanico: Revista Instituto de Geología, Universidad Nacional Autónoma de México, 3, 39-57.

Demant, A., 1981, Interpretación geodinámica del volcanismo del Eje Neovolcánico Transmexicano: Revista Instituto de Geología, Universidad Nacional Autónoma de México, 5, 217-222.

Demant, A., Robin, C., 1975, Las fases del vulcanismo en México, una síntesis en relación con la evolución geodinámica desde el Cretácico: Revista Instituto de Geología, Universidad Nacional Autónoma de México, 1, 66-79.

DeMets, C., Traylen, S., 2000, Motion of the Rivera plate since 10 Ma relative to the Pacific and North American and the mantle: Tectonophysics, 318, 119-159.

DeMets, C., Gordon, R., Argus, D., Stein, S., 1994, Effects of recent revisions to the geomagnetic reversal time scale on estimates of current plate motions: Geophysical Research Letters, 21, 21912194.

DePaolo, D., 1981, Trace element and isotopic effects of combined wallrock assimilation and fractional crystallization: Earth and Planetary Science Letters, 53, 189-202.

Dickinson, W., Hatherton, T., 1967, Andesitic volcanism and seismicity around the Pacific: Science, 157, 801-803.

Eggler, D., 1972, Water-saturated and undersaturated melting relations in a Paricutin andesite and an estimate of water content in the natural magma: Contributions to Mineralogy and Petrology, 34, 261-271.

Ego, F., Ansan, V., 2002, Why is the central Trans-Mexican Volcanic Belt $\left(102^{\circ}-99^{\circ} \mathrm{W}\right)$ in transtensive deformation?: Tectonophysics, 359, 189-208.

Elías-Herrera, M., Orterga-Gutiérrez, F., 1997, Petrology of high-grade metapelitic xenoliths in an oligocene rhyodacite plug-Precambrian crust beneath the southern Guerrero terrane, Mexico?: Revista Mexicana de Ciencias Geológicas, 14(1), 101-109.

Elías-Herrera, M., Ortega-Gutiérrez, F., 1998, The Early Cretaceous Arperos oceanic basin (western Mexico). Geochemical evidence for an aseismic ridge formed near a spreading center-Comment: Tectonophysics, 292, 321-326.

Elías-Herrera, M., Ortega-Gutiérrez, F., Lozano-Santa Cruz, R., 1998, Evidence for pre-Mesozoic sialic crust in the southern Guerrero terrane: Geochemistry of the Pepechuca high grade gneiss xenoliths: Actas INAGEQ, 4, 169-181.

Engebretson, A., Cox, A., Gordon, R., 1985, Relative motions between oceanic and continental plates in the Pacific Basin: Boulder, CO, Geological Society of America, Special Paper, 206, 64 p. 
Feigenson, M., Carr, M., 1986, Positively correlated Nd and Sr isotope ratios of lavas from the Central American volcanic front: Geology, $14,78-82$.

Feigenson, M., Carr, M., Maharaj, S., Juliano, S., Bolge, L., 2004, Lead isotope composition of Central american volcanoes: influence of the Galapagos plume: Geochemistry, Geophysics and Geosystems, 5(Q06001), doi:10.1029/2003GC000621, 1-14.

Ferrari, L., 1995, Miocene shearing along the northern boundary of the Jalisco block and the opening of the southern Gulf of California: Geology, 23(8), 751-754.

Ferrari, L., 2004, Slab detachment control on mafic volcanic pulse and mantle heterogeneity in central Mexico: Geology, 32(1), 77-80.

Ferrari, L., Rosas-Elguera, J., 1999, Alkalic (ocean-island basalt type) and calc-alkalic volcanism in the Mexican volcanic belt: A case for plume-related magmatism and propagating rifting at an active margin?, Comment: Geology, 27, 1055-1056.

Ferrari, L., Rosas-Elguera, J., 2000, Late Miocene to Quaternary extension at the northern boundary of the Jalisco block, western Mexico: the Tepic-Zacoalco rift revised, en Aguirre-Díaz, G., Delgado-Granados, H., Stock, J. (eds.), Cenozoic tectonics and volcanism of Mexico: Boulder, CO, Geological Society of America, Special Paper, 334, 42-64.

Ferrari, L., Pasquaré, G., Tibaldi, A., 1990, Plio-Quaternary tectonics of central Mexican Volcanic Belt and some constraints on its rifting mode: Geofísica Internacional, 29, 5-18.

Ferrari, L., Garduño, V., Pasquaré, G., Tibaldi, A., 1991, Geology of Los Azufres caldera, Mexico, and its relations with regional tectonics: Journal of Volcanology and Geothermal Research, 47, 129-148.

Ferrari, L., Garduño, V., Innocenti, F., Manetti, P., Pasquaré, G., Vaggelli, G., 1994, A widespread mafic volcanic unit at the base of the Mexican Volcanic Belt between Guadalajara and Querétaro: Geofísica Internacional, 33, 107-123.

Ferrari, L., Lopez-Martinez, M., Aguirre-Díaz, G., Carrasco-Núñez, G., 1999, Space-time patterns of Cenozoic arc volcanism in central Mexico: from the Sierra Madre Occidental to the Mexican volcanic belt: Geology, 27, 303-306.

Ferrari, L., Pasquaré, G., Venegas, S., Romero, F., 2000a, Geology of the western Mexican Volcanic Belt and adjacent Sierra Madre Occidental and Jalisco block, en Delgado-Granados, H., Aguirre-Díaz, G., Stock, J. (eds.), Cenozoic tectonics and volcanism of Mexico: Boulder, CO, Geological Society of America, Special Paper, 334, 65-84.

Ferrari, L., Vaggelli, G., Petrone, C., Manetti, P., Conticelli, S., 2000b, Late Miocene volcanism and intra-arc tectonics during the early development of the Trans-Mexican Volcanic Belt: Tectonophysics, 318, 161-185.

Ferrari, L., Petrone, C., Francalanci, L., 2001, Generation of oceanic-island basalt-type volcanism in the western Trans-Mexican volcanic belt by slab rollback, asthenosphere infiltration, and variable flux melting: Geology, 20(6), 507-510.

Ferrari, L., López-Martínez, M., González-Cervantes, N., Jacobo-Albarrán, J., Hernández-Bernal, M. S., 2003a, Volcanic record and age of formation of the Mexico city basin, en Reunión Annual 2003, Resúmenes: GEOS, 23(2), 120.

Ferrari, L., Petrone, C., Francalanci, L., Tagami, T., Eguchi, M., Conticelli, S., Manetti, P., Venegas-Salgado, S., 2003b, Geology of the San Pedro-Ceboruco graben, western Trans-Mexican Volcanic Belt: Revista Mexicana de Ciencias Geológicas, 20, 165-181.

Ferrari, L., Rosas-Elguera, J., Orozco-Esquivel, M., Carrasco-Núñez, G., Norato-Cortez, T., 2005a, Digital geologic cartography of the TransMexican Volcanic Belt and adjoining areas: Digital Geosciences, Universidad Nacional Autónoma de México, <http://satori. geociencias.unam.mx/digital_geosciences $>, 1$ mapa, 2 p. texto.

Ferrari, L., Tagami, T., Eguchi, M., Orozco-Esquivel, M. T., Petrone, C., Jacobo-Albarrán, J., López-Martínez, M., 2005b, Geology, geochronology and tectonic setting of late Cenozoic volcanism along the southwestern Gulf of Mexico: the Eastern Alkaline Province revisited: Journal of Volcanology and Geothermal Research, 146, 284-306.

Ferriz, H., Mahood, G., 1984, Eruption rates and compositional trends at Los Humeros Volcanic Center, Puebla, Mexico: Journal of
Geophysical Research, 89, 8511-8524.

Ferriz, H., Mahood, G., 1986, Volcanismo riolítico en el Eje Neovolcánico Mexicano: Geofísica Internacional, 25, 117-156.

Ferriz, H., Mahood, G., 1987, Strong compositional zonation in a silicic magmatic system: Los Humeros, Mexican Neovolcanic Belt: Journal of Petrology, 28, 171-209.

Flores-Ruiz, J., 1997, Estructura cortical de la Faja Volcánica Transmexicana: México DF, Universidad Nacional Autónoma de México, Colegio de Ciencias y Humanidades, Unidad Académica de los Ciclos Profesionales y de Posgrado, Instituto de Geofísica, Tesis doctoral, $150 \mathrm{p}$.

Foley, S., 1992, Vein-plus-wall-rock melting mechanisms in the lithosphere and the origin of potassic alkaline magmas: Lithos, 28, 435-453.

Foshag, W., González, J., 1954, Birth and development of Parícutin Volcano, Mexico: U. S. Geological Survey Bulletin, 965-D, 355489.

Frey, H., Lange, R., Hall, C., Delgado-Granados, H., 2004, Magma eruption rates constrained by $40 \mathrm{Ar} / 39 \mathrm{Ar}$ chronology and GIS for the Ceboruco-San Pedro volcanic field, western Mexico: Geological Society of America Bulletin, 116, 259-276.

Freydier, C., Martínez-R., J., Lapierre, H., Tardy, M., Coulon, C., 1996, The early Cretaceous Arperos oceanic basin (western Mexico). Geochemical evidence for an aseismic ridge formed near a spreading center: Tectonophysics, 259(4), 343-367.

Freydier, C., Lapierre, H., Briqueu, L., Tardy, M., Coulon, C., MartinezReyes, J., 1997, Volcaniclastic sequences with continental affinities within the late Jurassic early Cretaceous Guerrero intra-oceanic arc terrane (western Mexico): Journal of Geology, 105(4), 483-502.

García-Palomo, A., Macías, J., Garduño, V., 2000, Miocene to recent structural evolution of the Nevado de Toluca volcano region, Central Mexico: Tectonophysics, 318, 281-302.

García-Palomo, A., Macías, J., Tolson, G., Valdez, R., Mora-Chaparro, J., 2002, Volcanic stratigraphy and geological evolution of the Apan region, east-central sector of the Transmexican Volcanic Belt: Geofísica Internacional, 41, 133-150.

García-Perez, F., Urrutia-Fucugauchi, J., 1997, Crustal structure of the Arteaga Complex, Michoacán, southern Mexico, from gravity and magnetics: Geofísica Internacional, 36, 235-244.

Garduño, V., Tibaldi, A., 1991, Kinematic evolution of the continental active triple junction of the western Mexican Volcanic Belt: Comptes Rendus de l'Academie des Science, Paris, II, 312(2), 135-142.

Garduño-Monroy, V., Spinnler, J., Ceragioli, E., 1993, Geological and structural study of the Chapala Rift, state of Jalisco, Mexico: Geofísica Internacional, 32, 487-499.

Garduño-Monroy, V., Arreygue-Rocha, E., Israde-Alcántara, I., RodríguezTorres, G., 2001, Efectos de las fallas asociadas a sobreexplotación de acuíferos y la presencia de fallas potencialmente sísmicas en Morelia, Michoacán, México: Revista Mexicana de Ciencias Geológicas, 18, 37-54.

Garduño-Monroy, V., Saucedo-Girón, R., Jiménez, Z., Gavilanes-Ruiz, J., Cortés, A., Uribe-Cifuentes, R., 1998, La falla Tamazula-límite suroriental del bloque Jalisco y sus relaciones con el complejo volcánico de Colima, México: Revista Mexicana de Ciencias Geológicas, 15, 132-144.

Gastil, G., Jensky, W., 1973, Evidence of strike-slip displacement beneath the Trans-Mexican Volcanic Belt, en Kovach, R. L., Nur, A. (eds.), Proceedings of the Conference on Tectonic Problems of the San Andreas Fault System: Stanford, CA, Stanford University Publications, Geological Sciences, 13, 171-180.

Gastil, G., Krummenacher, D., Jensky, A., 1979, Reconnaissance geology of west-central Nayarit, Mexico: summary: Geological Society of America Bulletin, 90, 15-18.

Geolimex Working Group, 1994, Reflections of the subducting plate? First results of a mexican geotraverse en Miller, H., Rosenfeld, U., Weber-Diefenbach, K. (eds.), 13. Symposium on Latin-America Geosciences: Zentralblatt für Geologie und Paläontologie, Teil 1. Allgemeine, Angewandte, Regionale und Historische Geologie, $1-2,541-553$

Geyne, A., Fries, C., Segerstrom, K., Black, R., Wilson, I., 1963, Geology and mineral deposits of the Pachuca-Real del Monte district, state 
of Hidalgo, Mexico: Mexico, D. F., Consejo de Recursos Naturales no Renovables, Publicación (5E), 203 p., 16 láminas.

Gilbert, C., Mahood, G., Carmichael, I., 1985, Volcanic stratigraphy of the Guadalajara area, Mexico: Geofísica Internacional, 24, 169-191.

Gill, J., 1981, Orogenic andesites and plate tectonics: Berlin, SpringerVerlag, xiv, $390 \mathrm{p}$.

Gómez-Tuena, A., Carrasco-Núñez, G., 2000, Cerro Grande Volcano: The evolution of a Miocene stratocone in the Early Transmexican Volcanic Belt: Tectonophysics, 318, 249-280.

Gómez-Tuena, A., LaGatta, A., Langmuir, C., Goldstein, S., OrtegaGutiérrez, F., Carrasco-Núñez, G., 2003, Temporal control of subduction magmatism in the Eastern Trans-Mexican Volcanic Belt: mantle sources, slab contributions and crustal contamination: Geochemistry, Geophysics, Geosystems, 4(8), doi:10.1029/ 2003GC000524, 1-33. Disponible en línea.

Halliday, A., Lee, D., Tommasini, S., Davis, G., Paslick, C., Fitton, J., James, D., 1995, Incompatible trace elements in OIB and MORB and source enrichment in the sub-oceanic mantle: Earth and Planetary Science Letters, 133, 379-395.

Harris, J. M., 1986, Silicic volcanics of Volcan Tequila, Jalisco, Mexico: Berkeley, CA, University of California, Tesis de maestría, 98 p.

Hasenaka, T., 1986, The cinder cones of Michoacán-Gunajuato, central Mexico: Berkeley, CA, University of California, Tesis doctoral, $171 \mathrm{p}$.

Hasenaka, T., 1994, Size, distribution, and magma output rate for shield volcanoes of the Michoacan-Guanajuato volcanic field, Central Mexico: Journal of Volcanology and Geothermal Research, 63, 13-31.

Hasenaka, T., Carmichael, I., 1985, The cinder cones at MichoacanGuanajuato, central Mexico: their age, volume, and distribiution, and magma discharge rate: Journal of Volcanology and Geothermal Research, 25, 105-124.

Hasenaka, T., Carmichael, I., 1987, The cinder cones of MichoacanGuanajuato, Central Mexico: petrology and chemistry: Journal of Petrology, 28, 241-269.

Herrero, E., Pal, S., 1978, Paleomagnetic Study of Sierra de Chichinautzin: Geofísica Internacional, 17, 167-180.

Herrmann, U., Nelson, B., Ratschbacher, L., 1994, The origin of a terrane: $\mathrm{U} / \mathrm{Pb}$ zircon geochronology and tectonic evolution of the Xolapa complex (southern Mexico): Tectonics, 13(2), 455-474.

Hesse, M., Grove, T., 2003, Absarokites from the western Mexican Volcanic Belt: constraints on the mantle wedge conditions: Contributions to Mineralogy and Petrology, 146, 10-27.

Hickey-Vargas, R., Frey, F., Gerlach, D., López-Escobar, L., 1986, Multiple sources for basaltic arc rocks from the southern volcanic zone of the andes $\left(34^{\circ}-41^{\circ} \mathrm{S}\right)$ : trace element and isotopic evidence for contributions from subducted oceanic crust, mantle and continental crust: Journal of Geophysical Research, 91, 5963-5983.

Hirose, K., 1997, Melting experiments on lherzolite KLB-1 under hydrous conditions and generation of high-magnesian andesites: Geology, $25,42-44$.

Hirth, G., Kohlstedt, D., 2003, Rheology of the mantle wedge, en Eiler, J. (eds.), Inside the subduction factory: Washington, DC, American Geophysical Union, Geophysical Monograph, 138, 83-105.

Hochstaedter, A., Ryan, F., Luhr, J., Hasenaka, T., 1996, On B/Be ratios in the Mexican Volcanic Belt: Geochimica et Cosmochimica Acta, 60(4), 613-618

Hofmann, A., 2003, Sampling mantle heterogeneity through oceanic basalts: isotopes and trace elements, en Carlson, R. W. (ed.), Treatise on geochemistry. Volume 2, The mantle and core: Amsterdam, Elsevier, 61-101.

Höskuldsson, A., Robin, C., 1993, Late Pleistocene to Holocene eruptive activity of Pico de Orizaba, Eastern Mexico: Bulletin of Volcanology, 55, 571-587.

Irvine, T., Baragar, W., 1971, A guide to the chemical classification of the common volcanic rocks: Canadian Journal of Earth Sciences, $8,523-548$

Jacobo-Albarrán, J., 1986, Estudio petrogenetico de las rocas igneas de la porción central del Eje Neovolcánico: México, D. F., Instituto Mexicano del Petróleo, Subdirección de Tecnología de Exploración,
Reporte Interno, $47 \mathrm{p}$.

Johnson, C., Harrison, C., 1989, Neotectonics in central Mexico: Physics of the Earth and Planetary Interiors, 64, 187-210.

Jording, A., Ferrari, L., Arzate, J., Jodicke, H., 2000, Crustal variations and terrane boundaries in southern Mexico as imaged by mangetotelluric transfer functions: Tectonophysics, 327, 1-13.

Kay, R., 1978, Aleutian magnesian andesites: melts from subduction Pacific oceanic crust: Journal of Volcanology and Geothermal Research, 4, 117-132.

Kelemen, P., Hanghøj, K., Greene, A., 2003, One View of the Geochemistry of Subduction-related Magmatic arcs, with emphasis on primitive andesite and lower crust, en Rudnick, R. (ed.), Treatise on geochemistry, v. 3. The crust: Amsterdam, Elsevier, 593-659.

Keppie, J., Ortega-Gutiérrez, F., 1995, Provenance of Mexican Terranes: Isotopic Constrains: International Geology Review, 37, 813-824.

Keppie, J., Ortega-Gutiérrez, J., 1998, Middle American Precambrian basement: a missing piece of the reconstructed $1 \mathrm{Ga}$ orogen, en Ramos, V., Keppie, J. D. (eds.), Laurentia-Gondwana connections before Pangea: Boulder, CO, Geological Society of America Special Paper, 336, 199-210.

Kostoglodov, V., Bandy, W., 1995, Seismotectonic constraints on the convergence rates between the Rivera and North American plates: Journal of Geophysical Research, 100(B9), 17977-17989.

Kostoglodov, V., Singh, S., Santiago, J., Franco, S., Larson, K., Lowry, A., Bilham, R., 2003, A large silent earthquake in the Guerrero seismic gap, Mexico: Geophysical Research Letters, 30(15), doi:10.1029/ 2003GL017219, 9-1-9-4.

LaGatta, A., 2003, Arc magma genesis in the eastern Mexican volcanic belt: New York, NY, Columbia University, Tesis doctoral, 365 p.

Lange, R., Carmichael, I., 1990, Hydrous basaltic andesites associated with minette and related lavas in western Mexico: Journal of Petrology, 31, 1225-1259.

Lange, R., Carmichael, I., 1991, A potassic volcanic front in western Mexico: the lamprophyric and related lavas of San Sebastian: Geological Society of America Bulletin, 103, 928-940.

Langridge, R., Weldon, R., Moya, J., Suárez, G., 2000, Paleoseismology of the 1912 Acambay earthquake and the Acambay-Tixmadejé fault, Trans-Mexican Volcanic Belt: Journal of Geophysical Research, 105, 3019-3037.

Lapierre, H., Ortiz, L., Abouchami, W., Monod, O., Coulon, C., Zimmerman, J., 1992, A crustal section of an intra-oceanic island arc: the late Jurassic-early-Cretaceous Guanajuato magmatic sequence, central Mexico: Earth and Planetary Science Letters, 108, 61-77.

Lassiter, J., Luhr, J., 2001, Osmium abundance and isotope variations in mafic mexican volcanic rocks: evidence for crustal contamination and constraints on the geochemical behavior of osmium during partial melting and fractional crystallization: Geochemistry, Geophysics, Geosystems, 2 (3), doi:10.1029/2000GC000116.

Lawlor, P., Ortega-Gutiérrez, F., Cameron, K., Ochoa-Carrillo, H., Lopez, R., Sampson, D., 1999, U/Pb geochronology, geochemistry and provenance of the Grenvillian Huiznopala Gneiss of eastern Mexico: Precambrian Research, 94, 73-99.

Le Bas, M., Le Maitre, R., Streckeisen, A., Zanettin, B., 1986, A chemical classification of volcanic rocks on the total alkali-silica diagram: Journal of Petrology, 27(3), 745-750.

Le Maitre, R. W., ed., 1989, A classification of igneous rocks and glossary of terms: recommendations of the international union of geological sciences subcommission on the systematics of igneous rocks: Oxford, Blackwell, $193 \mathrm{p}$.

Leggett, J. K., 1982, Geochemistry of Cocos Plate pelagic-hemipelagic sediment in hole 487, DSDP leg 66, en Watkins, J., Moore, J. (eds.): Initial Reports of the Deep Ocean Drilling Project, 66, 683-686.

Lewis-Kenedi, C., Lange, R., Hall, C., Delgado-Granados, H., 2005, The eruptive history of the Tequila volcanic field, western Mexico: ages, volumes, and relative proportions of lava types: Bulletin of Volcanology, 67, 391-414.

Londsdale, P., 1991, Structural patterns of the Pacific floor offshore peninsular California, en Dauphin, J., Simoneit, B. (eds.), The gulf and the peninsular province of the Californias: Tulsa, OK, American Association of Petroleum Geologists, Memoir, 47, 87-125. 
López-Hernández, A., Castillo-Hernández, D., 1997, Exploratory drilling at Acoculco, Puebla, Mexico; A hidrothermal system with only nonthermal manifestation: Geothermal Research Council Transactions, 21, 429-433.

López-Infanzón, M., 1991, Petrologic study of the volcanic rocks in the Chiconquiaco-Palma Sola area, central Veracruz, Mexico: New Orleans, Tulane University, Tesis de maestría, 139 p.

Luhr, J. F., 1997a, Extensional tectonics and the diverse primitive volcanic rocks in the western Mexican Volcanic Belt: Canadian Mineralogist, $35,473-500$.

Luhr, J.F., 1997b, Extensional tectonics and the diverse primitive volcanic rocks in the western Mexican Volcanic Belt: Canadian Mineralogist, $2,473-500$

Luhr, J. F., 2000, The geology and petrology of Volcan San Juan Nayarit, Mexico and the compositionally zoned Tepic Pumice: Journal of Volcanology and Geothermal Research, 95, 109-156.

Luhr, J. F., 2002, Petrology and geochemistry of the 1991 and 1998-1999 lava flows from Volcán de Colima, México: implications for the end of the current eruptive cycle: Journal of Volcanology and Geothermal Research, 117, 169-194.

Luhr, J. F., Carmichael, I., 1980, The Colima Volcanic Complex, Mexico. I. Post-caldera andesites from Volcán Colima: Contributions to Mineralogy and Petrology, 71, 343-372.

Luhr, J. F., Carmichael, I. S. E., 1981, The Colima Volcanic Complex, Mexico. II. Late-Quaternary cinder cones: Contributions to Mineralogy and Petrology, 76, 127-147.

Luhr, J. F., Carmichael, I. S. E., 1982, The Colima Volcanic Complex, Mexico. III. Ash- and scoria-fall deposits from the upper slopes of Volcán Colima: Contributions to Mineralogy and Petrology, 80, $262-275$.

Luhr, J. F., Carmichael, I. S. E., 1985a, Contemporaneous eruptions of calc-alkaline and alkaline magmas along the volcanic front of the Mexican Volcanic Belt: Geofísica Internacional, 24, 203-216.

Luhr, J. F., Carmichael, I., 1985b, Jorullo Volcano, Michoacán, Mexico (1759-1774): The earliest stages of fractionation in calc-alkaline magmas: Contributions to Mineralogy and Petrology, 90, 142161.

Luhr, J., Carmichael, I., 1990, Petrological monitoring of cyclical eruptive activity at Volcán Colima, México: Journal of Volcanology and Geothermal Research, 42, 235-260.

Luhr, J., Nelson, S., Allan, J., Carmichael, I., 1985, Active rifting in southwestern Mexico: manifestations of an incipient eastward spreading-ridge jump: Geology, 13, 54-57.

Luhr, J., Aranda-Gómez, J. J., Pier, J., 1989a, Spinel-lherzoilite-bearing quaternary volcanic centers in San Luis Potosi, Mexico I. Geology, mineralogy, and petrology: Journal of Geophysical Research, 94(B6), 7916-7940.

Luhr, J., Allan, J., Carmichael, I., Nelson, S., Hasenaka, T., 1989b, Primitive calc-alkaline and alkaline rock types from the western Mexican volcanic belt: Journal of Geophysical Research, 94(B4), 4515-4530.

Mahood, G., 1981a, A summary of the geology and petrology of the Sierra La Primavera, Jalisco, Mexico: Journal of Geophysical Research, $86,10137-10152$.

Mahood, G., 1981b, Chemical evolution of a Pleistocene rhyolitic center: Sierra La Primavera, Jalisco, Mexico: Contributions to Mineralogy and Petrology, 77, 129-149.

Mahood, G., Halliday, A., 1988, Generation of high-silica rhyolite: A $\mathrm{Nd}, \mathrm{Sr}$, and $\mathrm{O}$ isotopic study of Sierra La Primavera, Mexican Neovolcanic Belt: Contributions to Mineralogy and Petrology, 100, 183-191.

Maldonado-Sánchez, G., Schaaf, P., 2005, Geochemical and isotope data from the Acatlán Volcanic Field, western Trans-Mexican Volcanic Belt: origin and evolution: Lithos, 82, 455-470.

Mammerickx, J., Klitgord, K., 1982, North East Pacific Rise: Evolution from 25 m.y.B.P. to the present: Journal of Geophysical Research, 87, 6751-6759.

Manea, M., Manea, V., Kostoglodov, V., 2003, Sediment fill in the middle America Trench inferred from gravity anomalies: Geofísica Internacional, 42(4), 603-612.
Manea, V., Manea, M., Kostoglodov, V., Currie, C., Sewell, G., 2004, Thermal structure, copuling and metamorphism in the Mexican subduction zone beneath Guerrero: Geophysical Journal International, 158, 775-784. Manea, V., Manea, M., Kostoglodov, V., Sewell, G., 2005, Thermo-mechanical model of the mantle wedge in Central Mexican subduction zone and a blob tracing approach for the magma transport: Physics of the Earth and Planetary Interiors, 149, I165-186.

Márquez, A., De Ignacio, C., 2002, Mineralogical and geochemical constraints for the origin and evolution of magmas in Sierra Chichinautzin, Central Mexican Volcanic Belt: Lithos, 62, 35-62.

Márquez, A., Oyarzún, R., Doblas, M., Verma, S., 1999a, Alkalic (oceanicisland basalt type) and calc-alkalic volcanism in the Mexican volcanic belt: A case for plume-related magmatism and propagating rifting at an active margin?: Geology, 27, 51-54.

Márquez, A., Oyarzún, R., Doblas, M., Verma, S., 1999b, Alkalic (oceanisland basalt type) and calc-alkalic volcanism in the Mexican volcanic belt: A case for plume-related magmatism and propagating rifting at an active margin?: Reply: Geology, 27, 1056.

Márquez, A., Verma, S., Anguita, F., Oyarzun, R., Brandle, J., 1999c, Tectonics and volcanism of Sierra Chichinautzin: extension at the front of the central transmexican volcanic belt: Journal of Volcanology and Geothermal Research, 93, 125-150.

Martín-Del Pozzo, A., 1982, Monogenetic volcanism in Sierra Chichinautzin, Mexico: Bulletin of Volcanology, 45, 9-24.

Martínez-Reyes, J., Nieto-Samaniego, A.F., 1990, Efectos geológicos de la tectónica reciente en la parte central de México: Revista Instituto de Geología, Universidad Nacional Autónoma de México, 9, 33-50.

Martínez-Serrano, R., Schaaf, P., Solís-Pichardo, G., Hernández-Bernal, M., Hernández-Treviño, T., Morales-Contreras, J., Macías, J., 2004, $\mathrm{Sr}, \mathrm{Nd}$ and $\mathrm{Pb}$ isotope and geochemical data from the Quaternary Nevado de Toluca volcano, a source of recent adakitic magmatism, and the Tenango Volcanic Field, Mexico: Journal of Volcanology and Geothermal Research, 138, 77-110.

McBirney, A., Taylor, H., Armstrong, R., 1987, Paricutín re-examined: a classic example of crustal assimilation in calc-alkaline magma: Contributions to Mineralogy and Petrology, 95, 4-20.

McDonald, G., Katsura, T., 1964, Chemical compositions of Hawaiian lavas: Journal of Petrology, 5, 82-133.

McDonough, W., Sun, S., 1995, The composition of the earth: Chemical Geology, 120(3-4), 223-253.

McKenzie, D., O'Nions, R., 1995, The source regions of ocean island basalts: Journal of Petrology, 36, 133-159.

Menard, H., 1955, Deformation of the northeastern pacific basin and the west coast of North America: Geological Society of America Bulletin, 66, 1149-1168.

Menard, H., 1978, Fragmentation of the Farallon plate by pivoting subduction: Journal of Geology, 86, 181-201.

Michaud, F., Quintero-Legorreta, O., Barrier, E., Burgois, J., 1991, La frontiére Nord du Bloc Jalisco (ouest Mexique): localisation et évolution de 13 Ma à l'actuel: Comptes Rendus de l'Academie des Science, Paris, II, 312, 1359-1365.

Middlemost, E., 1989, Iron oxidation ratios, norms and the classification of volcanic rocks: Chemical Geology, 77, 19-26.

Molina-Garza, R., Urrutia-Fucugauchi, J., 1993, Deep crustal structure of central Mexico derived from interpretation of Bouger gravity anomaly data: Journal of Geodynamics, 15, 181-201.

Moore, G., Carmichael, I., 1998, The hydrous phase equilibria (to 3 kbar) of an andesite and basaltic andesite from western Mexico: constraints on water content and conditions of phenocryst growth: Contributions to Mineralogy and Petrology, 130, 304-319.

Moore, J. C., Watkins, J. S., Bachman, S. B., Beghtel, F. W., Butt, A., Didyk, B., Foss, G., Leggett, J. K., Lundberg, N., McMillan, K. J., Niitsuma, N., Shephard, L. E., Stephan, J.-F., Shipley, T. H., Strander, H., 1982, Facies belts of the middle America Trench and forearc region, southern Mexico; results from Leg 66 DSDP, en Leggett, J. (eds.), Trench-forearc geology: sedimentation and tectonics on modern and ancient active plate margins: London, Geological Society, Special Publication, 10, 77-94.

Moore, G., Marone, C., Carmichael, I., Renne, P., 1994, Basaltic volcanism 
and extension near the intersection of the Sierra Madre volcanic province and the Mexican Volcanic Belt: Geological Society of America Bulletin, 106, 383-394.

Mooser, F., 1972, The mexican volcanic belt structure and tectonics: Geofísica Internacional, 12, 55-70.

Mooser, F., Maldonado-Koerdell, M., 1961, Tectónica penecontemporánea a lo largo de la costa mexicana del Océano Pacífico: Geofísica Internacional, 1, 3-20.

Mooser, F., Nairn, A. E. M., Negendank, J. F.W., 1974, Palaeomagnetic investigations of the Tertiary and Quaternary igneous rocks; VIII. A palaeomagnetic and petrologic study of volcanics of the Valley of Mexico: Geologische Rundschau, 63, 451-483.

Mora, J., Macías, J., Saucedo, R., Orlando, A., Manetti, P., Vaselli, O., 2002, Petrology of the 1998-2000 products of Volcán de Colima, México: Journal of Volcanology and Geothermal Research, 117, 195-212.

Mora-Álvarez, G., Caballero-Miranda, C., Urrutia-Fucugauchi, J., Uchiumi, S., 1991, Southward migration of volcanic activity in the Sierra de Las Cruces, basin of Mexico? -a preliminary K-Ar dating and palaeomagnetic study: Geofísica Internacional, 30, 61-70.

Morán-Zenteno, D., Corona-Chávez, P., Tolson, G., 1996, Uplift and subduction erosion in southwestern Mexico since the Oligocene: pluton geobarometry constraints: Earth and Planetary Science Letters, 141, 51-65.

Morán-Zenteno, D., Tolson, G., Martinez-Serrano, R., Martiny, B., Schaaf, P., Silva-Romo, G., Macias-Romo, C., Alba-Aldave, L., HernandezBernal, M., Solis-Pichardo, G., 1999, Tertiary arc-magmatism of the Sierra Madre del Sur, Mexico, and its transition to the volcanic activity of the Trans-Mexican Volcanic Belt: Journal of South American Earth Sciences, 12, 513-535.

Murrillo-Muñetón, G., 1994, Petrologic and geochronologic study of the Grenville-age granulaties and post-granulite plutons from the $\mathrm{La}$ Mixtequita area, state of Oaxaca, southern Mexico, and their tectonic significance: Los Angeles, CA, University of Southern California, Tesis de maestría, $163 \mathrm{p}$.

Nava, A., Núñez-Cornu, F., Córdoba, D., Mena, M., Ansorge, J., González, J., Rodríguez, M., Banda, E., Müller, S., Udias, A., García-García, M., Calderón, G., 1988, Structure of the middle America in Oaxaca, México: Tectonophysics, 154, 241-251.

Negendank, J. F. W., Emmermann, R., Krawczyk, R., Mooser, F., Tobschall, H., Wehrle, D., 1985, Geological and geochemical investigations on the eastern Trans-Mexican Volcanic Belt: Geofísica Internacional, 24, 477-575.

Nelson, S., 1980, Geology and petrology of Volcán Ceboruco, Nayarit, México: Geological Society of America Bulletin, 91, 2290-2431.

Nelson, S., Carmichael, I., 1984, Pleistocene to recent alkalic volcanism in the region of Sanganguey volcano, Nayarit, Mexico: Contributions to Mineralogy and Petrology, 85, 321-335.

Nelson, S., González-Caver, E., 1992, Geology and K-Ar dating of the Tuxtla Volcanic Field, Veracruz, Mexico: Bulletin of Volcanology, $55,85-96$.

Nelson, S., Hegre, J., 1990, Volcán Las Navajas, a Pliocene-Pleistocene trachyte/peralkaline rhyolite volcano in the northwestern Mexican volcanic belt: Bulletin of Volcanology, 52, 186-204.

Nelson, S., Lighthart, A., 1997, Field excursion to the Sierra Las Navajas, Hidalgo, Mexico -A Pliestocene peralkaline rhyolite complex with a large debris avalance deposit, en II Convención sobre la Evolución Geológica de México y Recursos Asociados, Libro-guía de las excursiones geológicas: Pachuca, México, Universidad Autónoma de Hidalgo, Instituto de Investigaciones en Ciencias de la Tierra; Universidad Nacional Autónoma de México, Instituto de Geología, 89-96.

Nelson, S., Livieres, R., 1986, Contemporaneous calc-alkaline and alkaline volcanism at Sanganguey Volcano, Nayarit, Mexico: Geological Society of America Bulletin, 97, 798-808.

Nelson, S.A., Gonzalez-Caver, E., Kyser, T.K., 1995, Constraints on the origin of alkaline and calc-alkaline magmas from the Tuxtla Volcanic Field, Veracruz, Mexico: Contributions to Mineralogy and Petrology, $122(1-2), 191-211$.

Nieto-Obregón, J., Delgado-Argote, L., Damon, P., 1981, Relaciones petrológicas y geocronológicas del magmatismo de la Sierra
Madre Occidental y el Eje Neovolcánico en Nayarit, Jalisco y Zacatecas, en XIV Convención Nacional, Memoria Técnica,: México, Asociación Ingenieros Mineros, Metalurgicos y Geólogos de México, 327-361.

Nieto-Obregón, J., Delgado-Argote, L., Damon, P., 1985, Geochronologic, petrologic and structural data related to large morphologic features between the Sierra Madre Occidental and the Mexican Volcanic Belt: Geofísica Internacional, 24, 623-663.

Nieto-Obregón, J., Urrutia-Fucugauchi, J., Cabral-Cano, E., Guzmán de la Campa, A., 1992, Listric faulting and continental rifting in western Mexico; a paleomagnetic and structural study: Tectonophysics, 208, 365-376.

Nieto-Samaniego, Á. F.., Ferrari, L., Alaniz-Alvarez, S. A., LabartheHernández, G., Rosas-Elguera, J., 1999, Variation of Cenozoic extension and volcanism across the southern Sierra Madre Occidental Volcanic Province, Mexico: Geological Society of America Bulletin, 111, 347-363.

Nixon, G., 1982, The relationship between Quaternary volcanism in central Mexico and the seismicity and structure of subducted ocean lithosphere: Geological Society of America Bulletin, 93, 514-523.

Nixon, G., 1988a, Petrology of the younger andesites and dacites of Iztaccíhuatl volcano, México: I. Disequilibrium phenocrysts assemblages as indicators of magma chamber processes: Journal of Petrology, 20, 213-264.

Nixon, G., 1988b, Petrology of the younger andesites and dacites of Iztaccíhuatl volcano, México: II. Chemical stratigraphy, magma mixing, and the composition of basaltic magma influx: Journal of Petrology, 29, 265-303.

Nixon, G. T., 1989, The geology of Iztaccíhuatl Volcano and adjaent areas of The Sierra Nevada and Valley of Mexico: Boulder, CO, Geological Society of America, Special Paper, (219), 58 p., 1 mapa.

Nixon, G., Demant, A., Armstrong, R., Harakal, J., 1987, K-Ar and geologic data bearing on the age and evolution of the Trans-Mexican Volcanic Belt: Geofísica Internacional, 26, 109-158.

Núñez-Cornú, F., Ruiz, L., Nava, F., Reyes-Dávila, G., Suárez-Plascencia, C., 2002, Characteristics of seismicity in the coast and north of Jalisco Block, Mexico: Physics of the Earth and Planetary Interiors, $132,141-155$.

Ochoa-Camarillo, H., 1997, Geología del anticlinorio de Huayacocotla, estado de Hidalgo, en II Convención sobre la Evolución Geológica de México y Recursos Asociados, Libro-guía de las excursiones geológicas: Pachuca, México, Universidad Autónoma de Hidalgo, Instituto de Investigaciones en Ciencias de la Tierra; Universidad Nacional Autónoma de México, Instituto de Geología, 1-17.

O’Hara, M., 1977, Geochemical evolution during fractional crystallization of a periodically refilled magma chamber: Nature, 266, 503-507.

O'Hara, M., Mathews, R., 1981, Geochemical evolution in a an advecting, periodically replenished, periodically tapped, continously fractionated magma chamber: Journal of the Geological Society, London, 138, 237-277.

Orozco-Esquivel, M. T., 1995, Zur petrologie des vulkangebietes von Palma-Sola, Mexiko. Ein beispiel für den übergang von anorogenem zu orogenem Vulkanismus: Alemania, Universität Karlsruhe, Tesis doctoral, $167 \mathrm{p}$.

Orozco-Esquivel, M. T., Ferrari, L., Eguchi, M., Tagami, T., Petrone, C., Jacobo-Albarran, J., 2003, The Eastern Alkaline Province (Mexico) revised: geology, geochronology and geochemistry of Neogene volcanism in Veracruz State, en $99^{\text {a }}$ Reunión Anual, Geological Society of America, Cordilleran Section, Puerto Vallarta, Jal., Libro de resúmenes, p. 58.

Ortega-Guitérrez, F., 1978, El Gneis Novillo y rocas metamórficas asociadas en los cañones del Novillo y la Peregrina, area de Ciudad Victoria, Tamaulipas: Revista del Instituto de Geología, Universidad Nacional Autónoma de México, 2, 19-30.

Ortega-Gutiérrez, F., 1981, Metamorphic belts of southern Mexico and their tectonic significance: Geofísica Internacional, 20, 177-202.

Ortega-Gutiérrez, F., 1984, Evidence of Precambrian evaporites in the Oaxacan granulite complex of southern Mexico: Precambrian Research, 23, 377-393.

Ortega-Gutiérrez, F., Mitre-Salazar, L. M., Roldán-Quintana, J., Aranda- 
Gómez, J. J., Morán-Zenteno, D. J., Alaniz-Álvarez, S. A., NietoSamaniego, Á. F.., 1992, Carta geológica de la Republica Mexicana: quinta edición escala 1:2.000,000: México, D. F., Universidad Nacional Autónoma de México, Instituto de Geología; Secretaría de Energía, Minas e Industria Paraestatal, Consejo de Recursos Minerales, 1 mapa, texto explicativo $74 \mathrm{p}$.

Ortega-Gutiérrez, F., Sedlock, R. L., Speed, R. C., 1994, Phanerozoic tectonic evolution of Mexico, en Speed, R. C. (ed.), Phanerozoic evolution of North American continent-ocean transitions: Boulder, CO, Geological Society of America, DNAG Continent-Ocean Transect Series, 265-306.

Ortega-Gutiérrez, F., Ruiz, J., Centeno-García, E., 1995, Oaxaquia, a Proterozoic microcontinent accreted to North America during the late Paleozoic: Geology, 23(12), 1127-1130.

Osete, M., Ruiz-Martínez, V., Cabellero, C., Galindo, C., UrrutiaFucugauchi, J., Tarling, D., 2000, Southward migration of continental volcanic activity in the Sierra de las Cruces, Mexico: paleomagnetic and radiometric evidence: Tectonophysics, 318, 201-215.

Pacheco, J., Mortera-Gutiérrez, C., Delgado-Granados, H., Singh, S., Valenzuela, R., Shapiro, N., Santoyo, M., Hurtado, A., Barrón, R., Gutiérrez-Moguel, E., 1999, Tectonic significance of an earthquake sequence in the Zacoalco half-graben, Jalisco, Mexico: Journal of South American Earth Sciences, 12, 557-565.

Pardo, M., Suárez, G., 1993, Steep subduction geometry of the Rivera plate beneath the Jalisco Block in western Mexico: Geophysical Research Letters, 20, 2391-2394.

Pardo, M., Suárez, G., 1995, Shape of the subducted Rivera and Cocos plate in southern Mexico: Seismic and tectonic implications: Journal of Geophysical Research, 100, 12357-12373.

Parman, S. W., Grove, T. L., 2004, Harzburgite melting with and without H2O: Experimental data and predictive modeling: Journal of Geophysical Research, 109(B02201), DOI:10.1029/2003JB002566, $1-20$.

Pasquaré, G., Garduño, V., Tibaldi, A., Ferrari, M., 1988, Stress pattern evolution in the central sector of the Mexican Volcanic Belt: Tectonophysics, 146, 353-364.

Pasquaré, G., Ferrari, L., Garduño, V., Tibaldi, A., Vezzoli, L., 1991, Geology of the central sector of the Mexican Volcanic Belt, states of Guanajuato and Michoacan: Boulder, CO, Geological Society of America, Map and Chart Series MCH072, 1 mapa con texto, $22 \mathrm{p}$.

Pérez-Venzor, J. A., Aranda-Gómez, J. J., McDowell, F. W., Solorio Munguía, J. G., 1996, Geología del Volcán Palo Huérfano, Guanajuato, México: Revista Mexicana de Ciencias Geológicas, 13(2), 174-183.

Petrone, C., Francalanci, L., Carlson, R., Ferrari, L., Conticelli, S., 2003, Unusual coexistence of subduction-related and intraplate-type magmatism: $\mathrm{Sr}, \mathrm{Nd}$ and $\mathrm{Pb}$ isotope and trace element data from the magmatism of the San Pedro-Ceboruco graben (Nayarit, Mexico): Chemical Geology, 193, 1-24.

Pier, J. G., Luhr, J. F., Podosek, F. A., Aranda-Gómez, J. J., 1992, The La Breña-El Jagüey Maar Complex, Durango, Mexico, II. Petrology and geochemistry: Bulletin of Volcanology, 54, 405-428.

Pilet, S., Hernandez, J., Bussy, F., Sylvester, P., 2004, Short-term metasomatic control of $\mathrm{Nb} / \mathrm{Th}$ ratios in the mantle sources of intraplate basalts: Geology, 32, 113-116.

Pindell, J., 1985, Alleghenian reconstruction and subsequent evolution of the Gulf of Mexico, Bahamas, and Proto-Caribbean Sea: Tectonics, 133-156.

Plank, T., Langmuir, C., 1998, The Chemical Composition of Subducting Sediment and its Consequences for the Crust and Mantle: Chemical Geology, 145, 325-394.

Polak, B., Kononov, V., Prasolov, E., Sharkov, I., Prol-Ledezma, R. M., González, A., Razo, A., Molina-Berbeller, R., 1985, First estimations of terrestrial heat flow in the TMVB and adjacent areas based on isotopic compositions of natural helium: Geofísica Internacional, $24,465-476$

Pradal, E., Robin, C., 1994, Long-lived magmatic phases at Los Azufres volcanic center, Mexico: Journal of Volcanology and Geothermal Research, 63, 201-215.
Prol-Ledezma, R., Juárez, G., 1985, Silica geotemperature mapping and thermal regime in the Mexican Volcanic Belt: Geofísica Internacional, 24, 609-622.

Prol-Ledezma, R., Sugrobov, V., Flores, E., Juarez, M., Smirov, Y., Gorshkov, A., Bondarenko, V., Rashidov, V., Nedopekin, L., Gavrilov, V., 1989, Heat flow variations along the middle America Trench: Marine Geophysical Research, 11, 69-76.

Quezadas-Flores, A., 1961, Las rocas del basamento de la cuenca TampicoMisantla: Boletin de la Asociación Mexicana de Geólogos Petroleros, $13,289-232$

Quintanar, L., Rodríguez-González, M.a., Campos-Enríquez, J., 2004, A Shallow Crustal Earthquake Doublet from the Trans- Mexican Volcanic Belt (Central Mexico): Bulletin of the Seismological Society of America, 94, 845-855.

Quintero-Legorreta, O., Michaud, F., Bourgois, J., Barrier, E., 1992, Evolución de la frontera septentrional del bloque Jalisco, México, desde hace $17 \mathrm{Ma}$ : Revista Instituto de Geología, Universidad nacional Autónoma de México, 10, 111-117.

Rapp, R., Watson, E., 1995, Dehydration melting of metabasalt at 8-32 $\mathrm{kb}$ : implications for continental growth and crust-mantle recycling: Journal of Petrology, 36, 891-931.

Ratschbacher, L., Riller, U., Meschede, M., Herrmann, U., Frisch, W., 1991, Second look at suspect terranes in southern Mexico: Geology, 19(12), 1233-1236.

Reid, M., 1983, Paricutín volcano revisited: Isotopic and trace element evidence for crustal assimilation: American Geophysical Union Transactions, 64(45), 907

Riggs, N., Carrasco-Núñez, G., 2004, Evolution of a complex isolated dome system, Cerro Pizarro, central México: Bulletin of Volcanology, $66,322-335$.

Righter, K., 2000, A comparison of basaltic volcanism in the Cascades and western Mexico: compositional diversity in continental arcs: Tectonophysics, 318, 99-117.

Righter, K., Carmichael, I., 1992, Hawaiites and related lavas in the Atenguillo graben, western Mexican Volcanic Belt: Geological Society of America Bulletin, 104, 1592-1607.

Righter, K., Carmichael, I., 1996, Phase equilibria of phlogopite lamprophyres from western Mexico: Biotite-liquid equilibria and P-T estimates for biotite-bearing igneous rocks: Contributions to Mineralogy and Petrology, 123(1), 1-21.

Righter, K., Rosas-Elguera, J., 2001, Alkaline lavas in the volcanic front of the western mexican volcanic belt: geology and petrology of the Ayutla and Tapalpa volcanic fields: Journal of Petrology, 42(12), 2333-2361.

Righter, K., Carmichael, I., Becker, T., Renne, R., 1995, Pliocene to Quaternary volcanism and tectonics at the intersection of the Mexican Volcanic Belt and the Gulf of California: Geological Society of America Bulletin, 107, 612-626.

Robin, C., 1976a, Présence simultanée de magmatismes de significations tectoniques opposées dans l'Est du Mexique: Bulletin de la Société Géologique de France, 18, 1637-1645.

Robin, C., 1976b, Las series volcánicas de la Sierra Madre Oriental (basaltos e ignombritas) descripción y caracteres químicos: Revista Instituto de Geología, Universidad Nacional Autónoma de México, $2,12-42$.

Robin, C., 1982, Relations volcanologie-magmatologie-geodynamique: application au passage entre volcanismes alcalin et andesitique dans le sud Mexicain (Axe Trans-mexicain et Province Alcaline Oriental). Clermont-Ferrand, Francia, Annales Scientifiques de l'Université de Clermont-Ferrand II, Tesis doctoral.

Robin, C., Cantagrel, J., 1982, Le Pico de orizaba (Mexique). Structure et evolution d' un grand volcan andesitique complexe: Bulletin of Volcanology, 45, 299-315.

Robin, C., Camus, G., Gourgaud, A., 1991, Eruptive and magmatic cycles at Fuego de Colima volcano (México): Journal of Volcanology and Geothermal Research, 45, 209-225.

Robin, C., Mossand, C., Camus, G., Cantagrel, J., Gourgaud, A., Vincent, P., 1987, Eruptive history of the Colima volcanic complex: Journal of Volcanology and Geothermal Research, 31, 99-114.

Rodríguez-Elizarrarás, S., Siebe, C., Komorowski, J., Abrams, M., 2002, 
The Quetzalapa pumice: a voluminous late Pleistocene rhyolite deposit in the eastern Trans-Mexican Volcanic Belt: Journal of Volcanology and Geothermal Research, 113, 177-212.

Rollinson, H., 1993, Using geochemical data; evaluation, presentation, interpretation: Essex, Longman Scientific \& Technical, xiv, 352 p.

Rosas-Elguera, J., Urrutia-Fucugauchi, J., 1998, Tectonic control on the volcano-sedimentary sequence of the Chapala graben, western Mexico: International Geology Review, 40, 350-362.

Rosas-Elguera, J., Urrutia-Fucugauchi, J., Maciel, R., 1989, Geología del extremo oriental del Graben de Chapala; breve discusión sobre su edad: zonas geotérmicas Ixtlan de Los Hervores-Los Negritos, México: Geotermia-Revista Mexicana de Geoenergía, 5, 3-18.

Rosas-Elguera, J., Ferrari, L., Garduño-Monroy, V., Urrutia-Fucugauchi, J., 1996, Continental boundaries of the Jalisco Block in the PlioceneQuaternary kinematics of western Mexico: Geology, 24, 921-924.

Rosas-Elguera, J., Ferrari, L., Lopez-Martinez, M., Urrutia-Fucugauchi, J., 1997, Stratigraphy and tectonics of the Guadalajara region and the triple junction area, western Mexico: International Geology Review, 39, 125-140.

Rosas-Elguera, J., Alva-Valdivia, L., Goguitchaichvili, A., UrrutiaFucugauchi, J., Ortega-Rivera, M. A., Archibald, D., 2003 Counterclockwise rotation of the Michoacan block: implications for the tectonics of western Mexico: International Geology Review, 45, 814-826.

Ross, M., Scotese, C., 1988, A hierarchical tectonic model of the Gulf of Mexico and Caribbean region: Tectonophysics, 155, 139-168.

Rossotti, A., Ferrari, L., López-Martínez, M., Rosas-Elguera, J., 2002, Geology of the boundary between the Sierra Madre Occidental and the Trans-Mexican Volcanic Belt in the Guadalajara region, western Mexico: Revista Mexicana de Ciencias Geológicas, 19, 1-15.

Ruiz, J., Patchett, P., Ortega-Gutiérrez, F., 1988, Proterozoic and Phanerozoic basement terranes of Mexico from $\mathrm{Nd}$ isotopic studies: Geological Society of America Bulletin, 100, 274-281.

Ruiz, J., Tosdal, R., Restrepo, P., Murillo-Muñetón, G., 1999, Pb Isotope evidence for Colombia-Southern Mexico connections in the Proterozoic, en Ramos, V., Keppie, J. D. (eds.), Laurentia-Gondwana connections before Pangea: Boulde, CO, Geological Society of America, Special Paper, 336, 183-197.

Sahagún, B., 1992, Historia general de las cosas de la Nueva España: Mexico, D. F., Editorial Porrúa, 1093 p.

Schaaf, P., Heinrich, W., Besch, T., 1994, Composition and Sm-Nd isotopic data of the lower crust beneath San Luis Potosí, cetral Mexico: Evidence from a granulite-facies xenolith suite: Chemical Geology, 118, 63-84.

Schaaf, P., Morán-Zenteno, D., Hernández-Bernal, M., Solís-Pichardo, G., Tolson, G., Köhler, H., 1995, Paleogene continental margin truncation in southwestern Mexico: geochronological evidence: Tectonics, 14(5), 1339-1350.

Schaaf, P., Stimac, J., Siebe, C., Macías, J., 2005, Geochemical evidence for mantle origin and crustal processes in volcanic rocks from Popocatépetl and surrounding monogenetic volcanoes, central Mexico: Journal of Petrology, 46(6), 1243-1282.

Schmidt, K., Bottazzi, P., Vannucci, R., Mengel, K., 1999, Trace element partitioning between phlogopite, clinopyroxene and leucite lamproite melt: Earth and Planetary Science Letters, 168, 287-299.

Sedlock, R., Ortega-Gutiérrez, F., Speed, R., 1993, Tectonostratigraphic terranes and the tectonic evolution of Mexico: Boulder, CO, Geologial Society of America, Special Paper, 278, 153 p.

Sekine, T., Katsura, T., Aramaki, S., 1979, Water-saturated phase relations of some andesites with application to the estimation of the initial temperature and water pressure at the time of eruption: Geochimica et Cosmochimica Acta, 43, 1367-1376.

Serpa, L., Smith, S., Katz, C., Skidmore, C., Sloan, R., Pavlis, T., 1992, A geophysical investigation of the southern Jalisco block in the state of Colima, Mexico: Geofísica Internacional, 31, 247-252.

Sheth, H., Torres-Alvarado, I., Verma, S., 2000, Beyond subduction and plumes: A unified tectonic-petrogenetic model for the Mexican volcanic belt: International Geology Review, 42(12), 1116-1132.

Shirey, S., Walker, R., 1998, Re-Os isotopes in cosmochemistry and hightemperature geochemistry: Annual Review of Earth and Planetary
Sciences, 26, 423-500.

Siebe, C., 2000, Age and archaeological implications of Xitle volcano, southwestern Basin of Mexico City: Journal of Volcanology and Geothermal Research, 104, 45-64.

Siebe, C., Verma, S., 1988, Major element geochemistry and tectonic setting of Las Derrumbadas rhyolitic domes, Puebla, Mexico: Chemie der Erde, 48, 177-189.

Siebe, C., Abrams, M., Macías, J., Obenholzner, J., 1996, Repeated volcanic disasters in Prehispanic time at Popocatepetl, central Mexico: Past key to the future?: Geology, 24, 399-402.

Siebe, C., Quintero-Legorreta, O., García-Palomo, A., Macías, J., 1999 , Effect of strain rate in the distribution of monogenetic and polygenetic volcanism in the Transmexican volcanic belt. Comment: Geology, 27, 572-573.

Siebe, C., Rodríguez-Lara, V., Schaaf, P., Abrams, M., 2004a, Geochemistry, Sr-Nd isotope composition, and tectonic setting of Holocene Pelado, Guespalapa and Chichinautzin scoria cones, south of Mexico City: Journal of Volcanology and Geothermal Research, 2712, 1-30.

Siebe, C., Rodríguez-Lara, V., Schaaf, P., Abrams, M., 2004b, Radiocarbon ages of Holocene Pelado, Guespalapa, and Chichinautzin scoria cones, south of Mexico City: implications for archaeology and future hazards: Bulletin of Volcanology, 66, 203-225.

Siebert, L., Carrasco-Núñez, G., 2002, Late-Pleistocene to precolumbian behind-the-arc mafic volcanism in the eastern Mexican Volcanic Belt; implications for future hazards: Journal of Volcanology and Geothermal Research, 115, 179-205.

Silver, L. T., Anderson, T. H., 1974, Possible left lateral early to middle Mesozoic disruption of the southwestern North America craton margin: Geological Society of America, Abstracts with Programs, 6(7), 955-956.

Smith, D., Nuckels, C., Jones, R., Cook, G., 1979, Distribution of heat flow and radioactive heat generation in northern Mexico: Journal of Geophysical Research, 84, 2371-2379.

Straub, S., Martín-Del Pozzo, A., 2001, The significance of phenocryst diversity in tephra from recent eruptions at Popocatépetl Stratovolcano (central Mexico): Contributions to Mineralogy and Petrology, 140, 487-510.

Strong, M., Wolff, J., 2003, Compositional variations within scoria cones: Geology, 31, 143-146.

Suárez, G., García-Acosta, V., Gaulon, R., 1994, Active crustal deformation in the Jalisco block, Mexico: evidence for a great historical earthquake in the 16th century: Tectonophysics, 234, 117-127.

Sun, S. S., McDonough, W. F., 1989, Chemical and isotopic systematics of oceanic basalts: Implications for mantle compositions and processes, en Saunders, A., Norry, M. (eds.), Magmatism in the ocean basins: London, Geological Society, Special Publication Classics, 313-345.

Suter, M., 1999, Effect of strain rate in the distribution of monogenetic and polygenetic volcanism in the Transmexican volcanic belt. Comment: Geology, 27, 571.

Suter, M., Quintero, O., Johnson, C., 1992, Active faults and and state of stress in in the central part of the Trans-Mexican Volcanic Belt. 1. The Venta de Bravo fault: Journal of Geophysical Research, 97, 11983-11994.

Suter, M., Carrillo-Martínez, M., López-Martínez, M., Farrar, E., 1995a, The Aljibes half-graben -Active extension at the boundary between the trans-Mexican volcanic belt and the Basin and Range Province, Mexico: Geological Society of America Bulletin, 107(6), 627641.

Suter, M., Quintero, O., López, M., Aguirre, G., Ferrar, E., 1995b, The Acambay graben: Active intraarc extension in the Trans-Mexican Volcanic Belt: Tectonics, 14, 1245-1262.

Suter, M., Carrillo-Martínez, M., Quintero-Legorreta, O., 1996, Macroseismic study of shallow earthquakes in the central and eastern parts of the trans-Mexican volcanic belt, Mexico: Seismological Society of America Bulletin, 86, 1952-1963.

Suter, M., López-Martínez, M., Quintero-Legorreta, O., Carrillo-Martínez, M., 2001, Quaternary intra-arc extension in the central TransMexican volcanic belt: Geological Society of America Bulletin, 113(6), 693-703 
Szynkaruk, E., Garduño-Monroy, V., Bocco, G., 2004, Active fault systems and tectono- topographic configuration of the central Trans-Mexican volcanic belt: Geomorphology, 61, 111-126.

Umhoefer, P., Dorsey, R., Willsey, S., Mayer, S., Renne, P., 2001, Stratigraphy and geochronology of the Comondú Group near Loreto, Baja California Sur, Mexico: Sedimentary Geology, 125-147.

Urbina, F., Camacho, H., 1913, La zona megasísmica de AcambayTixmadejé, Estado de México, conmovida el 19 de noviembre de 1912: Boletín del Instituto Geológico de México, 32, 125.

Urrutia-Fucugauchi, J., 1986, Crustal thickness, heat flow, arc magmatism, and tectonics of Mexico-Preliminary report: Geofísica Internacional, 25(4), 559-573.

Urrutia-Fucugauchi, J., Böhnel, H., 1987, Tectonic interpretation of the Trans-Mexican Volcanic Belt: Tectonophysics, 138, 319-323.

Urrutia-Fucugauchi, J., Del Castillo, L., 1977, Un modelo del Eje Volcánico Mexicano: Boletín de la Sociedad Geológica Mexicana, 38, 18-28.

Urrutia-Fucugauchi, J., Flores-Ruiz, J., 1996, Bouger gravity anomalies and regional crustal structure in central Mexico: International Geology Review, 38, 176-194.

Urrutia-Fucugauchi, J., Rosas-Elguera, J., 1994, Paleomagnetic study of the eastern sector of Chapala Lake and implications for the tectonics of west-central Mexico: Tectonophysics, 239, 61-71.

Valdés, C., Mooney, W., Singh, S., Meyer, R., Lomnitz, C., Luetgert, J., Helsley, C., Lewis, B., Mena, M., 1986, Crustal structure of Oaxaca, Mexico, from seismic refraction measurments: Bulletin of the Seismological Society of America, 76, 547-563.

Valdez-Moreno, G., Aguirre-Díaz, G., López-Martínez, M., 1998, El Volcán La Joya, Edos. de Querétaro y Guanajuato. Un estratovolcán antiguo del cinturón volcánico mexicano: Revista Mexicana de Ciencias Geológicas, 15(2), 181-197.

Velasco-Tapia, F., Verma, S., 2001, Estado actual de la investigación geoquímica en el campo monogenético de la Sierra de Chichinautzin: análisis de información y perspectivas: Revista Mexicana de Ciencias Geológicas, 18(1), 1-36.

Venegas, S., Herrera, F., Maciel, R., 1985, Algunas características de la Faja Volcánica Mexicana y sus recursos geotérmicos: Geofísica Internacional, 24, 97-157.

Verma, S., 1999, Geochemistry of evolved magmas and their relationship to subduction-unrelated mafic volcanism at the volcanic front of the central Mexican Volcanic Belt: Journal of Volcanology and Geothermal Research, 93, 151-171.

Verma, S., 2000a, Geochemistry of the subducting Cocos plate and the origin of subduction-unrelated mafic volcanism at the front of the central Mexican Volcanic Belt, en Delgado-Granados, H., AguirreDíaz, G., Stock, J. (eds.), Cenozoic tectonics and volcanism of Mexico: Boulder, CO, Geological Society of America, Special Paper, (334), 1-28.

Verma, S., 2000b, Geochemical evidence for a lithospheric source for magmas from Los Humeros caldera, Puebla, Mexico: Chemical Geology, 164, 35-60.

Verma, S., 2001a, Geochemical evidence for a lithospheric source for magmas from Acoculco caldera, eastern Mexican Volcanic Belt: International Geology Review, 43, 31-51.

Verma, S., 2001b, Geochemical and Sr-Nd-Pb isotopic evidence for a combined assimilation and fractional crystallisation process for volcanis rocks from the Huichapan caldera, Hidalgo, Mexico: Lithos, 56, 141-164.

Verma, S., 2001c, Geochemical evidence for a rift-related origin of bimodal volcanism at Meseta San Juan, north-central Mexican Volcanic Belt: International Geology Review, 43, 475-493.

Verma, S., 2002, Absence of Cocos plate subduction-related basic volcanism in southern Mexico: a unique caso on earth?: Geology, 30(12), 1095-1098.

Verma, S., Aguilar-y-Vargas, V., 1988, Bulk chemical composition of magmas in the Mexican Volcanic Belt (Mexico) and inapplicability of generalized arc-models: Chemie der Erde, 48, 203-221.

Verma, S., Carrasco-Núñez, G., 2003, Reapprisal of the geology and geochemistry of Volcán Zamorano, central Mexico: implications for discriminating the Sierra Madre Occidental and Mexican Volcanic
Belt provinces: International Geology Review, 45, 724-752.

Verma, S., Hasenaka, T., 2004, Sr, Nd, and Pb isotopic and trace element geochemical constraints for a veined-mantle source of magmas in the Michoacan-Guanajuato Volcanic Field, west-central Mexican Volcanic Belt: Geochemical Journal, 38(1), 43-65.

Verma, S., Nelson, S., 1989, Isotopic and trace element constraints on the origin and evolution of alkaline and calc-alkaline magmas in the northwestern Mexican volcanic belt.: Journal of Geophysical Research, 94, 4531-4544.

Verma, S., López-Martínez, M., Terrell, D., 1985, Geochemistry of Tertiary igneous rocks from Arandas-Atotonilco area, northeast Jalisco, Mexico: Geofísica Internacional, 24, 31-45.

Verma, S., Carrasco-Núñez, G., Milán, M., 1991, Geology and geochemistry of Amealco caldera, Qro., Mexico: Journal of Volcanology and Geothermal Research, 47, 105-127.

von Humboldt, A., 1808, Essai politique sur le Royaume de la Nouvelle Espagne: Paris, F. Shoell, 904 p.

Wallace, P., Carmichael, I., 1989, Minette lavas and associated leucitites from the western front of the Mexican Volcanic Belt: petrology, chemistry and origin: Contributions to Mineralogy and Petrology, 103, 470-492.

Wallace, P., Carmichael, I., 1992, Alkaline and calc-alkaline lavas near Los Volcanes, Jalisco, Mexico: geochemical diversity and its significance in volcanic arcs: Contributions to Mineralogy and Petrology, 111(4), 423-439.

Wallace, P., Carmichael, I., 1994, Petrology of Volcán Tequila, Jalisco, México: disequilibrim phenocryst assemblages and evolution of the subvolcanic magma system: Contributions to Mineralogy and Petrology, 117, 345-361.

Wallace, P., Carmichael, I., 1999, Quaternary volcanism near the Valley of Mexico: implications for subduction zone magmatism and the effects of crustal thickness variations on primitive magma compositions: Contributions to Mineralogy and Petrology, 135, 291-314.

Weber, B., Köhler, H., 1998, Evidence for a 1.4 to 1.2 Ga crust-forming event in the Grenville-aged Guichicovi Complex of Southern Mexico, en Keppie, J.D., ed., International Geological Correlation Program, Laurentia-Gondwanan connections before Pangea. IGCP Project. 376: México, Universidad Nacional Autónoma de México, Instituto de Geología, 36.

Wilcox, R., 1954, Petrology of Paricutin Volcano, Mexico: U. S. Geological Survey, Bulletin, 65-C, 281-354.

Yañez, P., Ruiz, J., Patchett, J., Ortega-Gutiérrez, F., Gehrels, G., 1991, Isotopic studies of the Acatlán Complex, southern México: implications for Paleozoic North American tectonics: Geological Society of America Bulletin, 103, 817-828.

Yañez-García, A., Casique, J., 1980, Informe geológico del proyecto geotérmico Los Humeros-Derrumbadas, estados de Puebla y Veracruz: México, Comisión Federal de Electricidad, 96 p.

Yarza de la Torre, E., 1992, Volcanes de México: México, D. F., Universidad Nacional Autónoma de México, Instituto de Geografia, 173 p.

Zamorano-Orozco, J., Tenarro-García, L., Lugo-Hubp, J., Sánchez-Rubio, G., 2002, Evolución geológica y gemorfología del complejo dómico Los Pitos, norte de la Cuenca de México: Revista Mexicana de Ciencias Geológicas, 19, 66-79.

Ziagos, J., Blackwell, D., Mooser, F., 1985, Heat flow in southern Mexico and the thermal effects of subduction: Journal of Geophysical Research, 90, 5410-5420.

Manuscrito recibido: Abril 15, 2005

Manuscrito corregido recibido: Agosto 22, 2005

Manuscrito aceptado: Agosto 30, 2005 